Summary of Radionuclide Reactive Transport Experiments in Fractured Tuff and Carbonate Rocks from Yucca Flat, Nevada Test Site

M. Zavarin, S. Roberts, P. Reimus, M. Johnson

October 13, 2006 
This document was prepared as an account of work sponsored by an agency of the United States Government. Neither the United States Government nor the University of California nor any of their employees, makes any warranty, express or implied, or assumes any legal liability or responsibility for the accuracy, completeness, or usefulness of any information, apparatus, product, or process disclosed, or represents that its use would not infringe privately owned rights. Reference herein to any specific commercial product, process, or service by trade name, trademark, manufacturer, or otherwise, does not necessarily constitute or imply its endorsement, recommendation, or favoring by the United States Government or the University of California. The views and opinions of authors expressed herein do not necessarily state or reflect those of the United States Government or the University of California, and shall not be used for advertising or product endorsement purposes.

This work was performed under the auspices of the U.S. Department of Energy by University of California, Lawrence Livermore National Laboratory under Contract W-7405-Eng-48. 


\section{Summary of Radionuclide Reactive Transport Experiments in Fractured Tuff and Carbonate Rocks from Yucca Flat, Nevada Test Site}

\footnotetext{
Mavrik Zavarin ${ }^{(1)}$, Sarah K. Roberts ${ }^{(2)}$, Paul W. Reimus ${ }^{(3)}$, Mackenzie R. Johnson ${ }^{(4)}$

(1) Chemistry, Materials and Life Sciences Directorate, Lawrence Livermore National Laboratory

${ }^{(2)}$ Energy and Environment Directorate, Lawrence Livermore National Laboratory

${ }^{(3)}$ Chemistry, Life \& Earth Sciences Directorate, Los Alamos National Laboratory

${ }^{(4)}$ Engineering Directorate, Lawrence Livermore National Laboratory
}

Prepared for the Underground Test Area Project

U. S. Department of Energy

National Nuclear Security Administration

Nevada Site Office

March 21, 2007 
TABLE OF CONTENTS

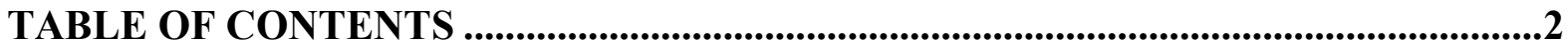

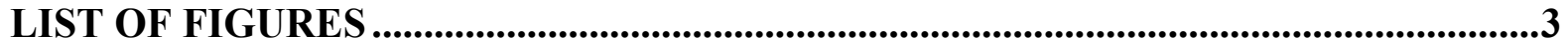

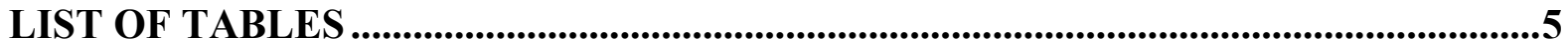

LIST OF ACRONYMS AND ABBREVIATIONS .........................................................6

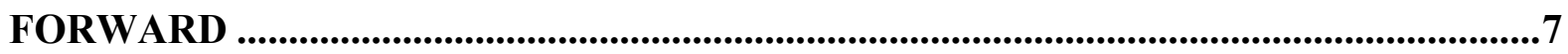

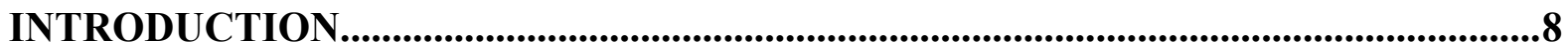

EXPERIMENTAL METHODS ...............................................................................................8

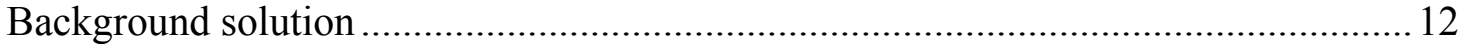

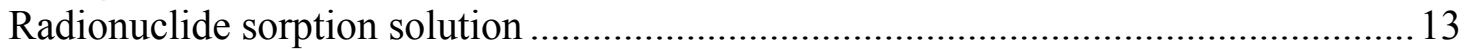

Fracture Transport Experiment Interpretation .......................................................... 14

Modeling Transient Flow Conditions ………………............................................... 19

Colloid-Facilitated Transport................................................................................... 19

The Modeling Approach of Zavarin et al. (2005).........................................................20

RELAP/RETRAN FRACTURE TRANSPORT EXPERIMENT MODEL RESULTS..22

SUMMARY OF MODELING RESULTS............................................................................24

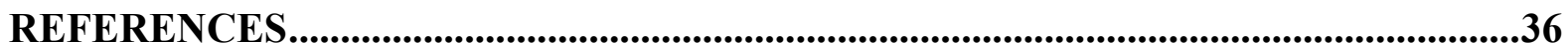

APPENDIX A: MODEL FITS TO LLNL TUFF FRACTURE TRANSPORT BREAKTHROUGH CURVES ..................................................................................38

APPENDIX B: MODEL FITS TO LLNL CARBONATE FRACTURE TRANSPORT BREAKTHROUGH CURVES ...................................................................................39

APPENDIX C: MODEL FITS TO LANL TUFF FRACTURE TRANSPORT

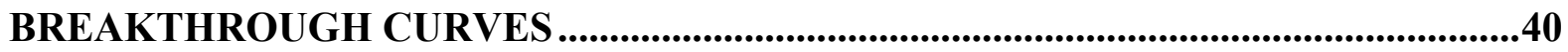

APPENDIX D: MODEL FITS TO LANL CARBONATE FRACTURE TRANSPORT BREAKTHROUGH CURVES .................................................................................................44 


\section{LIST OF FIGURES}

Figure 1. Schematic illustration of LLNL flowthrough transport experiments - (a) to (e) show steps in experiment preparation for slotted fractures. Sample core (a) has reference flats ground on end surfaces and at relative azimuths of 0,90 , and $180^{\circ}$ on the cylindrical surface (b); core is cut in half (c); is laid open and a 500 or $50 \mu \mathrm{m}$ wide slot is ground into one side (d); finally it is reassembled (e) for experiments. Top of diagram shows how fluid moved through the fractured core. Images (a)-(e) from Durham et al. (2001).

Figure 2. Schematic Illustration of LANL flowthrough transport experiments. The fractured cores were encapsulated within a Plexiglas tube using epoxy to fill the annular space, with the flow manifolds fixed in place on either end to allow introduction and collection of water. The sides of the core were sealed to serve as no-flow boundaries (Ware et al., 2005).

Figure 3. Breakthrough profiles of ${ }^{3} \mathrm{HHO}$ and Re in tuff and carbonate rock. In tuff, the tracer with higher diffusivity (i.e. ${ }^{3} \mathrm{HHO}$ ) produces lower concentrations during pulse breakthrough and higher concentrations during tailing. In carbonate rock, ${ }^{3} \mathrm{HHO}$ appears to produce lower concentrations during pulse breakthrough and during tailing, which is indicative of ${ }^{3} \mathrm{HHO}$ loss due to exchange with air during sampling and not diffusion... 18

Figure 4. Breakthrough profiles of ${ }^{3} \mathrm{HHO}$ and Re in carbonate rock (ER-6-1 2605, Synthetic slot). When corrected for ${ }^{3} \mathrm{HHO}$ loss due to exchange with air during sampling, little or no diffusion can be identified based on comparative breakthrough of ${ }^{3} \mathrm{HHO}$ and Re. ... 28

Figure A-1. Normalized breakthrough curves of ${ }^{3} \mathrm{HHO}, \mathrm{Re}, \mathrm{U},{ }^{237} \mathrm{~Np}$, and $\mathrm{Pu}$ in fracture from LLNL tuff fracture experiments (TCU) at a flow rate of $1.2 \mathrm{~mL} / \mathrm{hr}$. RELAP was used to obtain model fits.

Figure B-1. Normalized breakthrough curves of ${ }^{3} \mathrm{HHO}, \mathrm{Re}, \mathrm{U},{ }^{237} \mathrm{~Np}$, and Pu in fracture from LLNL carbonate fracture experiments (LCA) at a flow rate of $1.2 \mathrm{~mL} / \mathrm{hr}$. RELAP was used to obtain model fits.

Figure C-1. Normalized breakthrough curves of ${ }^{3} \mathrm{HHO},{ }^{11} \mathrm{C},{ }^{23} \mathrm{U},{ }^{137} \mathrm{Cs},{ }^{237} \mathrm{~Np},{ }^{90} \mathrm{Sr}$, and ${ }^{239} \mathrm{Pu}$ in fracture from UE-4a $2029 \mathrm{ft}$ (TCU) at flow rates of $0.5 \mathrm{~mL} / \mathrm{hr}$ and $2 \mathrm{~mL} / \mathrm{hr}$. RELAP was used to obtain model fits except where noted on plots. Kinetic model used for Np at 2 $\mathrm{ml} / \mathrm{hr}$ flow rate.

Figure C-2. Normalized breakthrough curves of ${ }^{3} \mathrm{HHO},{ }^{14} \mathrm{C},{ }^{233} \mathrm{U},{ }^{137} \mathrm{Cs},{ }^{237} \mathrm{~Np},{ }^{90} \mathrm{Sr}$, and ${ }^{239} \mathrm{Pu}$ in fracture from UE-7az $1770 \mathrm{ft}$ (TCU) at flow rates of $0.5 \mathrm{~mL} / \mathrm{hr}$ and $2 \mathrm{~mL} / \mathrm{hr}$. RELAP was used to obtain model fits except where noted on plots......................................... 41

Figure C-3. Normalized breakthrough curves of ${ }^{3} \mathrm{HHO},{ }^{14} \mathrm{C},{ }^{233} \mathrm{U},{ }^{137} \mathrm{Cs},{ }^{237} \mathrm{~Np},{ }^{9} \mathrm{Sr}$, and ${ }^{239} \mathrm{Pu}$ in fracture from UE-7ba $1823 \mathrm{ft}$ (TCU) at flow rates of $0.5 \mathrm{~mL} / \mathrm{hr}$ and $2 \mathrm{~mL} / \mathrm{hr}$. RELAP was used to obtain model fits except where noted on plots........................................ 42

Figure C-4. Normalized breakthrough curves of ${ }^{3} \mathrm{HHO},{ }^{14} \mathrm{C},{ }^{233} \mathrm{U},{ }^{137} \mathrm{Cs},{ }^{237} \mathrm{~Np},{ }^{90} \mathrm{Sr}$, and ${ }^{239} \mathrm{Pu}$ in fracture from UE-7ba $1863 \mathrm{ft}$ (TCU) at flow rates of $0.5 \mathrm{~mL} / \mathrm{hr}$ and $2 \mathrm{~mL} / \mathrm{hr}$. RELAP was used to obtain model fits except where noted on plots.......................................... 43

Figure D-1. Normalized breakthrough curves of ${ }^{3} \mathrm{HHO},{ }^{14} \mathrm{C},{ }^{233} \mathrm{U},{ }^{137} \mathrm{Cs},{ }^{237} \mathrm{~Np},{ }^{90} \mathrm{Sr}$, and ${ }^{239} \mathrm{Pu}$ in fracture from ER-6-1 $2400 \mathrm{ft}$ (LCA) at flow rates of $0.5 \mathrm{~mL} / \mathrm{hr}$ and $2 \mathrm{~mL} / \mathrm{hr}$. RELAP was used to obtain model fits except where noted on plots. 
Figure D-2. Normalized breakthrough curves of ${ }^{3} \mathrm{HHO},{ }^{14} \mathrm{C},{ }^{233} \mathrm{U},{ }^{137} \mathrm{Cs},{ }^{237} \mathrm{~Np},{ }^{90} \mathrm{Sr}$, and ${ }^{239} \mathrm{Pu}$ in fracture from ER-6-1 $2512 \mathrm{ft}$ (LCA) at flow rates of $0.5 \mathrm{~mL} / \mathrm{hr}$ and $2 \mathrm{~mL} / \mathrm{hr}$. RELAP was used to obtain model fits except where noted on plots.

Figure D-3. Normalized breakthrough curves of ${ }^{3} \mathrm{HHO},{ }^{14} \mathrm{C},{ }^{233} \mathrm{U},{ }^{137} \mathrm{Cs},{ }^{237} \mathrm{~Np},{ }^{90} \mathrm{Sr}$, and ${ }^{239} \mathrm{Pu}$ in fracture from ER-6-1 $2675 \mathrm{ft}$ (LCA) at flow rates of $0.5 \mathrm{~mL} / \mathrm{hr}$ and $2 \mathrm{~mL} / \mathrm{hr}$. RELAP was used to obtain model fits except where noted on plots. 46

Figure D-4. Normalized breakthrough curves of ${ }^{3} \mathrm{HHO},{ }^{14} \mathrm{C},{ }^{233} \mathrm{U},{ }^{137} \mathrm{Cs},{ }^{237} \mathrm{~Np},{ }^{90} \mathrm{Sr}$, and ${ }^{239} \mathrm{Pu}$ in fracture from ER-6-1 $2847 \mathrm{ft}$ (LCA) at flow rates of $0.5 \mathrm{~mL} / \mathrm{hr}$ and $2 \mathrm{~mL} / \mathrm{hr}$. RELAP was used to obtain model fits except where noted on plots.

Figure D-5. Normalized breakthrough curves of ${ }^{3} \mathrm{HHO},{ }^{14} \mathrm{C},{ }^{233} \mathrm{U},{ }^{137} \mathrm{Cs},{ }^{237} \mathrm{~Np},{ }^{90} \mathrm{Sr}$, and ${ }^{239} \mathrm{Pu}$ in fracture from ER-6-1 $2915 \mathrm{ft}$ (LCA) at flow rates of $0.5 \mathrm{~mL} / \mathrm{hr}$ and $2 \mathrm{~mL} / \mathrm{hr}$. RELAP was used to obtain model fits except where noted on plots.

Figure D-6. Normalized breakthrough curves of ${ }^{3} \mathrm{HHO},{ }^{14} \mathrm{C},{ }^{233} \mathrm{U},{ }^{137} \mathrm{Cs},{ }^{237} \mathrm{~Np},{ }^{90} \mathrm{Sr}$, and ${ }^{239} \mathrm{Pu}$ in fracture from ER-6-1 $3028 \mathrm{ft}$ (LCA) at flow rates of $0.5 \mathrm{~mL} / \mathrm{hr}$ and $2 \mathrm{~mL} / \mathrm{hr}$. RELAP was used to obtain model fits except where noted on plots.

Figure D-7. Normalized breakthrough curves of ${ }^{3} \mathrm{HHO},{ }^{14} \mathrm{C},{ }^{233} \mathrm{U},{ }^{137} \mathrm{Cs},{ }^{237} \mathrm{~Np},{ }^{90} \mathrm{Sr}$, and ${ }^{239} \mathrm{Pu}$ in fracture from ER-6-2 $2730 \mathrm{ft}$ (LCA) at flow rates of $0.5 \mathrm{~mL} / \mathrm{hr}$ and $2 \mathrm{~mL} / \mathrm{hr}$. RELAP was used to obtain model fits except where noted on plots.

Figure D-8. Normalized breakthrough curves of ${ }^{3} \mathrm{HHO},{ }^{14} \mathrm{C},{ }^{233} \mathrm{U},{ }^{137} \mathrm{Cs},{ }^{237} \mathrm{~Np},{ }^{90} \mathrm{Sr}$, and ${ }^{239} \mathrm{Pu}$ in fracture from ER-6-2 $2750 \mathrm{ft}$ (LCA) at flow rates of $0.5 \mathrm{~mL} / \mathrm{hr}$ and $2 \mathrm{~mL} / \mathrm{hr}$. RELAP was used to obtain model fits except where noted on plots 


\section{LIST OF TABLES}

Table 1. Summary of flowthrough transport experiments performed by LLNL and LANL........ 10

Table 2. Measured core dimensions, inlet and outlet tubing volumes, and measured porosity for

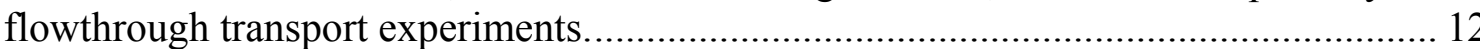

Table 3. Composition of background solutions used in flowthrough experiments. ..................... 13

Table 4. Sorption solution composition used in the flowthrough experiments. ......................... 14

Table 5. Relative values of radionuclide matrix diffusion coefficients. .................................. 17

Table 6. Retardation factors and transport parameters for fracture flowthrough experiments..... 31

Table 6, cont. Retardation factors and transport parameters for fracture flowthrough experiments.

Table 6, cont. Retardation factors and transport parameters for fracture flowthrough experiments. 33

Table 6, cont. Retardation factors and transport parameters for fracture flowthrough experiments.

Table 6, cont. Retardation factors and transport parameters for fracture flowthrough experiments. 


\section{LIST OF ACRONYMS AND ABBREVIATIONS}

BGS - Below ground surface

CAU - corrective action unit

DOE - U.S. Department of Energy

HSU - Hydrostratigraphic Unit

LANL - Los Alamos National Laboratory

LCA - lower carbonate aquifer

LCCU - lower clastic confining unit

LLNL - Lawrence Livermore National Laboratory

NTS - Nevada Test Site

TCU - tuff confining unit

UGTA - Underground Test Area

USGS - U.S. Geological Survey

WTA - welded tuff aquifer 


\section{FORWARD}

This report summarizes the results of two fracture transport experimental efforts from FY04 and FY05 conducted for the Underground Test Area (UGTA) project. In FY04 and FY05, researchers at Lawrence Livermore National Laboratory (LLNL) and Los Alamos National Laboratory (LANL) performed a series of laboratory experiments examining the transport of radionuclides in fractured tuff and carbonate rocks from the Yucca Flat basin of the Nevada Test Site (NTS). All LLNL and LANL fracture flowthrough data have been modeled using the RELAP (REactive transport LAPlace transform inversion computer code) or RETRAN (a transient version of RELAP) codes. Both codes solve a semi-analytical dual-porosity transport model of fracture transport. RELAP and RETRAN are described in detail in Reimus and Haga, (1999), Reimus et al. (2003), and Reimus et al. (2002). RELAP/RETRAN solves Laplacetransformed versions of the 1-D dual-porosity transport equations using a Laplace-to-time domain inversion algorithm. One of the solutions included in the RELAP model is the parallel plate, infinite matrix, equilibrium sorption fracture transport solution of Tang et al. (1981). However, RELAP/RETRAN may also account for finite matrices, rate-limited sorption, and radial flow. The RELAP/RETRAN modeling results are compared to LLNL fracture transport modeling (Zavarin et al., 2005) completed using either the CRUNCH code (Steefel and Yabusaki, 1995) combined with a surface complexation and ion exchange sorption database (Zavarin and Bruton, 2004a; 2004b) or using the analytical solution of Tang et al. (1981). Readers are referred to the original reports, "Radionuclide Transport in Tuff and Carbonate Fractures from Yucca Flat, Nevada Test Site" (Zavarin et al., 2005) and "Radionuclide Sorption and Transport in Fractured Rocks of Yucca Flat, Nevada Test Site" (Ware et al., 2005) for an in depth discussion of the individual sets of experiments, as well as all original data. 


\section{INTRODUCTION}

In the Yucca Flat basin of the Nevada Test Site (NTS), 747 shaft and tunnel nuclear detonations were conducted primarily within the tuff confining unit (TCU) or the overlying alluvium. The TCU in the Yucca Flat basin is hypothesized to inhibit radionuclide migration to the highly transmissive and regionally extensive lower carbonate aquifer (LCA) due to its wide-spread aerial extent, low permeability, and chemical reactivity. However, fast transport pathways through the TCU by way of fractures may provide a migration path for radionuclides to the LCA.

Radionuclide transport in both TCU and the LCA fractures is likely to determine the location of the contaminant boundary for the Yucca Flat/Climax Mine Corrective Action Unit (CAU). Radionuclide transport through the TCU may involve both matrix and fracture flow. However, radionuclide migration over significant distances is likely to be dominated by fracture transport. Transport through the LCA will almost certainly be dominated by fracture flow, as the LCA has a very dense, low porosity matrix with very low permeability.

Because of the complex nature of reactive transport in fractures, a stepwise approach to identifying mechanisms controlling radionuclide transport was used. The simplest LLNL experiments included radionuclide transport through synthetic parallel-plate fractured tuff and carbonate cores. These simplified fracture transport experiments isolated matrix diffusion and sorption effects from all other fracture transport processes (fracture lining mineral sorption, heterogeneous flow, etc.). Additional fracture transport complexity was added by performing induced fractured LCA flowthrough experiments (effect of aperture heterogeneity) or iron oxide coated parallel plate TCU flowthrough experiments (effect of fracture lining minerals). Finally naturally fractured tuff and carbonate cores were examined at LLNL and LANL. All tuff and carbonate core used in the experiments was obtained from the USGS Core Library, Mercury, Nevada. Readers are referred to the original reports "Radionuclide Transport in Tuff and Carbonate Fractures from Yucca Flat, Nevada Test Site" (Zavarin et al., 2005) and "Radionuclide Sorption and Transport in Fractured Rocks of Yucca Flat, Nevada Test Site" (Ware et al., 2005) for specific details not covered in this summary report.

\section{EXPERIMENTAL METHODS}

Table 1 summarizes all flowthrough transport experiments performed at LLNL and LANL. Listed in the table are: the core interval, the radionuclides ${ }^{1}$ in the sorption solution, the experiment type, the flow rate, and volume of the sorption solution pulse. Each LLNL experiment consisted of a single flowthrough experiment in which a cocktail of five to eight radionuclides were injected into a fractured core. As described above, the core may have been prepared as a synthetic slotted fracture, a synthetic slotted fracture with an iron oxide coating, a synthetic induced fracture, or a natural fracture. Furthermore, in one experiment, colloids were added to the injected radionuclide cocktail and background solutions.

\footnotetext{
${ }^{1}$ We use the term radionuclide for all non-sorbing tracers and sorbing species examined. However, some species (e.g. Re) are in fact not radioactive.
} 
Each LANL experiment consisted of several flowthrough "runs" in which sets of three radionuclides were injected. ${ }^{3} \mathrm{HHO}$ was always included as a non-sorbing tracer. ${ }^{2}$ Because each experiment included several runs, the pulse volume reported in Table 1 is a range that reflects the small differences in pulse volumes between each run. In general, flow rates and pulse volumes in LLNL and LANL experiments were similar, ranging from 0.5 to $2 \mathrm{~mL} / \mathrm{hr}$ and 15 to $50 \mathrm{~mL}$, respectively. In most cases, LANL used two flow rates for each core; LLNL used only one. LANL experiments only included natural fractures. All experiments were conducted at ambient temperature $\left(20-25^{\circ} \mathrm{C}\right)$.

The flowthrough apparatus used at LANL and LLNL are somewhat different. LLNL used a confining pressure to hold the fractured core in place (Figure 1) while LANL embedded their cores in epoxy (Figure 2). LLNL used an HPLC pump to flow solutions through the fracture while LANL used a syringe pump. However, core dimensions, reported in Table 2, are similar in scale. Fraction collectors were used in all experiments to collect effluent.

The analytical methods used at LLNL and LANL to characterize radionuclide transport are somewhat different as well. LANL measured radionuclide breakthrough using scintillation counting exclusively. As a result, all radionuclides could not be injected into fractures simultaneously. Instead, radionuclides were used in groups of three, with an alpha emitting radionuclide always paired with a beta- or gamma-emitting radionuclides and tritiated water $\left({ }^{3} \mathrm{HHO}\right)$. The reactive radionuclide pairings that were co-injected with ${ }^{3} \mathrm{HHO}$ were ${ }^{14} \mathrm{C}$ with ${ }^{233} \mathrm{U},{ }^{137} \mathrm{Cs}$ with ${ }^{237} \mathrm{~Np}$, and ${ }^{90} \mathrm{Sr}$ with ${ }^{239} \mathrm{Pu}$. These combinations were selected to minimize interferences during scintillation counting. LLNL measured radionuclide breakthrough using a combination of scintillation counting and inductively coupled plasma mass spectrometry (ICPMS). As a result, eight radionuclides could be injected and analyzed in a single flowthrough experiment. Also, at the conclusion of the LLNL flowthrough experiments, the cores were reopened and characterized using autoradiography, laser ablation (LA) ICP-MS, secondary ion mass spectrometry (SIMS), and other techniques (results are not discussed here). Because LANL performed several flowthrough experiments on the same core, core characterization at the end of the experiments was not attempted.

\footnotetext{
${ }^{2}$ The flowthrough runs were teminated only when the ${ }^{3} \mathrm{HHO}$ and other radionuclide concentrations returned to background levels.
} 
Table 1. Summary of flowthrough transport experiments performed by LLNL and LANL.

\begin{tabular}{|c|c|c|c|c|c|}
\hline Hole, Core Interval (ft) & $\begin{array}{l}\text { Experiment } \\
\text { Designation }\end{array}$ & Radionuclides & $\begin{array}{c}\text { Fracture } \\
\text { Experiment }^{(1)} \\
\text { Type }^{(1)}\end{array}$ & $\begin{array}{l}\text { Approx. Flow } \\
\text { Rate, } \mathrm{mL} / \mathrm{hr}^{(2)}\end{array}$ & $\begin{array}{c}\text { Approx. } \\
\text { Pulse } \\
\text { Volume, } \\
\text { mL }^{(3)}\end{array}$ \\
\hline \multicolumn{6}{|c|}{ LLNL } \\
\hline UE-7az, 1798.8-1799.5 & TCU-2 & ${ }^{3} \mathrm{H}, \mathrm{Re}, \mathrm{Np}, \mathrm{U}, \mathrm{Pu}, \mathrm{Cs}, \mathrm{Sr}, \mathrm{Sm}$ & \multirow{3}{*}{$\begin{array}{l}\text { Synthetic slot } \\
\text { Synthetic slot } \\
\text { with colloids } \\
\text { Synthetic slot } \\
\text { with FeOH } \\
\text { coating }\end{array}$} & 0.9 & 14.6 \\
\hline UE-7ba, 1626.2-1627.0 & TCU-5 & ${ }^{3} \mathrm{H}, \mathrm{Re}, \mathrm{Np}, \mathrm{U}, \mathrm{Pu}$ & & 0.95 & 11.8 \\
\hline UE-7az, 1678.2-1679.0 & TCU-6 & ${ }^{3} \mathrm{H}, \mathrm{Re}, \mathrm{Np}, \mathrm{U}, \mathrm{Pu}, \mathrm{Cs}, \mathrm{Sr}, \mathrm{Sm}$ & & 1.2 & 19.2 \\
\hline UE-7az, 1678.2-1679.0 & TCU-3 & ${ }^{3} \mathrm{H}, \mathrm{Re}, \mathrm{Np}, \mathrm{U}, \mathrm{Pu}, \mathrm{Cs}, \mathrm{Sr}, \mathrm{Sm}$ & Natural & 0.9 & 15.1 \\
\hline UE-7az, 1779.9-1780.2 & TCU-4 & ${ }^{3} \mathrm{H}, \mathrm{Re}, \mathrm{Np}, \mathrm{U}, \mathrm{Pu}, \mathrm{Cs}, \mathrm{Sr}, \mathrm{Sm}$ & Natural & 0.9 & 15.3 \\
\hline ER-6-1, 2604.7-2605.7 & LCA-1 & ${ }^{3} \mathrm{H}, \mathrm{Re}, \mathrm{Np}, \mathrm{U}, \mathrm{Pu}, \mathrm{Cs}, \mathrm{Sr}, \mathrm{Sm}$ & \multirow{3}{*}{$\begin{array}{l}\text { Synthetic slot } \\
\text { Synthetic slot } \\
\text { Synthetic } \\
\text { induced }\end{array}$} & 0.84 & 16.1 \\
\hline ER-6-1, 2732.2-2733.1 & LCA-2 & ${ }^{3} \mathrm{H}, \mathrm{Re}, \mathrm{Np}, \mathrm{U}, \mathrm{Pu}, \mathrm{Cs}, \mathrm{Sr}, \mathrm{Sm}$ & & 1.29 & 21.6 \\
\hline ER-6-1, 2552.1-2553.1 & LCA-3 & ${ }^{3} \mathrm{H},{ }^{13} \mathrm{C}, \mathrm{Re}, \mathrm{Np}, \mathrm{U}, \mathrm{Pu}, \mathrm{Cs}, \mathrm{Sr}, \mathrm{Sm}$ & & 1.16 & 19.4 \\
\hline \multicolumn{6}{|c|}{ LANL } \\
\hline \multirow{8}{*}{$\begin{array}{l}\text { UE-4a, 2028.9-2031.1 } \\
\text { (TCU) } \\
\text { UE-7az, 1769.1-1771.1 } \\
\text { (TCU) } \\
\text { UE-7ba, 1822.3-1823.7 } \\
\text { (TCU) } \\
\text { UE-7ba, 1862.5-1863.3 } \\
\text { (TCU) }\end{array}$} & high flow & ${ }^{3} \mathrm{H},{ }^{14} \mathrm{C}, \mathrm{U}, \mathrm{Cs}, \mathrm{Np}, \mathrm{Sr}, \mathrm{Pu}$ & Natural & 2 & $43-49$ \\
\hline & low flow & ${ }^{3} \mathrm{H},{ }^{14} \mathrm{C}, \mathrm{U}, \mathrm{Cs}, \mathrm{Np}, \mathrm{Sr}, \mathrm{Pu}$ & Natural & 0.5 & $22-23$ \\
\hline & high flow & ${ }^{3} \mathrm{H},{ }^{14} \mathrm{C}, \mathrm{U}, \mathrm{Cs}, \mathrm{Np}, \mathrm{Sr}, \mathrm{Pu}$ & Natural & 2 & $43-49$ \\
\hline & low flow & ${ }^{3} \mathrm{H},{ }^{14} \mathrm{C}, \mathrm{U}, \mathrm{Cs}, \mathrm{Np}, \mathrm{Sr}, \mathrm{Pu}$ & Natural & 0.5 & $22-23$ \\
\hline & high flow & ${ }^{3} \mathrm{H},{ }^{14} \mathrm{C}, \mathrm{U}, \mathrm{Cs}, \mathrm{Np}, \mathrm{Sr}, \mathrm{Pu}$ & Natural & 2 & $43-49$ \\
\hline & low flow & ${ }^{3} \mathrm{H},{ }^{14} \mathrm{C}, \mathrm{U}, \mathrm{Cs}, \mathrm{Np}, \mathrm{Sr}, \mathrm{Pu}$ & Natural & 0.5 & $22-23$ \\
\hline & high flow & ${ }^{3} \mathrm{H},{ }^{14} \mathrm{C}, \mathrm{U}, \mathrm{Cs}, \mathrm{Np}, \mathrm{Sr}, \mathrm{Pu}$ & Natural & 2 & $43-49$ \\
\hline & low flow & ${ }^{3} \mathrm{H},{ }^{14} \mathrm{C}, \mathrm{U}, \mathrm{Cs}, \mathrm{Np}, \mathrm{Sr}, \mathrm{Pu}$ & Natural & 0.5 & $22-23$ \\
\hline \multirow{3}{*}{$\begin{array}{l}\text { ER-6-1, 2399.4-2400.1 } \\
\text { (LCA) }\end{array}$} & high flow & ${ }^{3} \mathrm{H},{ }^{14} \mathrm{C}, \mathrm{U}, \mathrm{Cs}, \mathrm{Np}, \mathrm{Sr}, \mathrm{Pu}$ & Natural & 2 & $49-50$ \\
\hline & low flow & ${ }^{3} \mathrm{H},{ }^{14} \mathrm{C}, \mathrm{U}, \mathrm{Cs}, \mathrm{Np}, \mathrm{Sr}, \mathrm{Pu}$ & Natural & 0.5 & $21-23$ \\
\hline & low flow \#2 & ${ }^{3} \mathrm{H}, \mathrm{Cs}, \mathrm{Np}$ & Natural & 0.5 & $21-23$ \\
\hline \multirow{3}{*}{$\begin{array}{l}\text { ER-6-1, 2512.0-2512.8 } \\
\text { (LCA) }\end{array}$} & high flow & ${ }^{3} \mathrm{H},{ }^{14} \mathrm{C}, \mathrm{U}, \mathrm{Cs}, \mathrm{Np}, \mathrm{Sr}, \mathrm{Pu}$ & Natural & 2 & $49-50$ \\
\hline & low flow & ${ }^{3} \mathrm{H},{ }^{14} \mathrm{C}, \mathrm{U}, \mathrm{Cs}, \mathrm{Np}, \mathrm{Sr}, \mathrm{Pu}$ & Natural & 0.5 & $21-23$ \\
\hline & low flow \#2 & ${ }^{3} \mathrm{H}, \mathrm{Cs}, \mathrm{Np}$ & Natural & 0.5 & $21-23$ \\
\hline \multirow{3}{*}{$\begin{array}{l}\text { ER-6-1, 2675.0-2675.7 } \\
\text { (LCA) }\end{array}$} & high flow & ${ }^{3} \mathrm{H},{ }^{14} \mathrm{C}, \mathrm{U}, \mathrm{Cs}, \mathrm{Np}, \mathrm{Sr}, \mathrm{Pu}$ & Natural & 2 & $49-50$ \\
\hline & low flow & ${ }^{3} \mathrm{H},{ }^{14} \mathrm{C}, \mathrm{U}, \mathrm{Cs}, \mathrm{Np}, \mathrm{Sr}, \mathrm{Pu}$ & Natural & 0.5 & $21-23$ \\
\hline & low flow \#2 & ${ }^{3} \mathrm{H}, \mathrm{Cs}, \mathrm{Np}$ & Natural & 0.5 & $21-23$ \\
\hline \multirow{3}{*}{$\begin{array}{l}\text { ER-6-1, 2846.5-2847.3 } \\
\text { (LCA) }\end{array}$} & high flow & ${ }^{3} \mathrm{H},{ }^{14} \mathrm{C}, \mathrm{U}, \mathrm{Cs}, \mathrm{Np}, \mathrm{Sr}, \mathrm{Pu}$ & Natural & 2 & $49-50$ \\
\hline & low flow & ${ }^{3} \mathrm{H},{ }^{14} \mathrm{C}, \mathrm{U}, \mathrm{Cs}, \mathrm{Np}, \mathrm{Sr}, \mathrm{Pu}$ & Natural & 0.5 & $21-23$ \\
\hline & low flow \#2 & ${ }^{3} \mathrm{H}, \mathrm{Cs}, \mathrm{Np}$ & Natural & 0.5 & $21-23$ \\
\hline \multirow{3}{*}{$\begin{array}{l}\text { ER-6-1, 2915.0-2915.8 } \\
\text { (LCA) }\end{array}$} & high flow & ${ }^{3} \mathrm{H},{ }^{14} \mathrm{C}, \mathrm{U}, \mathrm{Cs}, \mathrm{Np}, \mathrm{Sr}, \mathrm{Pu}$ & Natural & 2 & $49-50$ \\
\hline & low flow & ${ }^{3} \mathrm{H},{ }^{14} \mathrm{C}, \mathrm{U}, \mathrm{Cs}, \mathrm{Np}, \mathrm{Sr}, \mathrm{Pu}$ & Natural & 0.5 & $21-23$ \\
\hline & low flow \#2 & ${ }^{3} \mathrm{H}, \mathrm{Cs}, \mathrm{Np}$ & Natural & 0.5 & $21-23$ \\
\hline \multirow{3}{*}{$\begin{array}{l}\text { ER-6-1, 3028.0-3029.0 } \\
\text { (LCA) }\end{array}$} & high flow & ${ }^{3} \mathrm{H},{ }^{14} \mathrm{C}, \mathrm{U}, \mathrm{Cs}, \mathrm{Np}, \mathrm{Sr}, \mathrm{Pu}$ & Natural & 2 & $45-50$ \\
\hline & low flow & $\mathrm{I},{ }^{14} \mathrm{C}, \mathrm{U}, \mathrm{Cs}, \mathrm{Np}$ & Natural & 0.5 & 23 \\
\hline & low flow \#2 & ${ }^{3} \mathrm{H}, \mathrm{Cs}, \mathrm{Np}$ & Natural & 0.5 & 23 \\
\hline \multirow{3}{*}{$\begin{array}{l}\text { ER-6-2, 2730.2-2730.7 } \\
\text { (LCA) }\end{array}$} & high flow & ${ }^{3} \mathrm{H},{ }^{14} \mathrm{C}, \mathrm{U}, \mathrm{Cs}, \mathrm{Np}, \mathrm{Sr}, \mathrm{Pu}$ & Natural & 2 & $45-50$ \\
\hline & low flow & ${ }^{3} \mathrm{H},{ }^{14} \mathrm{C}, \mathrm{U}, \mathrm{Cs}, \mathrm{Np}$ & Natural & 0.5 & 23 \\
\hline & low flow \#2 & ${ }^{3} \mathrm{H}, \mathrm{Cs}, \mathrm{Np}$ & Natural & 0.5 & 23 \\
\hline \multirow{3}{*}{$\begin{array}{l}\text { ER-6-2, 2749.9-2750.9 } \\
\text { (LCA) }\end{array}$} & high flow & ${ }^{3} \mathrm{H},{ }^{14} \mathrm{C}, \mathrm{U}, \mathrm{Cs}, \mathrm{Np}, \mathrm{Sr}, \mathrm{Pu}$ & Natural & 2 & $45-50$ \\
\hline & low flow & ${ }^{3} \mathrm{H},{ }^{14} \mathrm{C}, \mathrm{U}, \mathrm{Cs}, \mathrm{Np}$ & Natural & 0.5 & 23 \\
\hline & low flow \#2 & ${ }^{3} \mathrm{H}, \mathrm{Cs}, \mathrm{Np}$ & Natural & 0.5 & 23 \\
\hline
\end{tabular}




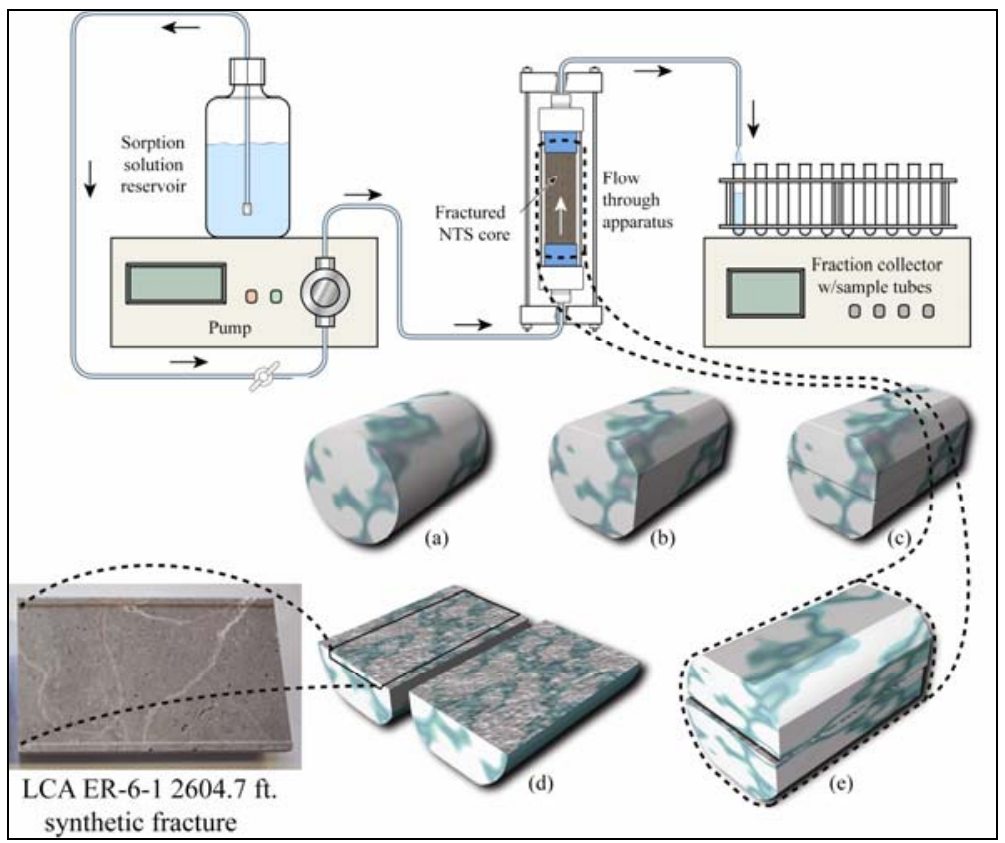

Figure 1. Schematic illustration of LLNL flowthrough transport experiments - (a) to (e) show steps in experiment preparation for slotted fractures. Sample core (a) has reference flats ground on end surfaces and at relative azimuths of 0,90 , and $180^{\circ}$ on the cylindrical surface (b); core is cut in half (c); is laid open and a 500 or $50 \mu \mathrm{m}$ wide slot is ground into one side (d); finally it is reassembled (e) for experiments. Top of diagram shows how fluid moved through the fractured core. Images (a)(e) from Durham et al. (2001).

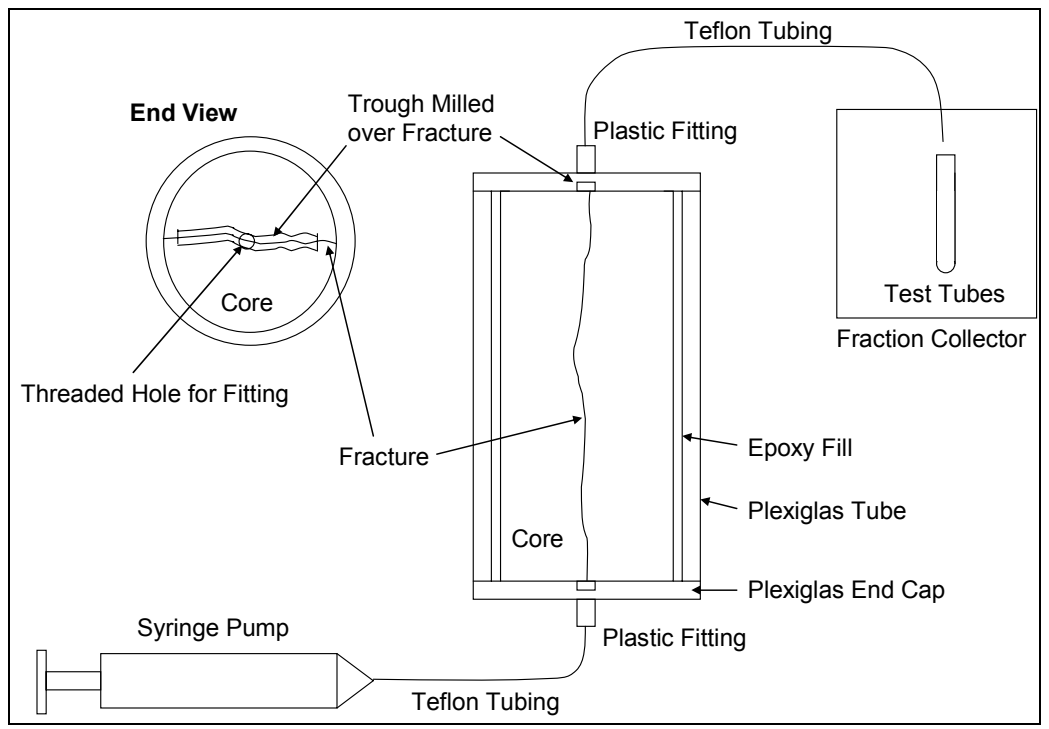

Figure 2. Schematic Illustration of LANL flowthrough transport experiments. The fractured cores were encapsulated within a Plexiglas tube using epoxy to fill the annular space, with the flow manifolds fixed in place on either end to allow introduction and collection of water. The sides of the core were sealed to serve as no-flow boundaries (Ware et al., 2005). 
Table 2. Measured core dimensions, inlet and outlet tubing volumes, and measured porosity for flowthrough transport experiments.

\begin{tabular}{cccccc}
\hline Hole, Core Interval (ft) & $\begin{array}{c}\text { Length, } \\
\text { cm }\end{array}$ & $\begin{array}{c}\text { Diameter, } \\
\text { cm }\end{array}$ & $\begin{array}{c}\text { Aperture, } \\
\text { cm }\end{array}$ & $\begin{array}{c}\text { Tubing } \\
\text { Volume, mL }\end{array}$ & Porosity \\
\hline & \multicolumn{5}{c}{ LLNL } \\
UE-7az, 1798.8-1799.5 (TCU) & 10.20 & 4.44 & 0.05 & 1.72 & 0.291 \\
UE-7az, 1678.2-1679.0 (TCU) & 9.62 & 4.43 & $\dagger$ & 1.72 & 0.337 \\
UE-7az 1779.9-1780.2 (TCU) & 5.84 & 4.45 & $\dagger$ & 1.72 & 0.308 \\
UE-7ba, 1626.2-1627.0 (TCU) & 10.18 & 4.44 & 0.05 & 1.79 & 0.309 \\
UE-7az, 1678.2-1679.0 (TCU) & 9.06 & 4.43 & 0.05 & 1.79 & 0.337 \\
ER-6-1, 2604.7-2605.7 (LCA) & 11.28 & 7.05 & 0.05 & 2.51 & 0.022 \\
ER-6-1, 2732.2-2733.1 (LCA) & 11.56 & 7.07 & 0.05 & 2.01 & 0.016 \\
ER-6-1, 2552.1-2553.1 (LCA) & 11.25 & 7.06 & $\dagger$ & 2.01 & 0.017 \\
\hline & & LANL & & & 0.370 \\
\hline UE-4a, 2028.9-2031.1 (TCU) & 20.50 & 8.00 & $\dagger$ & 1.95 & 0.365 \\
UE-7az, 1769.1-1771.1 (TCU) & 13.00 & 6.00 & $\dagger$ & 1.85 & 0.275 \\
UE-7ba, 1822.3-1823.7 (TCU) & 15.50 & 6.00 & $\dagger$ & 2.03 & 0.270 \\
UE-7ba, 1862.5-1863.3 (TCU) & 16.00 & 6.00 & $\dagger$ & 2.45 & 0.009 \\
ER-6-1, 2399.4-2400.1 (LCA) & 9.00 & 8.00 & $\dagger$ & 3.39 & 0.025 \\
ER-6-1, 2512.0-2512.8 (LCA) & 16.50 & 8.00 & $\dagger$ & 3.68 & 0.021 \\
ER-6-1, 2675.0-2675.7 (LCA) & 17.50 & 8.00 & $\dagger$ & 3.22 & 0.020 \\
ER-6-1, 2846.5-2847.3 (LCA) & 18.50 & 8.00 & $\dagger$ & 3.49 & 0.030 \\
ER-6-1, 2915.0-2915.8 (LCA) & 13.50 & 8.00 & $\dagger$ & 4.54 & 0.024 \\
ER-6-1, 3028.0-3029.0 (LCA) & 12.00 & 8.00 & $\dagger$ & 3.92 & 0.009 \\
ER-6-2, 2730.2-2730.7 (LCA) & 8.50 & 8.00 & $\dagger$ & 3.28 & 0.004 \\
ER-6-2, 2749.9-2750.9 (LCA) & 10.50 & 8.00 & $\dagger$ & & \\
\hline
\end{tabular}

$\uparrow$ No measured aperture for the natural fractures; see Table 6 for apertures derived from modeling.

\section{Background solution}

The solutions used in all flowthrough experiments were based on natural waters pumped from wells in Yucca Flat (Table 3). LLNL used synthetic groundwater for all flowthrough experiments. The TCU and LCA solutions were based on measured concentrations of major ions in groundwaters sampled from the respective hydrostratigraphic units and reported in the UGTA geochemistry database (SNJV, 2004). However, LCA waters typically have high $\mathrm{CO}_{2}$ which can degas under atmospheric conditions (e.g. LCA-1 $\mathrm{pCO}_{2}=1.7$ ) and result in calcite precipitation. In two LCA experiments (LCA-2, LCA-3), the solution $\mathrm{CO}_{2}$ fugacity was lowered and $\mathrm{pH}$ raised to reduce the potential for calcite precipitation (Table 3). In essence, solutions were allowed to come to equilibrium with atmospheric $\mathrm{CO}_{2}$ (i.e. $\mathrm{pCO}_{2} \sim 3.5$ ) and calcite solubility. In one TCU experiment, clinoptilolite colloids were added to the synthetic groundwater (and to the radionuclide spiked water) to examine the potential for colloid-facilitated transport. The colloid load was $90 \mathrm{mg} / \mathrm{L}$ and average particle size was $160 \mathrm{~nm}$. For their LCA flowthrough experiments, LANL used natural groundwater pumped from ER-6-1 \#2. The groundwater was collected on January 16, 2003 in 55-gallon plastic drums that were transported to and stored at LANL. The ER-6-1 \#2 water was analyzed just before the flowthrough experiments were initiated, which was approximately 15 months after the water was collected in the field. Ware et al. (2005) compared analyses of the same water at two earlier times by SNJV and DRI and 
concluded that no significant change in solution composition had occurred. There was also no evidence of microbial growth. Tor their TCU flowthrough experiments, LANL used synthetic water based on the chemistry of well ER-2-1. No pH adjustments or attempts to control $\mathrm{CO}_{2}$ overpressure were made in any LANL experiments.

All water, whether natural or synthetic, was filtered through a $0.2-\mu \mathrm{m}$ filter to remove large colloidal material and microbes that may have been present. However, in the case of the LANL synthetic water, this filtration was conducted shortly after the preparation of the water, and no subsequent filtration was done. This point is significant because some of the water aged for up to 6 months because of a 3-1/2-month stand down in operations at LANL. As will be shown later, there was evidence of colloid formation in the synthetic ER-2-1 water, possibly because of precipitation of amorphous silica or calcite. This colloid formation likely resulted in unintended colloid-facilitated transport of some of the radionuclides in LANL TCU flowthrough experiments. The LLNL synthetic water was filtered prior to the beginning of each flowthrough experiment, except for the colloid-facilitated transport experiment.

Table 3. Composition of background solutions used in flowthrough experiments.

\begin{tabular}{|c|c|c|c|c|c|c|c|c|c|}
\hline & pH & ${ }^{1} \mathrm{HCO}_{3}$ & $\mathbf{N a}$ & $\mathbf{C a}$ & nol/L - - & 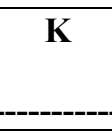 & Cl & $\begin{array}{c}\text { Calcite } \\
\text { Saturation } \\
\log (Q / K)\end{array}$ & $\mathrm{pCO}_{2}$ \\
\hline \multicolumn{10}{|c|}{ LLNL Synthetic TCU and LCA Groundwaters (by Experiment Designation) } \\
\hline TCU-2,3,4 & 8.3 & $4.2 \mathrm{E}-3$ & $4.4 \mathrm{E}-3$ & $1.2 \mathrm{E}-4$ & $2.0 \mathrm{E}-5$ & $1.4 \mathrm{E}-4$ & $4.9 \mathrm{E}-4$ & 0.08 & 2.9 \\
\hline TCU $-5^{2}$ & 8.1 & $3.2 \mathrm{E}-3$ & $4.6 \mathrm{E}-3$ & $2.4 \mathrm{E}-4$ & $5.8 \mathrm{E}-5$ & $1.8 \mathrm{E}-4$ & $3.2 \mathrm{E}-4$ & 0.07 & 2.8 \\
\hline TCU-6 & 8.3 & $3.8 \mathrm{E}-3$ & $4.4 \mathrm{E}-3$ & $1.5 \mathrm{E}-4$ & $2.3 \mathrm{E}-5$ & $1.5 \mathrm{E}-4$ & $4.2 \mathrm{E}-4$ & 0.1 & 2.9 \\
\hline LCA-1 & 7.1 & $5.0 \mathrm{E}-3$ & $2.6 \mathrm{E}-3$ & $5.2 \mathrm{E}-4$ & $7.3 \mathrm{E}-4$ & $2.4 \mathrm{E}-4$ & $5.1 \mathrm{E}-4$ & -0.5 & 1.7 \\
\hline LCA-2,3 & 7.9 & $5.5 \mathrm{E}-4$ & $2.7 \mathrm{E}-3$ & $1.4 \mathrm{E}-3$ & $7.9 \mathrm{E}-4$ & $2.5 \mathrm{E}-4$ & $5.3 \mathrm{E}-3$ & -0.2 & 3.4 \\
\hline \multicolumn{10}{|c|}{ LANL Groundwaters } \\
\hline $\begin{array}{l}\text { ER-2-1-tuff } \\
\text { (synthetic) }\end{array}$ & 8.7 & $2.9 \mathrm{E}-3$ & $3.2 \mathrm{E}-3$ & $8.7 \mathrm{E}-5$ & $2.1 \mathrm{E}-5$ & $1.4 \mathrm{E}-4$ & $1.6 \mathrm{E}-4$ & 0.2 & 3.5 \\
\hline $\begin{array}{l}\text { ER-6-1\#2- } \\
\text { LCA (natural) }\end{array}$ & 7.7 & $4.0 \mathrm{E}-3$ & $2.7 \mathrm{E}-3$ & 7.7E-4 & $5.4 \mathrm{E}-4$ & $1.9 \mathrm{E}-4$ & $3.0 \mathrm{E}-4$ & 0.2 & 2.3 \\
\hline
\end{tabular}

\section{Radionuclide sorption solution}

The radionuclide concentrations in the injection solutions used in the flowthrough experiments are listed in Table 4. ${ }^{3} \mathrm{HHO}$ was used as a non-sorbing tracer in all of the fracture transport experiments. The reactive transport behavior of the sorbing radionuclides could be determined by comparing their breakthrough curves with that of ${ }^{3} \mathrm{HHO}$. LLNL also used Re as a second non-sorbing (Andersson et al., 2004) tracer. ${ }^{3} \mathrm{HHO}$ and Re have significantly different diffusivities in water $\left(2.4 \times 10^{-5}\right.$ and $1.5 \times 10^{-5} \mathrm{~cm}^{2} / \mathrm{sec}$, respectively). The differences in their breakthrough reflect differences in their matrix diffusion, which can be used to quantify tortuosity.

The Cs concentration used at LLNL is 6 orders of magnitude higher than that used at LANL. LLNL used a high Cs concentration to overcome the background concentration of natural Cs in the tuff. LANL used radioactive ${ }^{137} \mathrm{Cs}$ and could distinguish between background Cs (non- 
radioactive) and introduced (radioactive) ${ }^{137} \mathrm{Cs}$. Differences in Sr concentration are similar for the same reason. Interestingly, these differences can be exploited to examine the effects of radionuclide concentration on transport (i.e. sorption non-linearity).

Table 4. Sorption solution composition used in the flowthrough experiments.

\begin{tabular}{|c|c|c|c|c|c|c|c|c|c|}
\hline Sample \# & ${ }^{3} \mathrm{HHO}$ & ${ }^{14} \mathrm{C}$ & $\mathrm{Re}_{\text {nat. }}$ & ${ }^{237} \mathrm{~Np}$ & $\begin{array}{l}\mathrm{U}_{\text {nat. }} \text { or } \\
{ }^{233} \mathrm{U}^{\mathrm{b}}\end{array}$ & ${ }^{238,239} \mathrm{Pu}$ & $\begin{array}{l}\mathrm{Sr}_{\text {nat. }} \text { or } \\
{ }^{90} \mathrm{Sr}^{\mathrm{a}}\end{array}$ & $\begin{array}{l}\mathrm{Cs}_{\text {nat. }} \text { or } \\
{ }^{137} \mathrm{Cs}^{\mathrm{a}}\end{array}$ & $\mathrm{Sm}_{\text {nat. }}$ \\
\hline \multicolumn{10}{|l|}{ LLNL } \\
\hline TCU-2 & \multirow{8}{*}{$\sim 1 \mathrm{E}-10$} & - & $9.8 \mathrm{E}-6$ & $4.5 \mathrm{E}-6$ & $4.5 \mathrm{E}-6$ & $5.6 \mathrm{E}-9$ & $1.0 \mathrm{E}-4$ & $1.1 \mathrm{E}-4$ & $8.2 \mathrm{E}-7$ \\
\hline TCU-3 & & - & $9.2 \mathrm{E}-6$ & $3.0 \mathrm{E}-6$ & $4.6 \mathrm{E}-6$ & $6.9 \mathrm{E}-9$ & $9.5 \mathrm{E}-5$ & $9.8 \mathrm{E}-5$ & 8.8E-7 \\
\hline TCU-4 & & - & $1.1 \mathrm{E}-5$ & $3.8 \mathrm{E}-6$ & $5.8 \mathrm{E}-6$ & $5.2 \mathrm{E}-9$ & $1.0 \mathrm{E}-4$ & $9.6 \mathrm{E}-5$ & $7.5 \mathrm{E}-7$ \\
\hline TCU-5 ${ }^{\mathrm{b}}$ & & - & $9.1 \mathrm{E}-6$ & $4.7 \mathrm{E}-6$ & $4.0 \mathrm{E}-6$ & $6.3 \mathrm{E}-9$ & $1.0 \mathrm{E}-6^{*}$ & $1.0 \mathrm{E}-7^{*}$ & $7.6 \mathrm{E}-8^{\mathrm{c}}$ \\
\hline TCU-6 & & - & $8.4 \mathrm{E}-6$ & $2.8 \mathrm{E}-6$ & $4.2 \mathrm{E}-6$ & $5.1 \mathrm{E}-9$ & $8.4 \mathrm{E}-5$ & $8.5 \mathrm{E}-5$ & $5.4 \mathrm{E}-7$ \\
\hline LCA-1 & & - & $9.3 \mathrm{E}-6$ & $6.5 \mathrm{E}-6$ & 4.7E-6 & $6.0 \mathrm{E}-9$ & $9.3 \mathrm{E}-5$ & $1.2 \mathrm{E}-4$ & $8.4 \mathrm{E}-7$ \\
\hline LCA-2 & & - & $9.5 \mathrm{E}-6$ & $5.4 \mathrm{E}-6$ & 4.3E-6 & $5.4 \mathrm{E}-9$ & $8.4 \mathrm{E}-5$ & $7.8 \mathrm{E}-5$ & $8.2 \mathrm{E}-7$ \\
\hline LCA-3 & & - & $8.2 \mathrm{E}-6$ & 4.7E-6 & $3.7 \mathrm{E}-6$ & $4.2 \mathrm{E}-9$ & $8.1 \mathrm{E}-5$ & $8.0 \mathrm{E}-5$ & 4.9E-7 \\
\hline \multicolumn{10}{|l|}{ LANL } \\
\hline & $\begin{array}{l}1.1 \times 10^{-10} \text { to } \\
2.5 \times 10^{-10}\end{array}$ & $\begin{array}{c}9.6 \times 10^{-9} \text { to } \\
2.1 \times 10^{-8}\end{array}$ & - & $\begin{array}{c}1.2 \mathrm{E}-6 \text { to } \\
7.8 \mathrm{E}-6\end{array}$ & $\begin{array}{c}6.4 \mathrm{E}-8 \text { to } \\
2.5 \mathrm{E}-7\end{array}$ & $\begin{array}{c}1.5 \mathrm{E}-8 \text { to } \\
1.1 \mathrm{E}-7\end{array}$ & $\begin{array}{c}8.3 \mathrm{E}-12 \text { to } \\
6.6 \mathrm{E}-11\end{array}$ & $\begin{array}{c}2.3 \mathrm{E}-11 \text { to } \\
2.3 \mathrm{E}-10\end{array}$ & - \\
\hline
\end{tabular}

\section{Fracture Transport Experiment Interpretation}

All fracture transport experiments were interpreted using the same semi-analytical dual-porosity transport models, RELAP or RETRAN. RELAP is described in detail in Reimus and Haga (1999) and Reimus et al. (2003). It essentially combines the Laplace-domain dual-porosity transport equations derived by Maloszewski and Zuber (1984; 1985), modified to account for linear, reversible sorption (either rate-limited or equilibrium), with Laplace-domain transfer functions that describe a finite-pulse injection. RELAP also has features to account for wellbore mixing and recirculation that apply to field tracer tests, but these were not used for this study. Maloszewski and Zuber $(1984 ; 1985)$ assumed that tracer transport in fractures was described by the one-dimensional advection-dispersion equation with one-dimensional diffusion occurring into the surrounding matrix perpendicular to the flow direction in fractures. The model assumes parallel-plate fractures of constant aperture, $2 b$, and either constant fracture spacing, $l$, or infinite spacing (a semi-infinite matrix), no concentration gradients across the fracture aperture, steady flow rate in fractures, and zero flow in the matrix. The infinite spacing case is equivalent to the solution by Tang et al. (1981) and used in the fracture transport interpretations reported in Zavarin et al. (2005).

RELAP provides a simultaneous least-squares fit of up to four species (sorbing and/or nonsorbing) by automatically adjusting the following model parameters, which arise from the dimensionless forms of the governing equations: 
- the mean fluid residence time in fractures $\left(\tau=\mathrm{L} / v_{f}\right)$

- the Peclet number $\left(P e=\mathrm{L} / \alpha\right.$ and $\alpha=$ dispersivity $\left.=D_{\mathrm{f}} / v_{\mathrm{f}}\right)$

- a matrix diffusion mass-transfer coefficient, $\frac{\phi}{b} \sqrt{D_{\mathrm{m}}}$

- a characteristic fracture spacing, $l$

- a fracture retardation factor, $R_{\mathrm{f}}$

- a matrix retardation factor, $R_{\mathrm{m}}$

- fracture and matrix sorption rate constants, $k_{\mathrm{f}}$ and $k_{\mathrm{m}}$. Note that when rate-limited sorption is assumed, the desorption rate constants, $k_{\mathrm{rf}}$ or $k_{\mathrm{rm}}$, become $k_{\mathrm{rm}}=k_{\mathrm{m}} \phi / \rho_{\mathrm{B}}\left(\mathrm{R}_{\mathrm{m}}-1\right)$ and $k_{\mathrm{rf}}=k_{\mathrm{f}}$ $\eta / \rho_{\mathrm{f}}\left(\mathrm{R}_{\mathrm{f}}-1\right)$.

where:

$\mathrm{L}=$ length of fracture, $\mathrm{m}$

$v_{\mathrm{f}}=$ fluid velocity in fractures (in $\mathrm{x}$ direction), $\mathrm{cm} / \mathrm{sec}$

$D_{\mathrm{f}}=$ dispersion coefficient in fractures, $\mathrm{cm}^{2} / \mathrm{sec}$

$D_{\mathrm{m}}=$ molecular diffusion coefficient in matrix, $\mathrm{cm}^{2} / \mathrm{sec}$

$\phi=$ matrix porosity

$b=$ fracture half aperture, $\mathrm{cm}$

$R_{\mathrm{f}}=$ retardation factor in fractures $=1+(\mathrm{SA} / \mathrm{V}) k_{a}\left(\right.$ or $1+\frac{2}{b} k_{A}$ for open parallel-plate

fractures). Alternatively, for fractures that are filled with aquifer material, $R_{\mathrm{f}}=1+\frac{\rho_{\mathrm{f}}}{\eta} K_{\mathrm{d}}$

$R_{\mathrm{m}}=$ retardation factor in matrix $=1+\frac{\rho_{\mathrm{B}}}{\phi} K_{\mathrm{d}}$

$K_{\mathrm{d}}=$ sorption partitioning coefficient $=$ mass of tracer sorbed per unit mass of aquifer material divided by solution concentration of tracer at equilibrium, $\mathrm{cm}^{3} / \mathrm{g}$

$k_{A}=K_{\mathrm{d}} / A_{\mathrm{sp}}$ sorption partitioning coefficient on a unit surface area basis (i.e., mass of tracer sorbed per unit surface area of aquifer material divided by solution concentration of tracer at equilibrium $-K_{\mathrm{d}}$ is defined above, and $A_{\mathrm{sp}}$ is defined below), $\mathrm{cm}^{3} / \mathrm{cm}^{2}$

$A_{\mathrm{sp}}=$ surface area per unit mass of material in fractures, $\mathrm{cm}^{2} / \mathrm{g}$

$\mathrm{SA} / \mathrm{V}=$ surface area of fracture surfaces per unit volume of solution in fracture, $\mathrm{cm}^{2} / \mathrm{cm}^{3}$

$\rho_{\mathrm{f}}=$ bulk density in fractures, $\mathrm{g} / \mathrm{cm}^{3}$

$\rho_{\mathrm{B}}=$ bulk density in matrix, $\mathrm{g} / \mathrm{cm}^{3}$

$\eta=$ porosity within fractures.

RELAP can also be used to model colloid-facilitated transport. In this case, colloid diffusion into the matrix is set to zero (assuming the colloids are too large to effectively diffuse into the matrix) and the fracture sorption rate constant, $k_{f}$, becomes the colloid filtration rate constant:

$k_{f}=$ filtration rate constant, $\mathrm{hr}^{-1}=\lambda v_{f}$, where $\lambda=$ filtration coefficient, $\mathrm{cm}^{-1}$.

A colloid desorption rate $\left(k_{r f}\right)$ can be included in the model. However, in most colloid-facilitated transport model fits described below, the colloid desorption rate constant was set to zero. In 
effect, sorbed colloids were not allowed to desorb from fracture walls.

The RELAP interpretive approach applied to the LANL flowthrough experiments involved first plotting the ${ }^{3} \mathrm{HHO}$ breakthrough curves from all runs in a given fracture as a function of volume eluted. These plots provided a qualitative indication of the reproducibility of the ${ }^{3} \mathrm{HHO}$ transport in each fracture and served to identify experiments with anomalous transport behavior. A change in the volume associated with the first arrival of tracer or in the general shape of the rising portion of ${ }^{3} \mathrm{HHO}$ breakthrough curves suggested a change in the fracture geometry. Such changes in geometry could occur as a result of (1) pressure differences between experiments (e.g. different flow rates), (2) fracture surfaces coming to rest in slightly different relative positions between high and low pressure cycles. Although the fractures were embedded in epoxy (Figure 2), RTV silicone was used to seal their edges, so the flow systems could not be considered completely rigid.

The quantitative RELAP interpretive process started with simultaneously fitting ${ }^{3} \mathrm{HHO}$ data sets from all reproducible flowthrough runs in the same fracture. The $\tau, P e$, and $\frac{\phi}{b} \sqrt{D_{\mathrm{m}}}$ were fitted subject to the constraint that (1) the ratio of the mean residence times at the two flow rates must be equal to the ratio of the inverse of the flow rates, and (2) the Peclet number remains constant. The fracture and matrix retardation factors were set to 1.0. When fitting any remaining (nonreproducible) flowthrough runs from the same fracture, $\tau, P e$, and $\frac{\phi}{b} \sqrt{D_{\mathrm{m}}}$ were again adjusted to fit ${ }^{3} \mathrm{HHO}$ breakthrough data sets. Relatively liberal adjustments to $\tau, P e$, and $\frac{\phi}{b} \sqrt{D_{\mathrm{m}}}$ were allowed to fit the non-reproducible flowthrough runs, particularly in cases where the volumes associated with first arrival and the overall curve shapes were significantly different from the reproducible ${ }^{3} \mathrm{HHO}$ curves. It was important to allow this flexibility to obtain better fits to the ${ }^{3} \mathrm{HHO}$ data from individual experiments in each fracture because the overall objective was to obtain estimates of fracture and matrix retardation factors (or sorption/desorption rate constants) of the sorbing radionuclides relative to ${ }^{3} \mathrm{HHO}$. Any errors associated with fitting the ${ }^{3} \mathrm{HHO}$ breakthrough curves would be propagated directly into errors in the estimated reactive transport parameters.

After obtaining a satisfactory fit to all the ${ }^{3} \mathrm{HHO}$ data in a given fracture, the other radionuclide breakthrough curves were fitted using the same parameters that provided good fits to the ${ }^{3} \mathrm{HHO}$ responses but with fracture and matrix retardation factors and/or sorption and desorption rate constants used as adjustable fitting parameters. It was assumed that the relative matrix diffusion coefficients for each radionuclide will be approximately equal to their relative matrix diffusion coefficients in free-water. This assumption has been shown to hold true for nonsorbing anions used as tracers in laboratory and field experiments (Reimus et al., 2002; Bechtel-SAIC, 2004). Table 5 lists the relative $\left(25^{\circ} \mathrm{C}\right)$ diffusion coefficients assumed in RELAP/RETRAN. Note that the diffusion coefficients used in Zavarin et al. (2005) differ slightly from those listed here. They were different for tritium and the actinides/lanthanides $\left(2.2 \times 10^{-5}\right.$ and $1.5 \times 10^{-5} \mathrm{~cm}^{2} / \mathrm{sec}$, 
respectively (Mills and Lobo, 1989)) $)^{3}$ due, primarily, to the different source of diffusion data. This difference is rather small and will not significantly affect the resulting data fits. All diffusion coefficients are referenced to $25^{\circ} \mathrm{C}$.

Table 5. Relative values of radionuclide matrix diffusion coefficients.

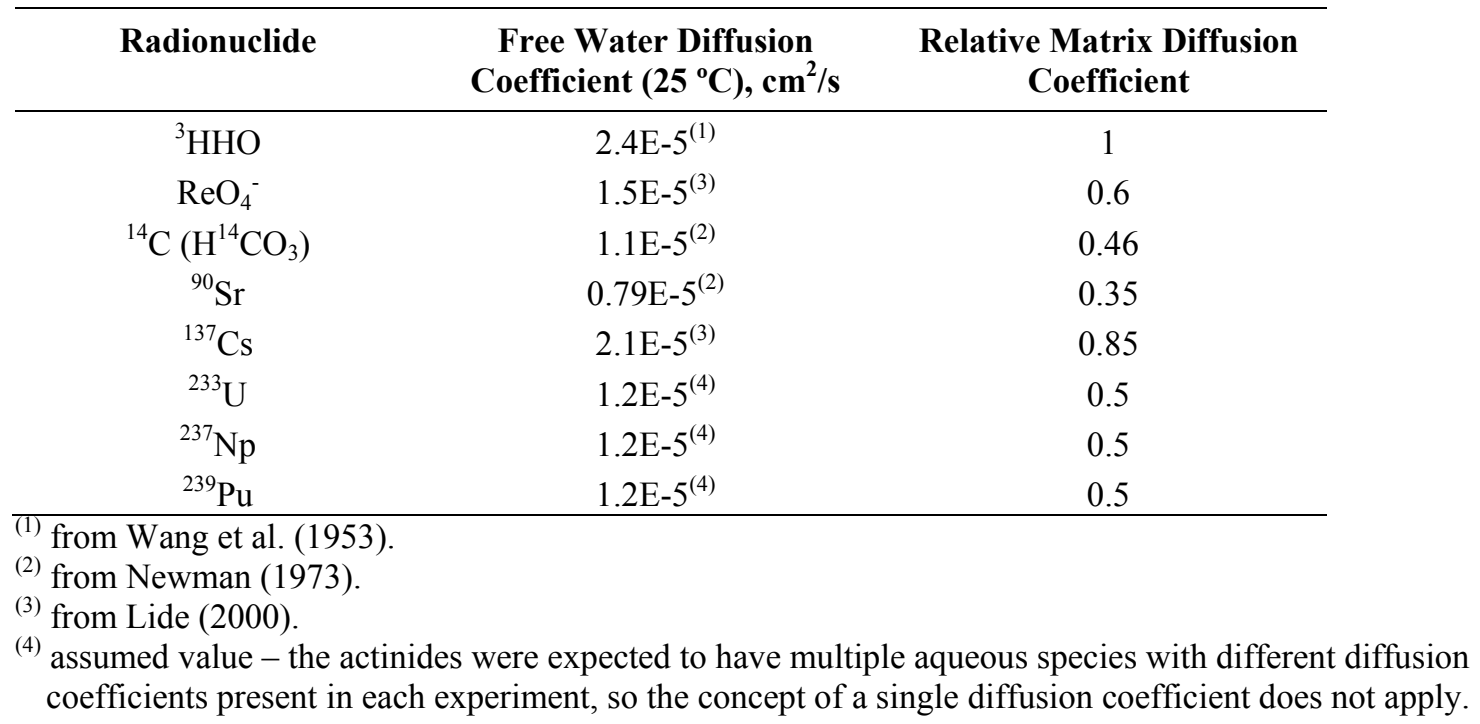

The approach to interpreting the LLNL fracture data sets was modified from that described above because only one experiment was conducted at a single flow rate in each fracture. However, each experiment included both ${ }^{3} \mathrm{HHO}$ and $\mathrm{Re}$ (as $\mathrm{ReO}_{4}{ }^{-}$) nonsorbing tracers and several of the experiments were artificially slotted so that they had known fracture apertures. This helped simplify the modeling and reduce the number of unknown parameters. For slotted fractures, the mean residence time in the experiments could be calculated directly as the known volume of the fracture divided by the flow rate. An estimate of tortuosity could be obtained by comparing ${ }^{3} \mathrm{HHO}$ and Re matrix diffusion behavior. Lide (2000) provides a free-water diffusion coefficient of $1.46 \times 10^{-5} \mathrm{~cm}^{2} / \mathrm{s}$ for $\mathrm{ReO}_{4}^{-}$, which is a factor of 0.6 that of ${ }^{3} \mathrm{HHO}$. However, when this ratio was used to simultaneously fit the ${ }^{3} \mathrm{HHO}$ and Re breakthrough curves, the difference in the normalized concentrations of the tracers was often underpredicted. Some ${ }^{3} \mathrm{HHO}$ was lost to exchange with air at the fraction collector, which resulted in artificially low ${ }^{3} \mathrm{HHO}$ concentrations (Figure 3). Some sample evaporation at the fraction collector could also have artificially increased the Re concentration. This combination of effects would tend to increase the difference in normalized concentration of the two non-sorbing tracers. However, the evaporation effect was expected to be smaller than the loss of ${ }^{3} \mathrm{HHO}$ due to air exchange. Thus, the fit to the Re breakthrough was favored at the expense of ${ }^{3} \mathrm{HHO}$ when these two breakthrough curves could not be fit simultaneously.

${ }^{3}$ The diffusion of all actinides and lanthanides (U, Np, Pu, and $\mathrm{Sm}$ ) was assumed to be equivalent to the diffusion of Tc in water based on similarity in the ion size of the predominant aqueous species; it was impractical to try to accurately predict the diffusivity of these radionuclides since multiple aqueous species were predicted to be present in solution and each would diffuse at a different rate. 

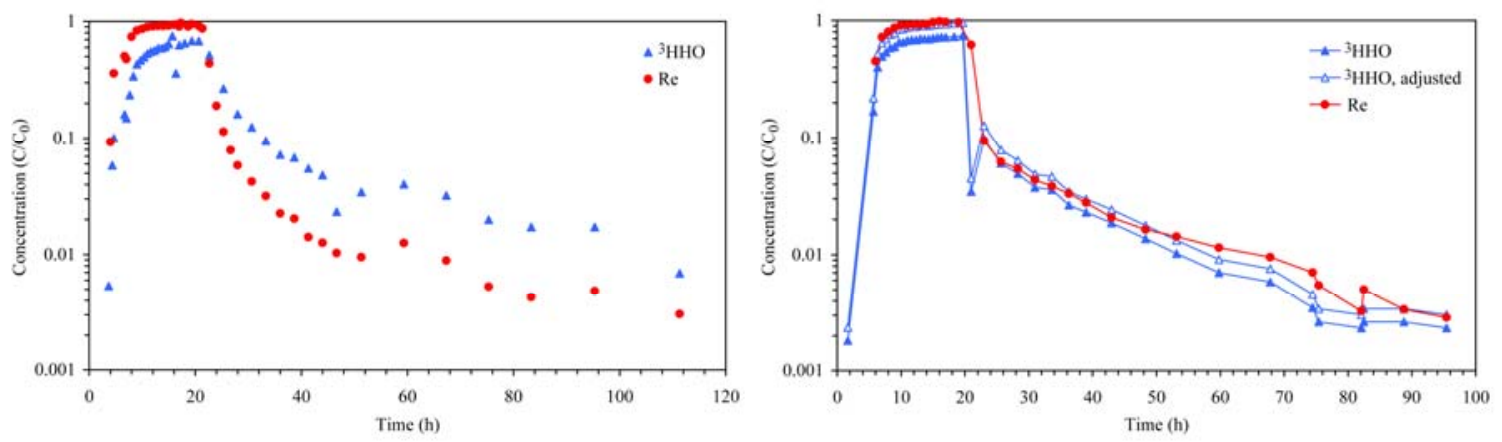

Figure 3. Breakthrough profiles of ${ }^{3} \mathrm{HHO}$ and Re in tuff and carbonate rock. In tuff, the tracer with higher diffusivity (i.e. ${ }^{3} \mathrm{HHO}$ ) produces lower concentrations during pulse breakthrough and higher concentrations during tailing. In carbonate rock, ${ }^{3} \mathrm{HHO}$ appears to produce lower concentrations during pulse breakthrough and during tailing, which is indicative of ${ }^{3} \mathrm{HHO}$ loss due to exchange with air during sampling and not diffusion.

Estimates of retardation factors for the sorbing radionuclides were obtained by adjusting fracture and matrix retardation factors while holding the residence time and tortuosity constant. Only the $\mathrm{U}$ and $\mathrm{Np}$ breakthrough curves from the LLNL experiments were quantitatively interpreted because the other reactive species tested $(\mathrm{Cs}, \mathrm{Sr}, \mathrm{Pu}$, and $\mathrm{Sm})$ either did not break through at all or were transport unretarded. The exception was $\mathrm{Pu}$, which showed some breakthrough in several experiments, including one TCU experiment in which zeolite colloids were included. The Pu breakthrough curves were interpreted quantitatively using a rate-limited sorption (or colloid-filtration) in the colloid facilitated TCU transport experiment. Pu breakthrough was interpreted using an equilibrium sorption assumption in two of the three LLNL LCA fracture experiments in which a significant amount of $\mathrm{Pu}$ was recovered. $\mathrm{Pu}$ transport was not quantitatively interpreted using RELAP in the remaining experiments. All LLNL data were also modeled in Zavarin et al. (2005); these modeling results are included for comparison in Table 6.

Distinguishing between sorption onto fracture surfaces and diffusion/sorption in the matrix can be an ambiguous process. In general, a significant delay in arrival time of a sorbing radionuclide relative to a nonsorbing tracer followed by a substantial rise in concentration and significant recovery of the radionuclide is indicative of fracture sorption. A relatively early first arrival followed by a very slow concentration rise and relatively low recovery is indicative of matrix sorption. However, some breakthrough curves are not straightforward to interpret. For instance, when a radionuclide breaks through very late or not at all, the result can be interpreted as very large matrix retardation, a moderately large fracture retardation, or a combination of the two. Likewise, small delays in arrival times and small decreases in peak concentrations can reflect small fracture retardation or small-to-moderate matrix retardation. For the RELAP interpretations, the properties of the rocks and the nonsorbing tracer breakthrough were used to help guide the interpretations of sorbing radionuclide breakthrough curves. Specifically, because of the high matrix porosities and the strong indications of matrix diffusion of ${ }^{3} \mathrm{HHO}$ in the TCU fracture experiments, indistinguishable sorption behavior was always attributed to matrix sorption. Conversely, the low matrix porosities and negligible apparent matrix diffusion of ${ }^{3} \mathrm{HHO}$ in the LCA experiments led to attributing indistinguishable sorption to fracture sorption. 


\section{Modeling Transient Flow Conditions}

In some of the LANL fracture experiments, the flow rates fluctuated significantly over the course of the experiments. Unplanned flow interruptions or accidental flow rate changes occurred in several of the later experiments. Also, in many of the experiments conducted at flow rates of 0.5 $\mathrm{ml} / \mathrm{hr}$, the flow rates were intentionally increased after peak concentrations were reached to facilitate flushing of the fractures for subsequent experiments. In some cases, the flow rate fluctuations were large enough that RELAP could not be effectively used to obtain transport parameter estimates because the steady-state fracture flow assumption built into RELAP was violated. In these cases, the numerical model RETRAN (Reimus et al., 2002; Bechtel-SAIC, 2004), which assumes the same dual-porosity fracture-matrix geometry as RELAP but accommodates non-steady flow, was used to simulate the fracture experiments. Breakthrough curves obtained under non-steady flow conditions and fitted using RETRAN are provided in Appendices C and D.

\section{Colloid-Facilitated Transport}

In some of the LANL and LLNL TCU fracture experiments, it was apparent that ${ }^{137} \mathrm{Cs}$, ${ }^{239} \mathrm{Pu}$, and Sm did not migrate as free solutes, but rather as solutes sorbed to colloids, as a combination of free solutes and solutes sorbed to colloids, or as colloidal precipitates. This behavior was also evident for ${ }^{14} \mathrm{C}$ in a few of the TCU experiments and for ${ }^{239} \mathrm{Pu}$ and $\mathrm{Sm}$ in the LCA fracture experiments. One of LLNL's experiments was designed to include zeolite colloids and evaluate the role of colloid-facilitated transport. In LANL experiments, either silicate or calcite colloids (the latter would explain the colloidal behavior of ${ }^{14} \mathrm{C}$ ) appear to have formed in the synthetic ER-2-1 water unintentionally and to sorb ${ }^{137} \mathrm{Cs}$ and ${ }^{239} \mathrm{Pu}$ quite strongly. The ${ }^{239} \mathrm{Pu}$ concentrations used in LANL experiments were also high enough to have potentially created $\mathrm{Pu}$ colloids over time (Rai et al., 1999). Typical indications of colloid facilitated transport include: (1) earlier arrival and faster increases in concentrations than non-sorbing tracers (e.g. $\left.{ }^{3} \mathrm{HHO}\right),(2)$ a much more pronounced leveling off of concentrations at the peak concentration than nonsorbing tracers, and (3) a rapid decline and lack of tailing. These characteristics are indicative of a species not diffusing or only very slowly diffusing into the matrix (i.e., colloid-facilitated transport). The characteristics are clearly represented in the LLNL's colloid-facilitated radionuclide transport experiments. The fact that ${ }^{137} \mathrm{Cs}$ and ${ }^{239} \mathrm{Pu}$ were two of the more strongly sorbing solutes in the LANL TCU batch sorption and desorption experiments (Ware et al., 2005) also suggests that the unretarded transport of these radionuclides would be associated with colloid-facilitated transport.

The RELAP/RETRAN interpretive approach for ${ }^{137} \mathrm{Cs}$ and ${ }^{239} \mathrm{Pu}$ in the TCU fractures was modified to account for the fact that they appeared to be transported by colloids. ${ }^{137} \mathrm{Cs}$ and ${ }^{239} \mathrm{Pu}$ breakthrough was simulated as colloid-facilitated transport. The rate-limited colloid filtration constant (or fracture sorption constant) was fitted while diffusion or sorption in the matrix was not allowed. Colloid filtration was assumed to be irreversible (i.e. an infinite sink); the colloid desorption rate was set to zero. Thus, the only parameter that was adjusted to fit the breakthrough curves was the forward colloid filtration rate constant. However, in some cases, the mean residence times and Peclet numbers of the colloids were adjusted slightly downward 
relative to what had been determined for ${ }^{3} \mathrm{HHO}$. The rationale for these adjustments was that colloids can experience lower effective volumes in fractures than solutes because of their limited ability to diffuse into low-velocity regions of the fractures, and they can also have greater dispersion than solutes because they tend to remain in high- or low-velocity streamlines longer than solutes, resulting in more longitudinal spreading.

There is significant uncertainty in the estimated colloid filtration rate constants because they depend on prior knowledge of the fraction of radionuclide sorbed to colloids at the start of each experiment. This data was not available for LANL experiments. Thus, it was always assumed that all of the ${ }^{137} \mathrm{Cs}$ and ${ }^{239} \mathrm{Pu}$ mass was sorbed to colloids. This assumption results in an upper bound estimate of colloid filtration rate constants (i.e. the highest possible filtration rate constants). Alternatively, if it was assumed that the radionuclide mass sorbed to colloids was equal to the mass recovered in each experiment, it would be concluded that there was no colloid filtration at all (i.e. filtration rate equals zero). Thus, due to the limited information on starting conditions of these radionuclides, filtration rate constants are reported as a range from 0 to a maximum value.

\section{The Modeling Approach of Zavarin et al. (2005)}

The RELAP/RETRAN modeling approach differs somewhat from the modeling reported in Zavarin et al. (2005). In Zavarin et al. (2005), either an analytical solution (based on Tang et al. (1981)) or a 2D fracture transport mechanistic model (using the CRUNCH code) was used.

The input parameters used to solve the transport equation of Tang et al. (1981) include the following (from Table 12 of Zavarin et al. (2005):

- Mean fluid velocity, $v_{f}$

- Fracture half-aperture, $b$

- Matrix porosity, $\phi$

- Pulse length, 1

- Fracture length, L

- Fracture retardation, $R_{f}$

- Matrix retardation, $R_{m}$

- Diffusion coefficient in water, $D_{0}$

- Tortuosity factor, $\tau^{*}$

- Dispersivity, $\alpha=D_{f} / v_{f}$

These are, essentially, the same parameters used in the CRUNCH code. These parameters can also be converted to those used in the RELAP/RETRAN models. For example, the mean fluid residence time, $\tau$, is equal to the fracture length divided by the mean fluid velocity, $\mathrm{L} / v_{f}$. The Peclet number, $P e$, is equal to $\mathrm{L} v_{f} / D_{f}$. The matrix mass transfer coefficient is equal to $\frac{\phi}{b} \sqrt{D_{\mathrm{m}}}$ where $D_{m}=D_{0} \tau^{*}$. However, several parameters used in the RELAP model are not included in the Tang et al. (1981) model. These are the fracture spacing and sorption kinetic parameters. The Tang et al. (1981) model assumes equilibrium sorption and infinite fracture spacing. 
Of the parameters listed above, many were measured directly while others were determined by fitting the Tang et al. (1981) model to breakthrough data. The matrix porosity, pulse length, and fracture lengths were measured. ${ }^{4}$ The radionuclide diffusion coefficient in water was taken from the literature. For synthetic slotted fractures, the fracture half-aperture was measured $(0.25 \mathrm{~mm})$. The fluid velocity was also calculated based on measured core and aperture dimensions and the flow rate. The tortuosity and dispersivity were fitted parameters.

For each transport experiment (TCU and LCA rocks), a consistent stepwise modeling approach was taken. All parameter adjustments were accomplished by manually varying the parameters until a visually good fit was found. The stepwise modeling approach included the following steps: 5

1. Tortuosity, dispersivity, the adjusted flow rate, and the fracture aperture (for natural fractures only) were fit to the non-sorbing tracer (tritium and Re) breakthrough data using the Tang et al. (1981) model. High dispersivity was used only if matrix diffusion could not account for tracer tailing.

2. The adjusted parameters from (1) were combined with matrix retardation factors to predict the behavior of sorbing radionuclides using the Tang et al. (1981) model.

3. In the case of Sr transport in LCA fractures, the CRUNCH code was used to calculate breakthrough because the background Sr concentration was high enough to affect the breakthrough profile.

4. If necessary, a fracture retardation factor was included to produce a good match.

5. In cases where sorption was so strong that there was essentially no radionuclide recovery in an experiment, a lower bound matrix retardation factor was calculated (i.e., the smallest matrix retardation factor that would result in no recovery).

In the following section, we report all data fits using the RELAP/RETRAN models and compare those results with the earlier data fitting exercise reported in Zavarin et al. (2005).

\footnotetext{
${ }^{4}$ Matrix porosity was measured on a piece of core directly adjacent to the fractured core used in flowthrough experiments. Thus, while the matrix porosity in the fractured core experiments may not be identical to the porosity measured in the adjacent core, we assume that they are. ${ }^{5}$ Note that we have omitted discussion regarding the use of our mechanistic sorption model in radionuclide retardation prediction. This report focuses entirely on fitted retardation and diffusion parameters.
} 


\section{RELAP/RETRAN FRACTURE TRANSPORT EXPERIMENT MODEL RESULTS}

The RELAP fits to the radionuclide breakthrough curves from the LLNL TCU and LCA fracture transport experiments are presented in Appendices A and B, respectively. The breakthrough curves show the radionuclide concentrations normalized to the injection concentrations as a function of time (time zero is when the injection was started). The flow rates, tracer injection volumes, and other experimental parameters needed for the interpretations of the LLNL experiments are reported in Zavarin et al. (2005) and reproduced in Tables 1 and 2.

The RELAP/RETRAN fits to the radionuclide breakthrough curves from the LANL TCU and LCA fracture transport experiments are presented in Appendices C and D, respectively. The breakthrough curves show the radionuclide concentrations normalized to the injection concentrations as a function of time (time zero is when the injection was started). Appendices $\mathrm{C}$ and $\mathrm{D}$ are organized so that all breakthrough curves in a given fracture are presented sequentially followed by all the breakthrough curves in the next fracture, etc. For each fracture experiment, the runs involving ${ }^{3} \mathrm{HHO},{ }^{14} \mathrm{C}$, and ${ }^{233} \mathrm{U}$ are presented first, followed by the runs involving ${ }^{3} \mathrm{HHO},{ }^{137} \mathrm{Cs}$, and ${ }^{237} \mathrm{~Np}$, and finally the runs involving ${ }^{3} \mathrm{HHO},{ }^{90} \mathrm{Sr}$, and ${ }^{239} \mathrm{Pu}$. As indicated in Table 1, there were typically two runs in a given fracture for each of the radionuclide combinations; one at a flow rate of $\sim 2 \mathrm{ml} / \mathrm{hr}$, and the other at a flow rate of $\sim 0.5 \mathrm{ml} / \mathrm{hr}$. The breakthrough curves from the higher flow rate runs are always presented first for any given radionuclide combination. Higher flow rate experiments were generally conducted before lower flow rate experiments.

The transport parameter estimates obtained from the RELAP/ETRAN interpretations of the LANL and LLNL fracture transport experiments are summarized in Table 6. For LLNL experiments, both the RELAP interpretations and the Tang et al. (1981) interpretations originally reported in Zavarin et al. (2005) are listed. To simplify the comparisons between RELAP and Tang et al. (1981) model results, all fitting parameters were converted to units used in either model.

Matrix retardation is reported as a retardation factor $(\mathrm{R})$. A matrix partitioning coefficient $\left(\mathrm{k}_{\mathrm{d}}\right)$ can be calculated using the following relationship:

$\mathrm{R}=1+\mathrm{k}_{\mathrm{d}} \rho_{\mathrm{b}} / \phi$

where bulk density for tuff $\left(\rho_{\mathrm{b}}=2.13^{*}(1-\phi)\right)$ and carbonate $\left(\rho_{\mathrm{b}}=2.85^{*}(1-\phi)\right)$ rock can be calculated using the rock porosity and mineral densities of zeolite and dolomite, respectively. Fracture retardation is also reported as a retardation factor $(\mathrm{R})$. A fracture partitioning coefficient $\left(\mathrm{k}_{\mathrm{f}}\right)$ can be calculated if the fracture surface area per unit volume were known. However, this value is not known for these fracture experiments.

Except in the case of the LLNL synthetic slotted fractures, the average fracture apertures listed in Table 6 were calculated as $2 \mathrm{~b}=\mathrm{Q} \tau / \mathrm{LW}$, where $2 \mathrm{~b}=$ aperture $(\mathrm{cm}), \mathrm{Q}=$ flow rate $(\mathrm{ml} / \mathrm{hr}), \tau=$ mean nonsorbing tracer residence time in fracture $(\mathrm{hr}), \mathrm{L}=$ fracture length $(\mathrm{cm})$, and $\mathrm{W}=$ fracture width $(\mathrm{cm})$. The apertures represent an average effective aperture as opposed to a true 
average physical geometric aperture or a hydraulic aperture that reflects the fracture hydraulic conductivity. Generally, the hydraulic aperture can be expected to be larger than the true average physical aperture in a variable-aperture fracture because fracture flow will tend to occur where the local apertures are largest and offer the least resistance to flow. This tendency for flow to occur in areas of larger aperture gives rise to flow channeling within fractures and a resulting tendency for transporting solutes to "experience" apertures that are larger than the physical average. In principal, the physical and hydraulic apertures will be equal only in a true parallel-plate flow system where the fracture aperture is constant everywhere.

For RELAP/RETRAN modeling data, the dispersivity reported in Table 6 was calculated using the fracture length and the reported Peclet number $(\alpha=\mathrm{L} / \mathrm{Pe})$. Similarly, the tortuosity reported in Table 6 was calculated using aperture, porosity and diffusivity in water $\left(\tau^{*}=(\mathrm{MTC} * \mathrm{~b} / \phi)^{2} / \mathrm{D}_{0}\right.$, where MTC is the mass transfer coefficient, $\frac{\phi}{b} \sqrt{D_{\mathrm{m}}}$. It should be recognized and acknowledged that the fitted dispersivities are accounting for any process that result in tracer spreading in the flow systems, including processes that are not classical dispersion. For instance, a major source of spreading that might actually be dominating apparent dispersion in the experimental flow systems is tracer spreading and holdup in the inlet (especially) and outlet manifolds of the systems. The tubing and manifolds in these systems constitute a significant fraction of the overall system volume (sometimes more than the fractures themselves), so any imperfect distribution or mixing of tracers in the manifolds will result in artificial tailing that will be interpreted as dispersion. It should be stressed that the dispersivities derived from these experiments should not be interpreted as true fracture dispersivities, and they should not be used to develop or assess fracture dispersivity scaling relationships because of the potential for tracer spreading artifacts in these low-volume systems. Rather, the dispersivities should be thought of as a mathematical means of accounting for all tracer spreading in the system so that more accurate estimates of matrix diffusion parameters and retardation factors can be obtained from the experiments.

RELAP was the default computer model used for the interpretations. RETRAN was used only for the LANL experiments in which there were significant flow rate changes early enough in an experiment to affect the shape of the breakthrough curves (generally not in the late tailing portion of an experiment). The figure captions in appendices $\mathrm{C}$ and $\mathrm{D}$ indicate whether RELAP or RETRAN was used. A note at the bottom of Table 6 indicates whether a finite or semiinfinite matrix was used in the model. For a finite matrix, the average distance from the fracture centerline to the no-flow boundary at the cylindrical periphery of the cores was used. A finite matrix was assumed only when it appeared to provide a significantly better fit to the data than a semi-infinite matrix. A finite matrix was only required for TCU fractures; matrix diffusion in the LCA cores was typically quite low.

An attempt was always made to simulate the breakthrough curves of the sorbing radionuclides assuming equilibrium sorption behavior in both the fractures and matrix (i.e., fast sorption and desorption relative to transport time scales). Retardation factors estimated assuming equilibrium sorption are listed in Table 6 for all radionuclides that did not appear to be transported with colloids. However, in some cases it was apparent that the breakthrough curve of a radionuclide 
could be much better fitted by assuming rate-limited sorption or colloid filtration. In these cases, a retardation factor is listed with a corresponding rate constant.

In some cases, it was apparent that neither an equilibrium nor a rate-limited sorption model provided a satisfactory fit to a sorbing radionuclide breakthrough curve. These cases typically exhibited a rising limb of a breakthrough curve that could be fit quite well assuming equilibrium sorption, but the tail of the breakthrough curve was significantly overpredicted by RELAP or RETRAN. While the fit to the tail could be improved by assuming rate-limited sorption, the fit to the rising limb was significantly degraded when this assumption was made. Apparently, the processes controlling radionuclide breakthrough are more complex that the RELAP model can accommodate. For example, the data may suggest fast sorption onto variable sorption affinity sites, some of which exhibit much slower desorption rates than others. This behavior was most commonly observed for ${ }^{237} \mathrm{~Np}$, although it was also observed for other radionuclides (particularly, ${ }^{239} \mathrm{Pu}$ in the LCA fractures). This result is consistent with LANL batch sorption and desorption experimental results (Ware et al., 2005), which indicated relative fast sorption rates but steadily decreasing desorption rates over the course of desorption experiments. In these situations, retardation factors (assuming equilibrium sorption) that yielded good fits to the rising limbs of the breakthrough curves are reported in Table 6 , and are footnoted to indicate that the tails of the breakthrough curves did not conform to equilibrium, single-sorption-site assumptions. The implication is that effective retardation factors over much longer time and length scales than in the fracture experiments (i.e., at CAU modeling scales) may be significantly larger than those deduced from fitting the rising limbs of the breakthrough curves.

As indicated in Table 6, matrix sorption accounted for the observed retardation in the TCU (unless a radionuclide transported as a colloid), and fracture sorption accounted for most of the observed retardation in the LCA. This result is consistent with the much higher matrix porosities and the much greater matrix diffusion of ${ }^{3} \mathrm{HHO}$ in the TCU fractures relative to the LCA fractures. However, it is also in part a reflection of our interpretive approach used in RELAP/RETRAN modeling exercises.

\section{SUMMARY OF MODELING RESULTS}

Key radionuclide transport behaviors that can be summarized from these experiments include the following:

\section{Nonsorbing (or Conservative) Tracers in TCU}

Matrix diffusion mass transfer coefficients range from 0.2 to $1.3 \mathrm{hr}^{-0.5}$ in LLNL experiments and 0.4 to $1.8 \mathrm{hr}^{-0.5}$ in LANL experiments. There does not appear to be a significant difference between synthetic and natural fractures, indicating that fracture lining minerals do not inhibit diffusion. The tortuosity, which can be calculated using the mass transfer coefficient, porosity, aperture, and diffusivity in water, ranges from 0.04 to 0.1 . The RELAP results are consistent with earlier LLNL modeling. However, the modeled dispersivity is typically higher and reflects the non-uniqueness of the fitted parameters. It should also be noted that the fitted dispersivities account for any process that results in tracer spreading in the flow systems, including processes that are not classical dispersion (e.g. artifacts of the experiment flow system), as described 
earlier.

\section{${ }^{14} \mathrm{C}$ in $\mathrm{TCU}$}

There appears to be no significant fracture retardation of ${ }^{14} \mathrm{C}$ and very little, if any, matrix retardation. The maximum matrix retardation factor was 2.4 but the majority of experiments yielded no significant matrix or fracture retardation.

\section{$\mathrm{Sr}$ in $\mathrm{TCU}$}

Fracture retardation of $\mathrm{Sr}$ was assigned a value of 1 because it was apparent that matrix retardation was the dominant sorption process. Sr concentrations above background were not observed in LLNL experiments and ${ }^{90} \mathrm{Sr}$ elution was very low in LANL experiments. RELAP fits to LANL data estimated matrix retardation factors of 85 to over 3,400. However, the low retardation factors were the result of fits to data where there was significant residual ${ }^{90} \mathrm{Sr}$ from earlier experiments; these should be considered lower bounds. Previous modeling of LLNL data estimated matrix retardation factor minimums of 2,000 to 30,000. Based on mechanistic model simulations reported in Zavarin et al. (2005), retardation factors of 1,600 to 67,000 were expected in these strongly zeolitized tuffs. Thus, matrix retardation of $\mathrm{Sr}$ is extremely high. Furthermore, it appears that retardation is effective at high $\mathrm{Sr}$ and low ${ }^{90} \mathrm{Sr}$ concentrations.

\section{Cs in TCU}

Cs concentrations above background were not observed in LLNL experiments and were not modeled using RELAP. Previous modeling of LLNL data estimated matrix retardation factor minimums of 1,000 to 35,000 (fracture retardation factors set to 1). Based on mechanistic model simulations reported in Zavarin et al. (2005), retardation factors of 7,900 to 360,000 were expected in these strongly zeolitized tuffs. ${ }^{137} \mathrm{Cs}$ elution in LANL experiments was pronounced and was indicative of colloid-facilitated transport. As stated earlier, it is apparent that colloids formed unintentionally in LANL TCU solutions. If ${ }^{137} \mathrm{Cs}$ was associated with colloids via reversible ion exchange, we would expect colloid facilitated transport to be a relatively poor transport mechanism, especially when considering the very strong Cs affinity for the matrix. It is possible that the precipitated colloids coprecipitated ${ }^{137} \mathrm{Cs}$, resulting in an essentially irreversible ${ }^{137} \mathrm{Cs}$ association with colloids.

\section{$\mathbf{U}$ in TCU}

In LLNL experiments, $U$ transport was best interpreted as a combination of fracture and matrix retardation. Fracture retardation factors ranged from 1.4 to 12 and matrix retardation factors ranged from 12 to 40. Zeolite colloids did not affect $U$ transport rates. Zavarin et al. (2005) reported similar low fracture and matrix retardation factors ( 1 to 5 and 2 to 40 , respectively). In LANL experiments, fracture retardation was always 1.0 while matrix retardation factors ranged from 6 to 55. Interestingly, differences between slotted and natural fractures were slight; suggesting that fracture lining minerals did not dramatically affect $U$ transport rates. Even when a synthetic slotted fracture was lined with iron oxide (experiment designation TCU-6), its effect on U transport was rather small.

It should be noted that fracture retardation in LLNL's synthetic slotted fracture experiments is surprising. In essence, these fractures are topographically flat and completely free of fracture lining minerals. Thus, the assigned fracture retardation must be the result of $U$ sorption to the 
matrix minerals along the fracture wall. It underscores the problem of distinguishing between fracture and matrix retardation. The difference between fracture retardation and matrix retardation is subtle and cannot always be clearly distinguished, particularly for very weakly or very strongly sorbing radionuclides.

\section{Np in TCU}

In general, $\mathrm{Np}$ transport was similar to that of U. In LLNL experiments, Np transport was best interpreted with a combination of fracture and matrix retardation. Fracture retardation factors ranged from 1 to 1.4 and matrix retardation factors ranged from 3.5 to 100 . Zeolite colloids did not affect $\mathrm{Np}$ transport rates. Zavarin et al. (2005) reported similar low fracture and matrix retardation factors ( 1 and 1.5 to 100, respectively). In LANL experiments, fracture retardation was always 1.0 while matrix retardation factors ranged from 4 to 95 . Interestingly, differences between slotted and natural fractures were not significant; suggesting that fracture lining minerals did not dramatically affect $\mathrm{Np}$ transport rates.

\section{Pu in TCU}

$\mathrm{Pu}$ transport, if observed, always appeared to occur as a result of colloid facilitated transport. This was the case even when colloids were not intentionally introduced. In LLNL experiments where colloids were not introduced, between 0 and $3 \%$ of the Pu eluted at the time of peak tracer breakthrough. The source of the colloids is unknown. However, a small amount of colloidal $\mathrm{Pu}(\mathrm{IV})$ may have been present in the starting solution and could account for the observed breakthrough. RELAP fitting of these experiments was not attempted. LLNL modeling did not account for colloid-facilitated transport. Thus, the attempted fits are very poor. Nevertheless, the reported matrix retardation factors ranged from $>600$ to $>15000$. As stated in Zavarin et al. (2005), these values represent very poor fits and are lacking the appropriate mechanisms to adequately model the transport behavior of $\mathrm{Pu}$. However, it is evident from these data that, in the absence of colloids, Pu migration is highly retarded.

For the LLNL experiment in which colloids were introduced, a RELAP model was successful using a fracture retardation factor of 60 and a colloid filtration rate constant of $0.4 \mathrm{hr}^{-1}$.

Interestingly, the earlier LLNL modeling resulted in a reasonably good fit to the rising portion of the breakthrough curve simply by setting the effective matrix retardation factor to 2 . It suggests that the effective retardation of $\mathrm{Pu}$ in the presence of significant colloid loads will be dramatically reduced.

For the LANL experiments, it was apparent that colloids had formed in the solutions prior to running the experiments. All experiments indicated significant colloid-facilitated Pu transport (5 to $20 \%$ recovery). Assuming that all $\mathrm{Pu}$ was initially associated with colloids, RELAP model fits resulted in colloid filtration rate constants of 0.12 to $2.3 \mathrm{hr}^{-1}$. Colloid desorption rates were set to zero (i.e. no colloid desorption). Importantly, these colloid filtration rate constants are similar to the one calculated for LLNL's colloid-facilitated transport experiment $\left(0.4 \mathrm{hr}^{-1}\right)$. As modeled, these rates suggest that colloid-facilitated transport may not be significant at field transport time scales, and contradict observed field-scale transport behavior reported by (Kersting et al., 1999). It suggests that additional transport processes, not captured in these fracture transport experiments and the RELAP modeling, may govern colloid-facilitated transport behavior at the field scale. 


\section{Sm in TCU}

Sm transport experiments were conducted only by LLNL and were not modeled here.

Nevertheless, it should be mentioned that the breakthrough of this strongly sorbing lanthanide was observed only in the presence of colloids. As in the case of $\mathrm{Pu}$, its transport will not be significant in the absence of colloids. LLNL modeling reported matrix retardation minimums ranging from 750 to 20,000. In the presence of colloids, an effective matrix retardation factor of 2 was reported (Zavarin et al., 2005).

\section{Nonsorbing (or Conservative) Tracers in LCA}

Matrix diffusion mass transfer coefficients were $0.01,0.1$, and $0.43 \mathrm{hr}^{-0.5}$ in three LLNL experiments and ranged from 0.02 to $0.04 \mathrm{hr}^{-0.5}$ in LANL experiments. The apparently high mass transfer coefficient in one of the LLNL experiments is likely an artifact of ${ }^{3} \mathrm{HHO}$ loss during the experiment (Figure 4). Zavarin et al. (2005) reported mass transfer coefficients ranging from 0.2 to $0.3 \mathrm{hr}^{-0.5}$. High matrix diffusion mass transfer coefficients were required when low dispersivities were assigned to fracture experiments (i.e. Zavarin et al, 2005). Conversely, low matrix diffusion mass transfer coefficients were required when relatively high dispersivities were assigned certain fractures. Differences in model results reflect the very low diffusivity in carbonate rock. Values are significantly lower than in TCU experiments and reflect the lower porosity of the carbonate rock. The tortuosity, which can be calculated using the mass transfer coefficient, porosity, aperture, and diffusivity in water, ranges from 0.004 to 2.7. Much of the variability in tortuosity results from modeling uncertainty derived from the very low diffusion rates observed in these samples. Tortuosity values greater than 1 may reflect uncertainty in the very low measured porosities of these rocks or the strong correlation with dispersivity. While the tortuosity estimates are very uncertain, they should not influence the retardation factor estimates for the sorbing radionuclides which were all based on fracture sorption and not matrix sorption.

Matrix diffusion and dispersivity parameters are highly correlated and difficult to distinguish. The parameters are best distinguished by comparing the transport behavior of two non-sorbing radionuclides with substantially differing diffusivities (e.g. ${ }^{3} \mathrm{HHO}$ and $\mathrm{Re}$ ). When corrected for the loss of ${ }^{3} \mathrm{HHO}$ in LLNL experiments, it is apparent that diffusion is negligible at the scale of experiments described here (Figure 4). 


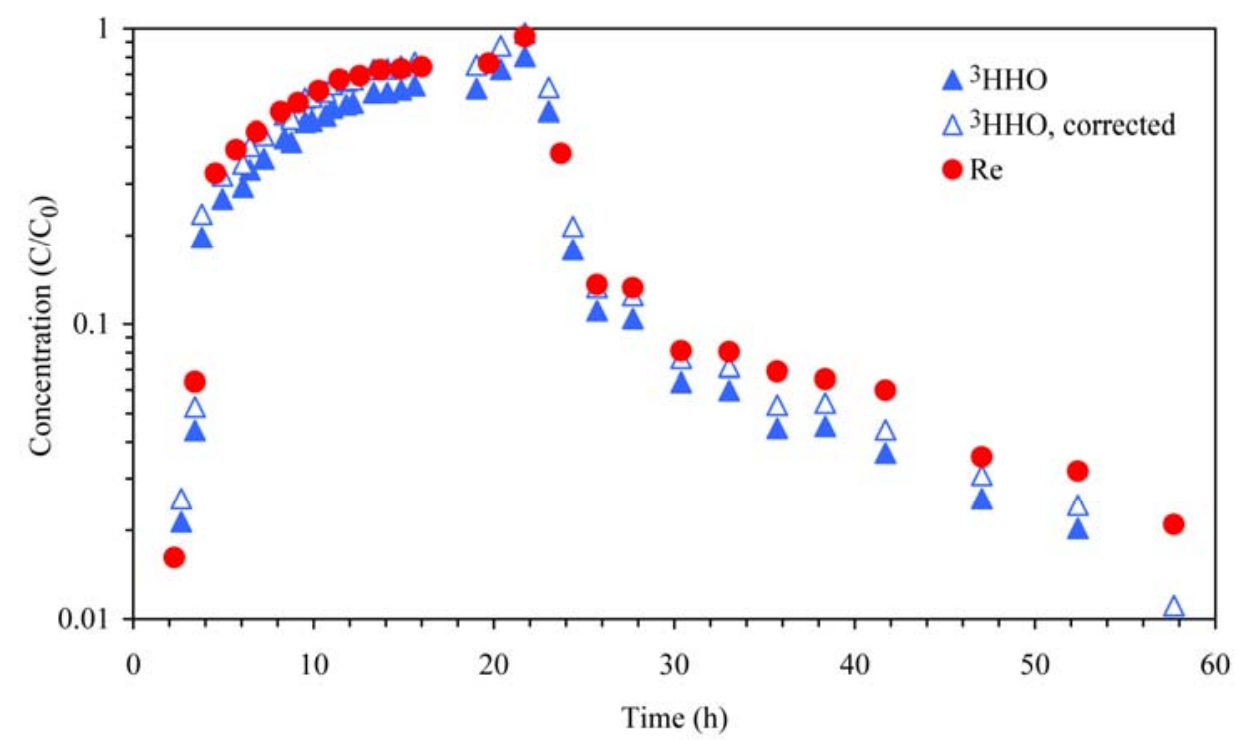

Figure 4. Breakthrough profiles of ${ }^{3} \mathrm{HHO}$ and Re in carbonate rock (ER-6-1 2605, Synthetic slot). When corrected for ${ }^{3} \mathrm{HHO}$ loss due to exchange with air during sampling, little or no diffusion can be identified based on comparative breakthrough of ${ }^{3} \mathrm{HHO}$ and Re.

\section{${ }^{14} \mathrm{C}$ in LCA}

There appears to be very little fracture or matrix retardation of ${ }^{14} \mathrm{C}$. The maximum fracture retardation factor was 5 . It is apparent that ${ }^{14} \mathrm{C}$ migrates nearly unretarded through these fractured carbonate experiments. However, the retardation of ${ }^{14} \mathrm{C}$ as a result of isotope exchange on calcite surfaces may play a role over longer time and larger field scales. These processes have yet to be accurately quantified.

\section{Sr in LCA}

$\mathrm{Sr}$ retardation can be grouped into two categories. The first includes the synthetic slotted and induced fracture experiments conducted by LLNL as well as some LANL natural fracture experiments. These experiments exhibited very little fracture retardation and essentially no matrix retardation. Fracture retardation factors ranged from 1 to 2.5. The second category includes a subset of the natural fracture experiments conducted by LANL in which significant fracture retardation was observed. For these experiments, fracture retardation factors range from 4.25 to $>30$. It is apparent that fracture lining minerals are the source of this retardation. The identity of the fracture lining minerals was not quantitatively identified.

\section{Cs in LCA}

As in the Sr case, Cs retardation can be grouped into two categories. The first has limited fracture lining minerals that can sorb Cs; fracture retardation factors range from 1 to 4 . The second has sufficient fracture lining minerals to dramatically retard Cs; fracture retardation factors range from 40 to 320 . Because both $\mathrm{Sr}$ and $\mathrm{Cs}$ have high affinities for clays and zeolites, we expect that they represent a significant fraction of the fracture lining mineralogy. It should also be noted that the synthetic and induced fracture experiments conducted by LLNL clearly show that both $\mathrm{Cs}$ and Sr retardation is negligible when only the carbonate matrix is present. Thus, Cs and Sr retardation in the LCA will be controlled primarily by fracture lining 
mineralogy.

\section{$\mathbf{U}$ in LCA}

$\mathrm{U}$ transport in LCA is nearly unretarded. Fracture retardation factors from all experiments ranged from 1 to 3.8 (matrix retardation factors were set to 1). Interestingly, the highest fracture retardation factor was found in the synthetic induced fracture experiment conducted by LLNL. Since this fracture experiment is devoid of fracture lining minerals, the retardation may be more appropriately interpreted as matrix retardation. Zavarin et al. (2005) included both fracture and matrix retardation. In that case, synthetic slotted and induced fracture matrix retardation and fracture retardation factors ranged from 6 to 20 and 1 to 2, respectively. The difference in modeling results underscores the problem of distinguishing between fracture and matrix retardation. In many cases, the difference between fracture retardation and matrix retardation is subtle and cannot be clearly distinguished.

\section{Np in LCA}

In general, $\mathrm{Np}$ transport is very similar to that of $\mathrm{U}$. However, higher retardation factors were observed on occasion. Np transport was interpreted as fracture retardation only, resulting in a range of fracture retardation factors from 1.6 to 32 . It appears that the high fracture retardation factors may be the result of fracture lining minerals; very low retardation was observed in fracture experiments that were free of fracture lining minerals.

\section{Pu in LCA}

Pu migration was observed in all fracture transport experiments even though no experiments intentionally included colloids. LLNL reported the fraction of $\mathrm{Pu}$ associated with colloids in LCA-2 and LCA-3 experiments as 0\%. LANL analyzed their sorption solutions at the end of the fracture transport experiments and reported that $\sim 11 \%$ of Pu was associated with colloids ( $>5 \mathrm{~nm}$ particle size). Thus, it appears that $\mathrm{Pu}$ can migrate for at least some time and distance in fractured carbonate as an aqueous phase. The fact that the $\mathrm{Pu}$ was retarded in first arrival time relative to ${ }^{3} \mathrm{HHO}$ or Re in the LLNL fracture experiments and in some of the LANL fracture experiments supports the hypothesis of $\mathrm{Pu}$ transporting as a solute in the LCA fractures. Colloidfacilitated transport is typically characterized by arrival times that are as early or even slightly earlier than nonreacting solutes. However, we cannot rule out some colloid-facilitated transport as well.

Fracture retardation factors of 4 and 12 are reported for LLNL experiments using the RELAP model. Matrix retardation factors of $\sim 100$ and 50 are reported in Zavarin et al. (2005). However, neither modeling exercise could accurately reproduce the Pu breakthrough profile. Thus, it is apparent that relevant processes controlling Pu transport were not included in these modeling exercises. The processes are likely to be a combination of colloid facilitated transport, rate-limited sorption/desorption, rate limited redox transformation, and possibly non-linear sorption.

LANL experiments were modeled using either a fracture retardation factor or a combination of fracture retardation and sorption/colloid filtration rate constants. The latter method was used when it appeared that colloid-facilitated transport may better describe the breakthrough results (i.e., when the $\mathrm{Pu}$ first arrival coincided with the first arrival of ${ }^{3} \mathrm{HHO}$ ). Numerically, the 
fracture sorption rate constant is identical to the colloid filtration constant used in this RELAP modeling exercise. When colloid filtration was not invoked, fracture retardation ranged from 2.4 to 50. When colloid filtration was invoked, fracture retardation factors ranged from 19 to "irreversible" and filtration rate constants ranged from 0.08 to $0.64 \mathrm{hr}^{-1}$. However, it should be noted that fits to some of the Pu breakthrough profiles were quite poor, suggesting that relevant processes were missing, as described above. 
Table 6. Retardation factors and transport parameters for fracture flowthrough experiments.

\begin{tabular}{|c|c|c|c|c|c|c|c|c|}
\hline $\begin{array}{l}\text { LLNL } \\
\text { Fracture } \\
\text { Experiments }\end{array}$ & $\begin{array}{l}\text { UE-7az 1799, } \\
\text { Synthetic slot } \\
\text { (TCU) }\end{array}$ & $\begin{array}{l}\text { UE-7az 1679, } \\
\text { Natural (TCU) }\end{array}$ & $\begin{array}{l}\text { UE-7az 1780, } \\
\text { Natural (TCU) }\end{array}$ & $\begin{array}{l}\text { UE-7ba } 1627, \\
\text { Synthetic slot } \\
\text { with colloids } \\
\text { (TCU) }\end{array}$ & $\begin{array}{l}\text { UE-7az 1679, } \\
\text { Synthetic slot with } \\
\text { FeOH coating } \\
\text { (TCU) }\end{array}$ & $\begin{array}{l}\text { ER-6-1 2605, } \\
\text { Synthetic slot } \\
\text { (LCA) }\end{array}$ & $\begin{array}{l}\text { ER-6-1 2733, } \\
\text { Synthetic slot } \\
\text { (LCA) }\end{array}$ & $\begin{array}{l}\text { ER-6-1 2553, } \\
\text { Synthetic } \\
\text { induced (LCA) }\end{array}$ \\
\hline \multicolumn{9}{|c|}{ Fracture Retardation factor } \\
\hline $\mathrm{Sr}$ & no rec (1) & no rec (1) & no rec (1) & NA & no rec (1) & $1(1)$ & $1.1(1)$ & no rec (1) \\
\hline Cs & no rec (1) & no rec (1) & no rec (1) & NA & no rec (1) & $1(1)$ & $1(1)$ & no rec (1) \\
\hline $\mathrm{U}$ & $2.2(2)$ & $1.4(2)$ & $2.2(2)$ & $3.5(1)$ & $12(5)$ & $2.3(1)$ & $1.5(1)$ & $3.5(2)$ \\
\hline $\mathrm{Np}-237$ & $1(1)$ & $1(1)$ & $1.4(1)$ & $1(1)$ & $1(1) 1$ & $2.1(1)$ & $2.6(1)$ & $3.5(2)$ \\
\hline$\underline{\mathrm{Pu}-238 / 242}$ & nd (1) & nd (1) & nd (1) & $60,0.4 \dagger(1)$ & nd (1) & nd (1) & $3.5(1)$ & $2.5(1)$ \\
\hline \multicolumn{9}{|c|}{ Matrix Retardation factor } \\
\hline $\mathrm{Sr}$ & no rec $(\geq 4000)$ & no rec $(\geq 2000)$ & no rec $(\geq 30000)$ & $\mathrm{Na}$ & no rec $(\geq 3000)$ & $1(1)$ & $1(1)$ & no rec (2) \\
\hline Cs & no rec $(\geq 1500)$ & no rec $(\geq 1000)$ & no rec $(\geq 35000)$ & $\mathrm{Na}$ & no rec $(\geq 2500)$ & $1(1)$ & $1(1)$ & no rec (1) \\
\hline $\mathrm{U}$ & $16(4)$ & $12(2)$ & $40(40)$ & $31(8)$ & $13(10)$ & $1(6)$ & $1(6)$ & $1(20)$ \\
\hline $\mathrm{Np}-237$ & $26(6)$ & $7(1.5)$ & $100(100)$ & $18(5)$ & $3.5(2.5)$ & $1(10)$ & $1(8)$ & $1(25)$ \\
\hline$\underline{\mathrm{Pu}-238 / 242}$ & nd $(\geq 600)$ & nd $(\geq 1000)$ & nd $(\geq 15000)$ & $1(2)$ & nd $(\geq 1000)$ & No rec & $1(\sim 100)$ & $1(50)$ \\
\hline Mean & $2.2(1.9)$ & $5(0.7)$ & $4(2.2)$ & 2.05 (1.9) & $1.5(1.7)$ & $4.5(3.3)$ & $4.0(3.4)$ & $4.0(2.0)$ \\
\hline Velocity, cm/hr & $4.6(5.4)$ & $1.9(13.5)$ & $1.5(2.7)$ & $5.0(5.4)$ & $6.2(5.4)$ & $2.5(2.5)$ & $2.9(3.4)$ & $2.8(5.7)$ \\
\hline$P e$ & $120(102)$ & $1.6(96)$ & $10(58)$ & $4.4(20)$ & $8(91)$ & $2(11)$ & $5(23)$ & $1.2(23)$ \\
\hline $\begin{array}{l}\phi / b^{*} D_{m}{ }^{0.5}, \mathrm{hr}^{-0.5} \\
\text { for }{ }^{3} \mathrm{HHO}\end{array}$ & $0.7(1.33)$ & $0.44(3.84)$ & $0.19(0.26)$ & $0.91(1.15)$ & $1.3(1.25)$ & $0.43 *(0.26)$ & $0.01 *(0.19)$ & $0.01 *(0.26)$ \\
\hline $\begin{array}{l}\text { dispersivity, } D_{f}, \\
\text {, }\end{array}$ & $0.001(0.001)$ & $0.060(0.001)$ & $0.006(0.001)$ & $0.023(0.005)$ & $0.011(0.001)$ & $0.06(0.01)$ & $0.02(0.005)$ & $0.09(0.005)$ \\
\hline tortuosity & $0.042(0.15)$ & $0.050(0.15)$ & $0.042(0.02-0.3)$ & $0.063(0.1-0.2)$ & $0.104(0.1)$ & $2.7 *(1)$ & $0.004 *(1)$ & $0.04 *(0.6)$ \\
\hline Aperture, cm & $0.05(0.05)$ & $0.11(0.02)$ & $0.14(0.1)$ & $0.05(0.05)$ & $0.05(0.05)$ & $0.05(0.05)$ & $0.07(0.05)$ & $0.058(0.03)$ \\
\hline
\end{tabular}

Note: A finite matrix with a fracture spacing of $6 \mathrm{~cm}$ was assumed in all calculations for the tuff cores, and a semi-infinite matrix was assumed in all calculations for the carbonate cores.

Data in ( ) indicates previous LLNL model fit parameters

$\geq=$ indicates that the value is a minimum

$\dagger=$ rate constant, $\mathrm{hr}^{-1}$; breakthrough fitted assuming rate-limited sorption/colloid filtration in fracture

nd. = not determined (very low, but early recovery; suspected of being colloid-facilitated)

no $\mathrm{rec}=$ no recovery of radionuclide; matrix retardation factors not estimated

na $=$ element not in sorption solution

* Poorly constrained because of negligible matrix diffusion in LCA fractures 
Table 6, cont. Retardation factors and transport parameters for fracture flowthrough experiments.

\begin{tabular}{|c|c|c|c|c|c|c|c|c|}
\hline $\begin{array}{l}\text { LANL Fracture } \\
\text { Experiments }\end{array}$ & $\begin{array}{l}\text { UE-4a } \\
2029, \text { high } \\
\text { flow (TCU) }\end{array}$ & $\begin{array}{l}\text { UE-4a 2029, } \\
\text { low flow } \\
\text { (TCU) }\end{array}$ & $\begin{array}{l}\text { UE-7az } \\
\text { 1770, high } \\
\text { flow (TCU) }\end{array}$ & $\begin{array}{l}\text { UE-7az 1770, } \\
\text { low flow } \\
\text { (TCU) }\end{array}$ & $\begin{array}{l}\text { UE-7b, 1823, } \\
\text { high flow } \\
\text { (TCU) }\end{array}$ & $\begin{array}{l}\text { UE-7ba 1823, } \\
\text { low flow } \\
\text { (TCU) }\end{array}$ & $\begin{array}{l}\text { UE-7ba 1863, } \\
\text { high flow } \\
\text { (TCU) }\end{array}$ & $\begin{array}{l}\text { UE-7ba 1863, } \\
\text { low flow } \\
\text { (TCU) }\end{array}$ \\
\hline \multicolumn{9}{|l|}{ Fracture Retardation factor } \\
\hline $\mathrm{C}-14$ & 1 & 1 & 1 & 1 & 1 & 1 & 1 & 1 \\
\hline Sr-90 & 1 & 1 & 1 & 1 & 1 & 1 & 1 & 1 \\
\hline Cs-137 & $0-0.5 \dagger$ & $0-0.24 \dagger$ & $0-3.0 \dagger$ & $0-1.6 \dagger$ & $0-0.58 \dagger$ & $0-0.3 \dagger$ & $0-0.39 \dagger$ & $0-0.35 \dagger$ \\
\hline U-233 & 1 & 1 & 1 & 1 & 1 & 1 & 1 & 1 \\
\hline $\mathrm{Np}-237$ & 1 & 1 & 1 & 1 & 1 & 1 & 1 & 1 \\
\hline $\mathrm{Pu}-239$ & $0-0.75 \dagger$ & $0-0.2 \dagger$ & $0-2.3 \dagger$ & $0-0.5 \dagger$ & $0-0.75 \dagger$ & $0-0.12 \dagger$ & $0-1.2 \dagger$ & $0-0.3 \dagger$ \\
\hline \multicolumn{9}{|l|}{ Matrix Retardation factor } \\
\hline $\mathrm{C}-14$ & 2.4 & 1 & 1.7 & 1 & 1 & 1 & 1 & 1 \\
\hline Sr-90 & 510 & 85 & $\geq 3400$ & $\geq 310$ & 1700 & $\geq 170$ & 1700 & $\geq 170$ \\
\hline Cs-137 & Colloidal & Colloidal & Colloidal & Colloidal & Colloidal & Colloidal & Colloidal & Colloidal \\
\hline $\mathrm{U}-233$ & & & 32 & 16 & 55 & & & 9 \\
\hline $\mathrm{Np}-237+\uparrow$ & $\begin{array}{l}(140,2.25) \\
\text { or } 95\end{array}$ & $\begin{array}{l}(25,0.18), \text { or } \\
4\end{array}$ & 10.5 & $(25,0.5)$, or 7 & $(78,12)$, or 45 & $\begin{array}{l}(67.5,3), \text { or } \\
30\end{array}$ & $\begin{array}{l}(170,12), \text { or } \\
75\end{array}$ & $(195,1)$, or 60 \\
\hline $\mathrm{Pu}-239$ & Colloidal & Colloidal & Colloidal & Colloidal & Colloidal & Colloidal & Colloidal & Colloidal \\
\hline $\begin{array}{l}\text { Mean residence time, hr } \\
\text { (low, high) }\end{array}$ & 5 & 22 & $2,3.5$ & 8 & $5,6.5$ & 20,22 & 3 & 9,12 \\
\hline Velocity, cm/hr & 4.1 & 0.93 & $6.5,3.7$ & 1.6 & $3.1,2.4$ & $0.78,0.71$ & 5.3 & $1.8,1.3$ \\
\hline$P e$ (low, high) & 5 & 5 & 1.5 & 1.5 & 6,10 & 10 & 10 & 10 \\
\hline $\begin{array}{l}\phi / b^{*} D_{m}{ }^{0.5}, \text { hr }^{-0.5} \text { for }{ }^{3} \mathrm{HHO} \\
\text { (low, high) }\end{array}$ & $1.45,1.56$ & $0.509,1.27$ & $1.39,1.51$ & $1.61,1.8$ & $0.48,0.54$ & $0.4,0.48$ & $0.82,0.9$ & $0.62,0.84$ \\
\hline $\begin{array}{l}\text { dispersivity, } D_{f}, \mathbf{m} \\
\text { (low, high) }\end{array}$ & 0.041 & 0.041 & 0.087 & 0.087 & $0.016,0.026$ & 0.016 & 0.016 & 0.016 \\
\hline tortuosity (low, high) & $0.15,0.17$ & $0.02,0.13$ & $0.11,0.31$ & $0.13,0.16$ & $0.12,0.15$ & $0.06,0.11$ & $0.10,0.12$ & 0.10 \\
\hline Aperture range, $\mathrm{cm}$ & 0.058 & 0.062 & $0.048,0.086$ & 0.048 & $0.102,0.132$ & $0.096,0.112$ & 0.06 & $0.06,0.08$ \\
\hline
\end{tabular}

Note: All sorption was assumed to occur in the matrix unless a fit could be significantly improved by assuming fracture sorption (which was never the

case except for ${ }^{137} \mathrm{Cs}$ and ${ }^{239} \mathrm{Pu}$ ). UE-7az, 1770, UE-7ba, 1823, UE-7ba, 1863 were fitted using a finite matrix with a no-flux boundary, and UE-4a, 2029 was fitted using a semi-infinite matrix.

$\geq=$ indicates that the value is a minimum

$\dagger=$ colloid filtration rate constant range; breakthrough fitted assuming rate-limited and irreversible colloid filtration in fracture

Colloidal = colloid-facilitated transport strongly suspected; matrix retardation factors not applicable

$\dagger \dagger^{237} \mathrm{~Np}$ transport was better fitted assuming rate-limited sorption, although a matrix retardation factor assuming equilibrium sorption was also estimated

by fitting the rising limb of the responses. The numbers in parentheses are the retardation factor and sorption rate constant (hr ${ }^{-1}$ ), respectively, for the rate-limited fit, and the last number is the retardation factor for the equilibrium fit. If only one number appears, it is the retardation factor for the equilibrium fit. 
Table 6, cont. Retardation factors and transport parameters for fracture flowthrough experiments.

\begin{tabular}{|c|c|c|c|c|c|c|c|c|c|}
\hline $\begin{array}{l}\text { LANL Fracture } \\
\text { Experiments }\end{array}$ & $\begin{array}{l}\text { ER-6-1 } \\
\text { 2400, high } \\
\text { flow (LCA) }\end{array}$ & $\begin{array}{l}\text { ER-6-1 2400, } \\
\text { low flow } \\
\text { (LCA) }\end{array}$ & $\begin{array}{l}\text { ER-6-1 } \\
2400, \text { low } \\
\text { flow \#2 } \\
\text { (LCA) } \\
\end{array}$ & $\begin{array}{l}\text { ER-6-1 2512, } \\
\text { high flow } \\
\text { (LCA) }\end{array}$ & $\begin{array}{l}\text { ER-6-1 } \\
\text { 2512, low } \\
\text { flow (LCA) }\end{array}$ & $\begin{array}{l}\text { ER-6-1 } \\
2512 \text {, low } \\
\text { flow \#2 } \\
\text { (LCA) } \\
\end{array}$ & $\begin{array}{l}\text { ER-6-1 } \\
\text { 2675, high } \\
\text { flow (LCA) }\end{array}$ & $\begin{array}{l}\text { ER-6-1 } \\
\text { 2675, low } \\
\text { flow (LCA) }\end{array}$ & $\begin{array}{l}\text { ER-6-1 } \\
\text { 2675, low } \\
\text { flow \#2 } \\
\text { (LCA) } \\
\end{array}$ \\
\hline \multicolumn{10}{|c|}{ Fracture Retardation factor } \\
\hline $\mathrm{C}-14$ & 1.5 & 1 & na & 1.2 & 1 & na & 2.5 & 1.5 & na \\
\hline Sr-90 & 2 & 4.25 & na & 20 & $\geq 30$ & na & 1 & 2.5 & na \\
\hline Cs-137 & 68 & $\geq 100$ & $\geq 100$ & 58 & 50 & $\geq 50$ & 2.8 & 3.5 & 4 \\
\hline $\mathrm{U}-233$ & 1.2 & 1.4 & na & 1.5 & 1.6 & na & 1.3 & 1.3 & na \\
\hline $\mathrm{Np}-237$ & 5.7 & 6 & 7 & 5 & 3 & 2.6 & 3.5 & 8 & 8 \\
\hline $\mathrm{Pu}-239$ & $0-0.28 \dagger$ & $0-0.36+$ & na & $0-0.18 \dagger$ & $40,0-0.14 \uparrow$ & na & $19,0-0.64 \dagger$ & $33,0-0.24 \dagger$ & na \\
\hline \multicolumn{10}{|c|}{ Matrix Retardation factor } \\
\hline $\mathrm{C}-14$ & 1 & 1 & na & 1 & 1 & na & 1 & 1 & na \\
\hline Sr-90 & 1 & 1 & na & 1 & 1 & na & 1 & 1 & na \\
\hline Cs-137 & 1 & 1 & 1 & 1 & 1 & 1 & 1 & 1 & 1 \\
\hline $\mathrm{U}-233$ & 1 & 1 & na & 1 & 1 & na & 1 & 1 & na \\
\hline $\mathrm{Np}-237$ & 1 & 1 & 1 & 1 & 1 & 1 & 1 & 1 & 1 \\
\hline $\mathrm{Pu}-239$ & 1 & 1 & na & 1 & 1 & na & 1 & 1 & na \\
\hline $\begin{array}{l}\text { Mean residence } \\
\text { time, hr (low, high) }\end{array}$ & 7.5 & 20,24 & 20 & 11 & 40,45 & 44 & 9,12 & 28 & 28 \\
\hline Velocity, $\mathrm{cm} / \mathrm{hr}$ & 1.2 & $0.45,0.38$ & 0.45 & 1.5 & $0.41,0.37$ & 0.38 & $1.9,1.5$ & 0.63 & 0.63 \\
\hline$P e$ (low, high) & 2 & 2,5 & 2 & 5 & 4,5 & 4 & $1.2,2$ & 4 & 4 \\
\hline $\begin{array}{l}\phi / b^{*} D_{m}{ }^{0.5}, \mathrm{hr}^{-0.5} \text { for } \\
{ }^{\mathrm{HHO}} \\
\text { (low, high) }\end{array}$ & $0.018^{*}$ & $0.018^{*}$ & $0.018^{*}$ & $0.018^{*}$ & $0.018^{*}$ & $0.018^{*}$ & $0.018^{*}$ & $0.018^{*}$ & $0.018^{*}$ \\
\hline $\begin{array}{l}\text { dispersivity, } D_{f}, \mathbf{m} \\
\text { (low, high) }\end{array}$ & 0.045 & $0.018,0.045$ & 0.045 & 0.033 & $\begin{array}{l}0.033 \\
0.0413\end{array}$ & 0.041 & $0.088,0.146$ & 0.044 & 0.044 \\
\hline $\begin{array}{l}\text { tortuosity } \\
\text { (low, high) }\end{array}$ & $0.45^{*}$ & $0.19,0.27^{*}$ & $0.19 *$ & $0.04 *$ & $0.03,0.04 *$ & $0.04 *$ & $0.03,0.06^{*}$ & $0.02 *$ & $0.02 *$ \\
\hline Aperture range, $\mathrm{cm}$ & 0.198 & $0.128,0.154$ & 0.128 & 0.158 & $0.140,0.156$ & 0.154 & $0.122,0.162$ & 0.092 & 0.092 \\
\hline
\end{tabular}

Note: All sorption was assumed to occur in fractures unless a fit could be significantly improved by assuming matrix sorption. A semi-infinite matrix was assumed in all calculations.

$\geq=$ indicates that the value is a minimum

$\dagger=$ fracture retardation factor and colloid filtration rate constant range, respectively. When colloid filtration modeled as irreversible, only a range is reported

na $=$ element not in sorption solution

* Poorly constrained because of negligible matrix diffusion in LCA fractures 
Table 6, cont. Retardation factors and transport parameters for fracture flowthrough experiments.

\begin{tabular}{|c|c|c|c|c|c|c|c|c|c|}
\hline $\begin{array}{l}\text { LANL Fracture } \\
\text { Experiments }\end{array}$ & $\begin{array}{l}\text { ER-6-1 } \\
\text { 2847, high } \\
\text { flow (LCA) }\end{array}$ & $\begin{array}{l}\text { ER-6-1 } \\
\text { 2847, low } \\
\text { flow (LCA) }\end{array}$ & $\begin{array}{l}\text { ER-6-1 } \\
2847, \text { low } \\
\text { flow \#2 } \\
\text { (LCA) } \\
\end{array}$ & $\begin{array}{l}\text { ER-6-1 } \\
\text { 2915, high } \\
\text { flow (LCA) }\end{array}$ & $\begin{array}{l}\text { ER-6-1 } \\
\text { 2915, low } \\
\text { flow (LCA) } \\
\end{array}$ & $\begin{array}{l}\text { ER-6-1 } \\
\text { 2915, low } \\
\text { flow \#2 } \\
\text { (LCA) } \\
\end{array}$ & $\begin{array}{l}\text { ER-6-1 } \\
\text { 3028, high } \\
\text { flow (LCA) }\end{array}$ & $\begin{array}{l}\text { ER-6-1 } \\
\text { 3028, low } \\
\text { flow (LCA) } \\
\end{array}$ & $\begin{array}{l}\text { ER-6-1 } \\
\text { 3028, low } \\
\text { flow \#2 } \\
\text { (LCA) } \\
\end{array}$ \\
\hline \multicolumn{10}{|c|}{ Fracture Retardation factor } \\
\hline C-14 & 1.5 & 1 & na & 1.5 & 1.1 & na & 1.5 & 1 & na \\
\hline Sr-90 & 1 & 1.5 & na & 1.4 & 2 & na & 1.5 & na & na \\
\hline Cs-137 & 2.2 & 2.8 & 3 & 1.8 & 2 & 2.3 & 280 & $\geq 140$ & $\geq 100$ \\
\hline U-233 & 1 & 1.3 & na & 1.2 & 1.2 & na & 1.5 & 1.6 & na \\
\hline Np-237 & 4 & 5.2 & 4.8 & $\geq 50$ & 5 & 5 & 5 & 8 & 9 \\
\hline $\mathrm{Pu}-239$ & 2.4 & $42,0.2 \uparrow$ & na & $0-0.17 \dagger$ & $0-0.08 \dagger$ & na & 16 & na & na \\
\hline \multicolumn{10}{|c|}{ Matrix Retardation factor } \\
\hline $\mathrm{C}-14$ & 1 & 1 & na & 1 & 1 & na & 1 & 1 & na \\
\hline Sr-90 & 1 & 1 & na & 1 & 1 & na & 1 & na & na \\
\hline Cs-137 & 1 & 1 & 1 & 1 & 1 & 1 & 1 & 1 & 1 \\
\hline $\mathrm{U}-233$ & 1 & 1 & na & 1 & 1 & na & 1 & 1 & na \\
\hline $\mathrm{Np}-237$ & 1 & 1 & 1 & 1 & 1 & 1 & 1 & 1 & 1 \\
\hline $\mathrm{Pu}-239$ & 1 & 1 & na & 1 & 1 & na & 1 & na & na \\
\hline $\begin{array}{l}\text { Mean residence } \\
\text { time, hr (low, high) }\end{array}$ & 5.5 & 22,26 & 22 & 21,23 & 45,85 & 35 & 6 & 25,27 & 22 \\
\hline Velocity, cm/hr & 3.4 & $0.84,0.71$ & 0.84 & $0.64,0.59$ & $0.30,0.16$ & 0.39 & 2.0 & $0.48,0.44$ & 0.55 \\
\hline$P e$ (low, high) & 7.5 & 7.5 & 7.5 & $2.2,7$ & $1.6,5$ & 2 & 1 & $1.3,2$ & 3 \\
\hline $\begin{array}{l}\phi / b * D_{m}{ }^{0.5}, \mathrm{hr}^{-0.5} \text { for } \\
{ }^{3} \mathrm{HHO} \\
\text { (low, high) }\end{array}$ & $0.04 *$ & $0.018,0.04 *$ & $0.04 *$ & $0.04 *$ & $0.04 *$ & $0.04 *$ & $0.04 *$ & $0.04 *$ & $0.04 *$ \\
\hline $\begin{array}{l}\text { dispersivity, } D_{f}, \mathbf{m} \\
\text { (low, high) }\end{array}$ & 0.025 & 0.025 & 0.025 & $0.019,0.061$ & 0.084 & 0.068 & 0.120 & $0.06,0.092$ & 0.040 \\
\hline $\begin{array}{l}\text { tortuosity } \\
\text { (low, high) }\end{array}$ & $0.06^{*}$ & $0.02,0.06^{*}$ & $0.06^{*}$ & $0.73,0.87^{*}$ & $0.20,0.70^{*}$ & $0.12 *$ & $0.12 *$ & $0.12,0.19^{*}$ & $0.09 *$ \\
\hline Aperture range, $\mathrm{cm}$ & 0.07 & $0.072,0.086$ & 0.072 & $0.37,0.404$ & $0.192,0.362$ & 0.150 & 0.118 & $0.12,0.15$ & 0.106 \\
\hline
\end{tabular}

Note: All sorption was assumed to occur in fractures unless a fit could be significantly improved by assuming matrix sorption. A semi-infinite matrix was assumed in all calculations

$\geq=$ indicates that the value is a minimum

$\dagger=$ fracture retardation factor and colloid filtration rate constant range, respectively. When colloid filtration modeled as irreversible, only a range is reported. When reaction modeled as reversible, only one value is reported.

na $=$ element not in sorption solution

* Poorly constrained because of negligible matrix diffusion in LCA fractures 
Table 6, cont. Retardation factors and transport parameters for fracture flowthrough experiments.

\begin{tabular}{|c|c|c|c|c|c|c|}
\hline $\begin{array}{l}\text { LANL Fracture } \\
\text { Experiments }\end{array}$ & $\begin{array}{l}\text { ER-6-2 2730, } \\
\text { high flow } \\
\text { (LCA) }\end{array}$ & $\begin{array}{l}\text { ER-6-2 2730, } \\
\text { low flow } \\
\text { (LCA) }\end{array}$ & $\begin{array}{l}\text { ER-6-2 2730, } \\
\text { low flow \#2 } \\
\text { (LCA) }\end{array}$ & $\begin{array}{l}\text { ER-6-2 2750, } \\
\text { high flow } \\
\text { (LCA) }\end{array}$ & $\begin{array}{l}\text { ER-6-2 2750, } \\
\text { low flow } \\
\text { (LCA) }\end{array}$ & $\begin{array}{l}\text { ER-6-2 2750, } \\
\text { low flow \#2 } \\
\text { (LCA) }\end{array}$ \\
\hline \multicolumn{7}{|c|}{ Fracture Retardation factor } \\
\hline C-14 & 5 & 1 & na & 1.8 & 1 & na \\
\hline Sr-90 & 33 & na & na & 2 & na & na \\
\hline Cs-137 & 320 & 280 & 160 & 33 & 42 & 40 \\
\hline $\mathrm{U}-233$ & 1.6 & 2.7 & na & 1.5 & 1.5 & na \\
\hline Np-237 & 22 & 32 & 28 & 8.5 & 5 & 6 \\
\hline $\mathrm{Pu}-239$ & 50 & na & na & 18 & na & na \\
\hline \multicolumn{7}{|c|}{ Matrix Retardation factor } \\
\hline C-14 & 1 & 1 & na & 1 & 1 & na \\
\hline Sr-90 & 1 & na & na & 1 & na & na \\
\hline Cs-137 & 1 & 1 & 1 & 1 & 1 & 1 \\
\hline $\mathrm{U}-233$ & 1 & 1 & na & 1 & 1 & na \\
\hline $\mathrm{Np}-237$ & 1 & 1 & 1 & 1 & 1 & 1 \\
\hline $\mathrm{Pu}-239$ & 1 & na & na & 1 & na & na \\
\hline $\begin{array}{l}\text { Mean residence time, hr } \\
\text { (low, high) }\end{array}$ & 1.8 & $1,7.4$ & 7.2 & 4 & 16,18 & 15 \\
\hline Velocity, cm/hr & 4.7 & $8.5,1.1$ & 1.2 & 2.6 & $0.66,0.58$ & 0.70 \\
\hline$P e$ (low, high) & 2.4 & 2.4 & 2.4 & 6 & 6 & 6 \\
\hline $\begin{array}{l}\phi / b * D_{m}{ }^{0.5}, \mathrm{hr}^{-0.5} \text { for } \\
{ }^{3} \mathrm{HHO} \\
\text { (low, high) }\end{array}$ & $0.04 *$ & $0.04 *$ & $0.04 *$ & $0.04 *$ & $0.04 *$ & $0.04 *$ \\
\hline $\begin{array}{l}\text { dispersivity, } D_{f}, \mathbf{m} \\
\text { (low, high) }\end{array}$ & 0.035 & 0.035 & 0.035 & 0.018 & 0.018 & 0.018 \\
\hline tortuosity (low, high) & $0.16^{*}$ & $0.08,0.17^{*}$ & $0.08^{*}$ & $0.66^{*}$ & $2.03,2.52 *$ & $1.76^{*}$ \\
\hline Aperture range, $\mathrm{cm}$ & 0.05 & $0.036,0.052$ & 0.035 & 0.05 & $0.088,0.098$ & 0.082 \\
\hline
\end{tabular}

Note: All sorption was assumed to occur in fractures unless a fit could be significantly improved by assuming matrix sorption.

A semi-infinite matrix was assumed in all calculations.

na $=$ element not in sorption solution

* Poorly constrained because of negligible matrix diffusion in LCA fractures 


\section{REFERENCES}

Andersson, P., J. Byegard, E. L. Tullborg, T. Doe, J. Hermanson and A. Winberge (2004). "In situ tracer tests to determine retention properties of a block scale fracture network in granitic rock at the Aspo Hard Rock Laboratory, Sweden." Journal of Contaminant Hydrology 70(3-4): 271-297.

Bechtel-SAIC (2004). Saturated Zone In-Situ Testing, ANL-NBS-HS-000039 Rev.1, Bechtel SAIC Corporation, Las Vegas, Nevada.

Durham, W. B., W. L. Bourcier and E. A. Burton (2001). "Direct observation of reactive flow in a single fracture." Water Resources Research 37(1): 1-12.

Kersting, A. B., D. W. Efurd, D. L. Finnegan, D. J. Rokop, D. K. Smith and J. L. Thompson (1999). "Migration of plutonium in ground water at the Nevada Test Site." Nature 397(6714): 56-59.

Lide, D. R. (2000). CRC Handbook of Chemistry and Physics. Boca Raton, Florida, CRC Press.

Maloszewski, P. and A. Zuber (1984). Interpretation of Artifitial and Environmental Tracers in Fissured Rocks with a Porous Matrix. Isotope Hydrology 1993. Proceedings of an International Symposium on Isotope Hydrology in Water Resources Developement, Vienna, Austria, International Atomic Energy Commission.

Maloszewski, P. and A. Zuber (1985). "On the Theory of Tracer Experiments in Fissured Rocks with a Porous Matrix." Journal of Hydrology 79(3-4): 333-358.

Mills, R. and V. M. M. Lobo (1989). Self-Diffusion in Electrolyte Solutions: A Critical Examination of Data Compiled for the Literature. Amsterdam, Elsevier.

Newman, J. (1973). Electrochemical Systems. Englewood Cliffs, New Jersey, Prentice Hall.

Rai, D., N. J. Hess, A. R. Felmy, D. A. Moore, M. Yui and P. Vitorge (1999). "A thermodynamic model for the solubility of $\mathrm{PuO} 2(\mathrm{am})$ in the aqueous $\mathrm{K}+-\mathrm{HCO} 3--\mathrm{CO} 32--\mathrm{OH}-\mathrm{H} 2 \mathrm{O}$ system." Radiochimica Acta 86(3-4): 89-99.

Reimus, P., M. Haga, A. R. Humphrey, D. A. Counce, T. J. Callahan and S. D. Ware (2002). Diffusion Cell and Fracture Transport Experiments to Support Interpretations of the Bullion Forced Gradient Experiment, LA-UR-02-6884, Los Alamos National Laboratory, Los Alamos, New Mexico.

Reimus, P., G. Pohll, T. Mihevc, J. Chapman, M. Haga, B. Lyles, S. Kosinski, R. Niswonger and P. Sanders (2003). "Testing and parameterizing a conceptual model for solute transport in a fractured granite using multiple tracers in a forced gradient test." Water Resources Research 39(12).

Reimus, P. W. and M. J. Haga (1999). Analysis of tracer responses in the Bullion forced-gradient experiment at Pahute Mesa, Nevada, LA-13615-MS, Los Alamos National Laboratory, Los Alamos, New Mexico.

Skagius, K. and I. Neretnieks (1986). "Porosities and Diffusivities of Some Nonsorbing Species in Crystalline Rocks." Water Resources Research 22(3): 389-398.

SNJV (2004). Geochem04.mdb and A User's Guide to the Comprehensive Water Quality Database for Groundwater in the Vicinity of the Nevada Test Site Las Vegas, Nevada, DOE-NNSA. 
Steefel, C. I. and S. B. Yabusaki (1995). OS3D/GIMRT, Software for modeling multicomponent-multidimensional reactive transport, User manual and programmer's guide Richland, WA, Pacific Northwest National Laboratory.

Tang, D. H., E. O. Fring and E. A. Sudicky (1981). "Contaminant transport in fractured porous media: Analytical solution for a single fracture." Water Resources Research 17(3): 555 564.

Wang, J.H., C.V. Robinson and I.S. Edelman (1953). "Self-diffusion and Structure of Liquid Water. III. Measurement of the Self-diffusion of Liquid Water with $\mathrm{H}^{2}, \mathrm{H}^{3}$, and $\mathrm{O}^{18}$ as Tracers." J. Am. Chem. Soc. 75:466-470.

Ware, S. D., A. Abdel-Fattah, M. Ding, P. W. Reimus, C. Sedlacek, M. Haga, E. Garcia and S. Chipera (2005). Radionuclide Sorption and Transport in the Lower Carbonate Aquifer and Tuff Confining Unit of Yucca Flat, Nevada Test Site, draft report, Los Alamos National Laboratory, Los Alamos, New Mexico.

Zavarin, M. and C. J. Bruton (2004a). A Non-Electrostatic Surface Complexation Approach to Modeling Radionuclide Migration at the Nevada Test Site: Aluminosilicates, UCRL-TR208672, Lawrence Livermore National Laboratory, Livermore, California.

Zavarin, M. and C. J. Bruton (2004b). A Non-Electrostatic Surface Complexation Approach to Modeling Radionuclide Migration at the Nevada Test Site: Iron Oxides and Calcite, UCRL-TR-208673, Lawrence Livermore National Laboratory, Livermore, California.

Zavarin, M., M. R. Johnson, S. K. Roberts, R. Pletcher, T. P. Rose, A. B. Kersting, G. Eaton, Q. $\mathrm{Hu}$, E. Ramon, J. Walensky and P. Zhao (2005). Radionuclide Transport in Tuff and Carbonate Fractures from Yucca Flat, Nevada Test Site, UCRL-TR-219836, Lawrence Livermore National Laboratory, Livermore, California. 


\section{APPENDIX A: MODEL FITS TO LLNL TUFF FRACTURE TRANSPORT BREAKTHROUGH CURVES}
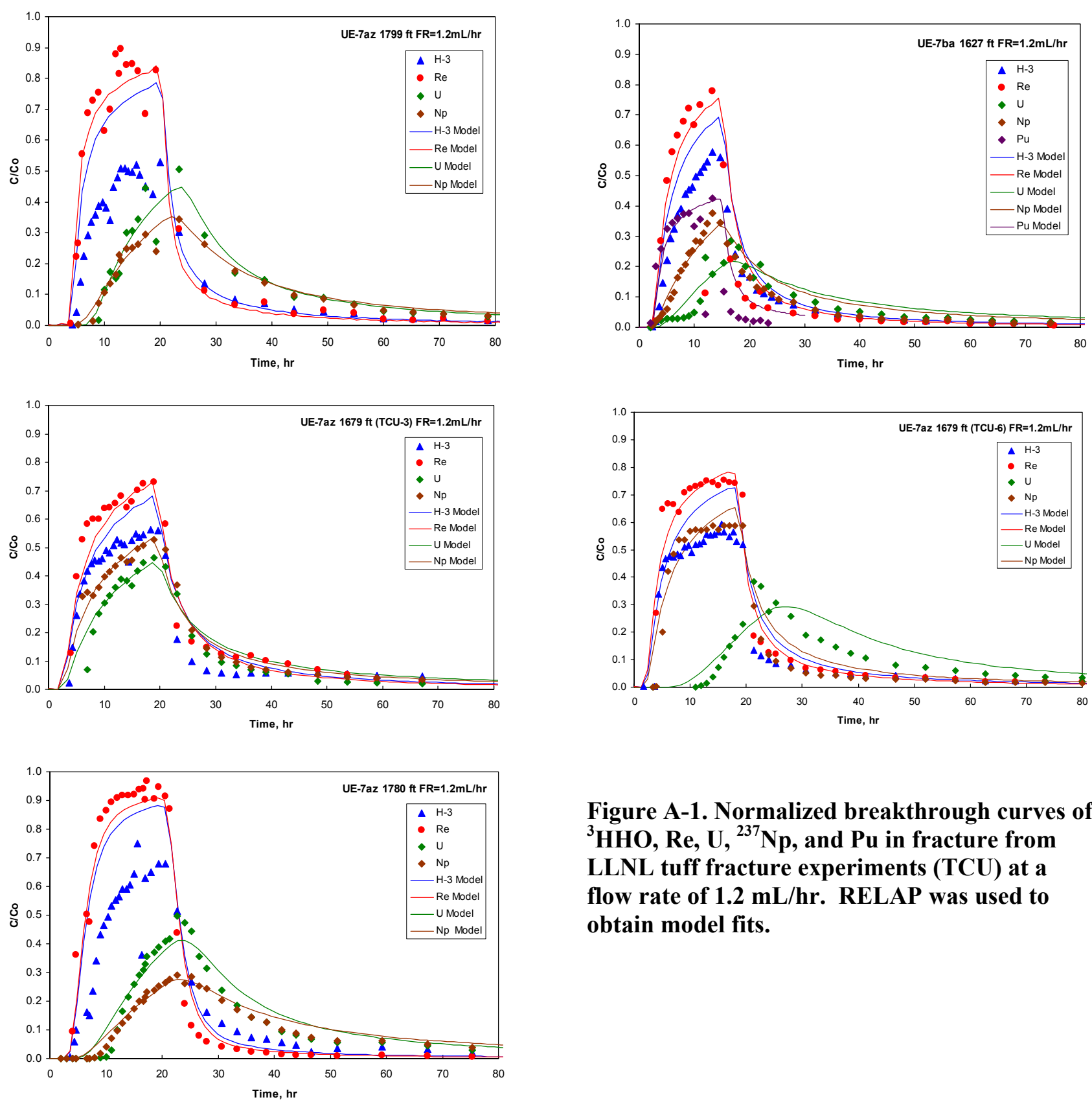

Figure A-1. Normalized breakthrough curves of ${ }^{3} \mathrm{HHO}, \mathrm{Re}, \mathrm{U},{ }^{237} \mathrm{~Np}$, and $\mathrm{Pu}$ in fracture from LLNL tuff fracture experiments (TCU) at a flow rate of $1.2 \mathrm{~mL} / \mathrm{hr}$. RELAP was used to obtain model fits. 


\section{APPENDIX B: MODEL FITS TO LLNL CARBONATE FRACTURE TRANSPORT BREAKTHROUGH CURVES}
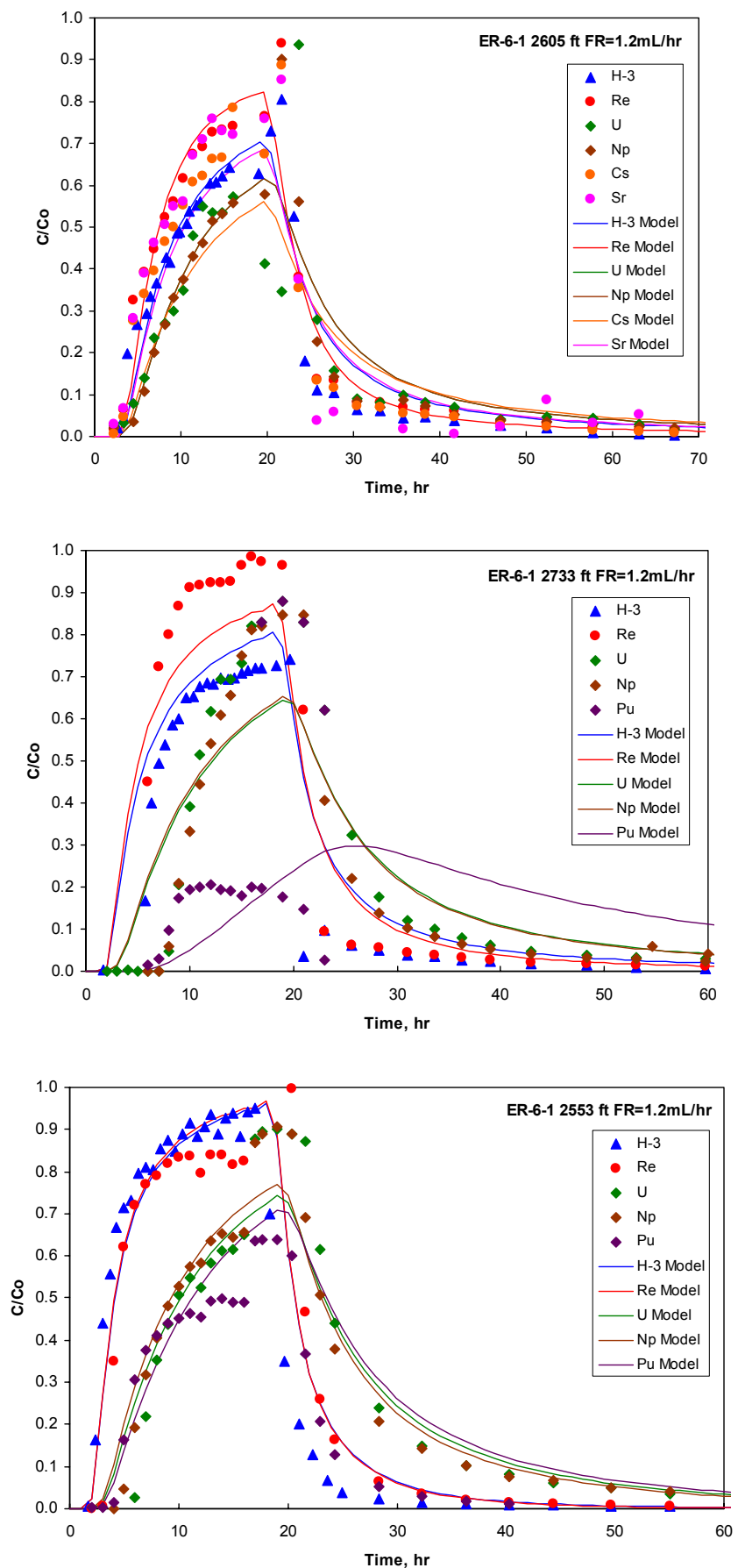

Figure B-1. Normalized breakthrough curves of ${ }^{3} \mathrm{HHO}, \mathrm{Re}, \mathrm{U},{ }^{237} \mathrm{~Np}$, and Pu in fracture from LLNL carbonate fracture experiments (LCA) at a flow rate of $1.2 \mathrm{~mL} / \mathrm{hr}$. RELAP was used to obtain model fits. 


\section{APPENDIX C: MODEL FITS TO LANL TUFF FRACTURE TRANSPORT BREAKTHROUGH CURVES}
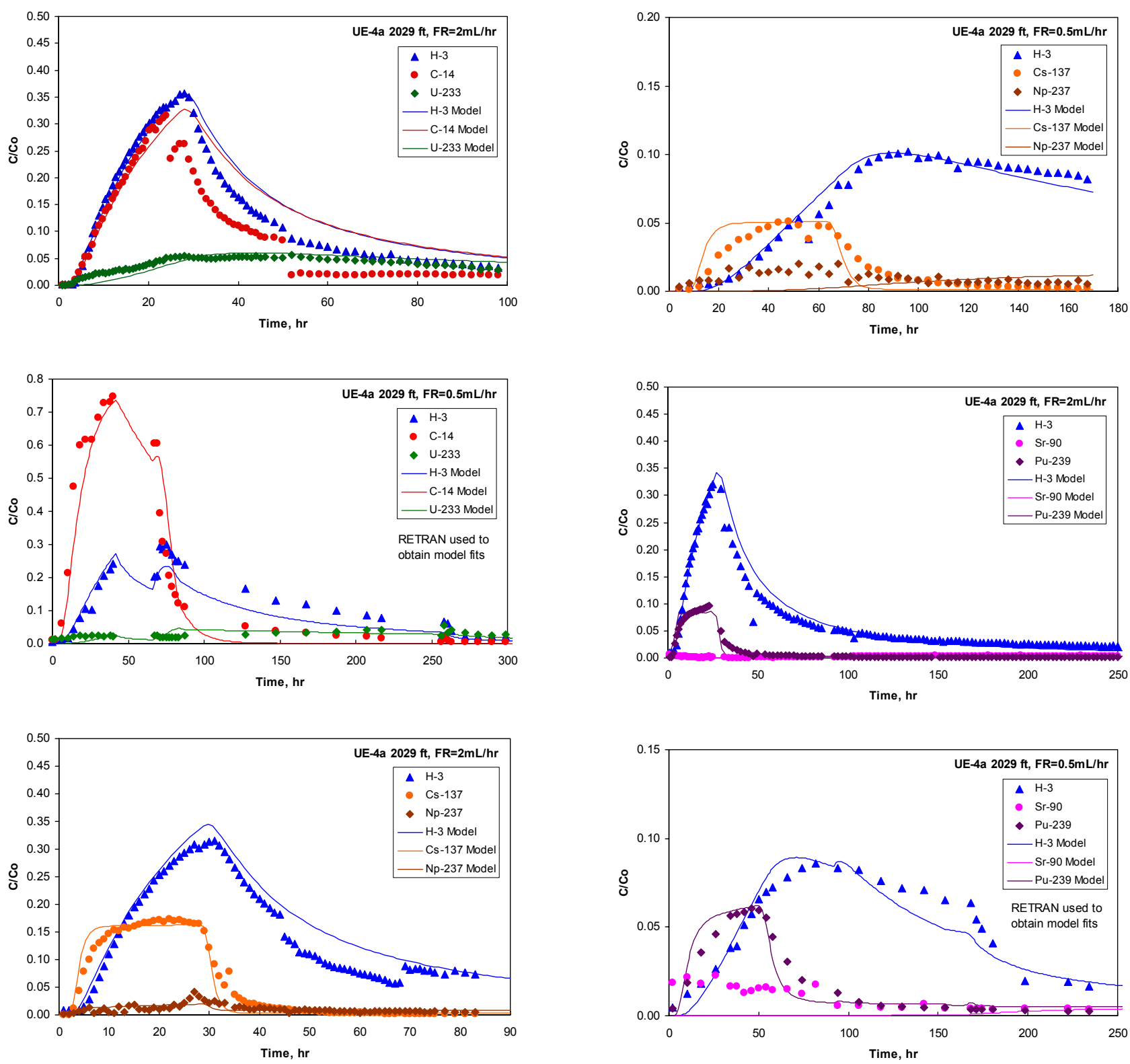

Figure C-1. Normalized breakthrough curves of ${ }^{3} \mathrm{HHO},{ }^{14} \mathrm{C},{ }^{233} \mathrm{U},{ }^{137} \mathrm{Cs},{ }^{237} \mathrm{~Np},{ }^{90} \mathrm{Sr}$, and ${ }^{239} \mathrm{Pu}$ in fracture from UE-4a $2029 \mathrm{ft}$ (TCU) at flow rates of $0.5 \mathrm{~mL} / \mathrm{hr}$ and $2 \mathrm{~mL} / \mathrm{hr}$. RELAP was used to obtain model fits except where noted on plots. Kinetic model used for $\mathrm{Np}$ at $2 \mathrm{ml} / \mathrm{hr}$ flow rate. 

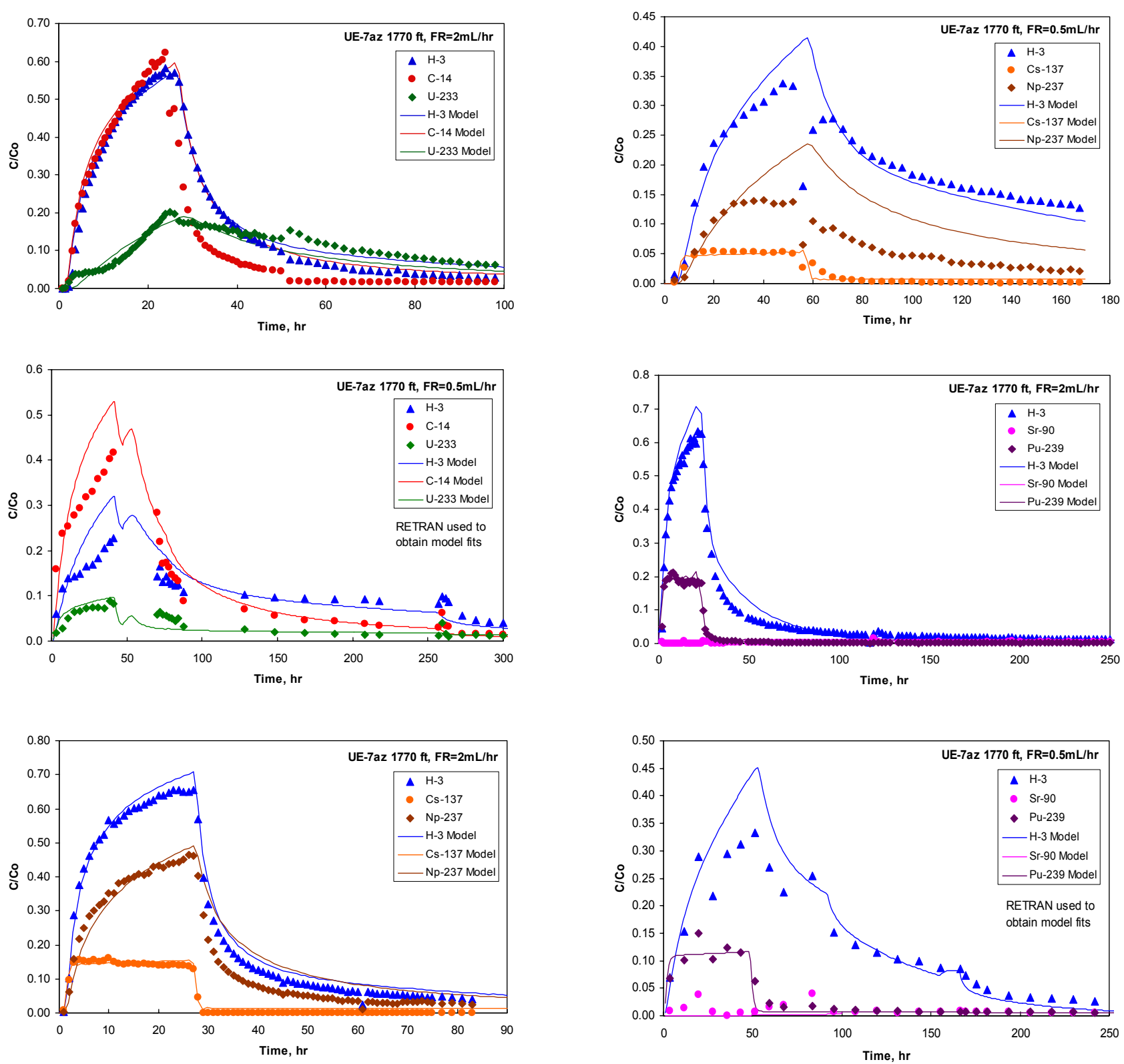

Figure C-2. Normalized breakthrough curves of ${ }^{3} \mathrm{HHO},{ }^{14} \mathrm{C},{ }^{233} \mathrm{U},{ }^{137} \mathrm{Cs},{ }^{237} \mathrm{~Np},{ }^{90} \mathrm{Sr}$, and ${ }^{239} \mathrm{Pu}$ in fracture from UE-7az $1770 \mathrm{ft}$ (TCU) at flow rates of $0.5 \mathrm{~mL} / \mathrm{hr}$ and $2 \mathrm{~mL} / \mathrm{hr}$. RELAP was used to obtain model fits except where noted on plots. 

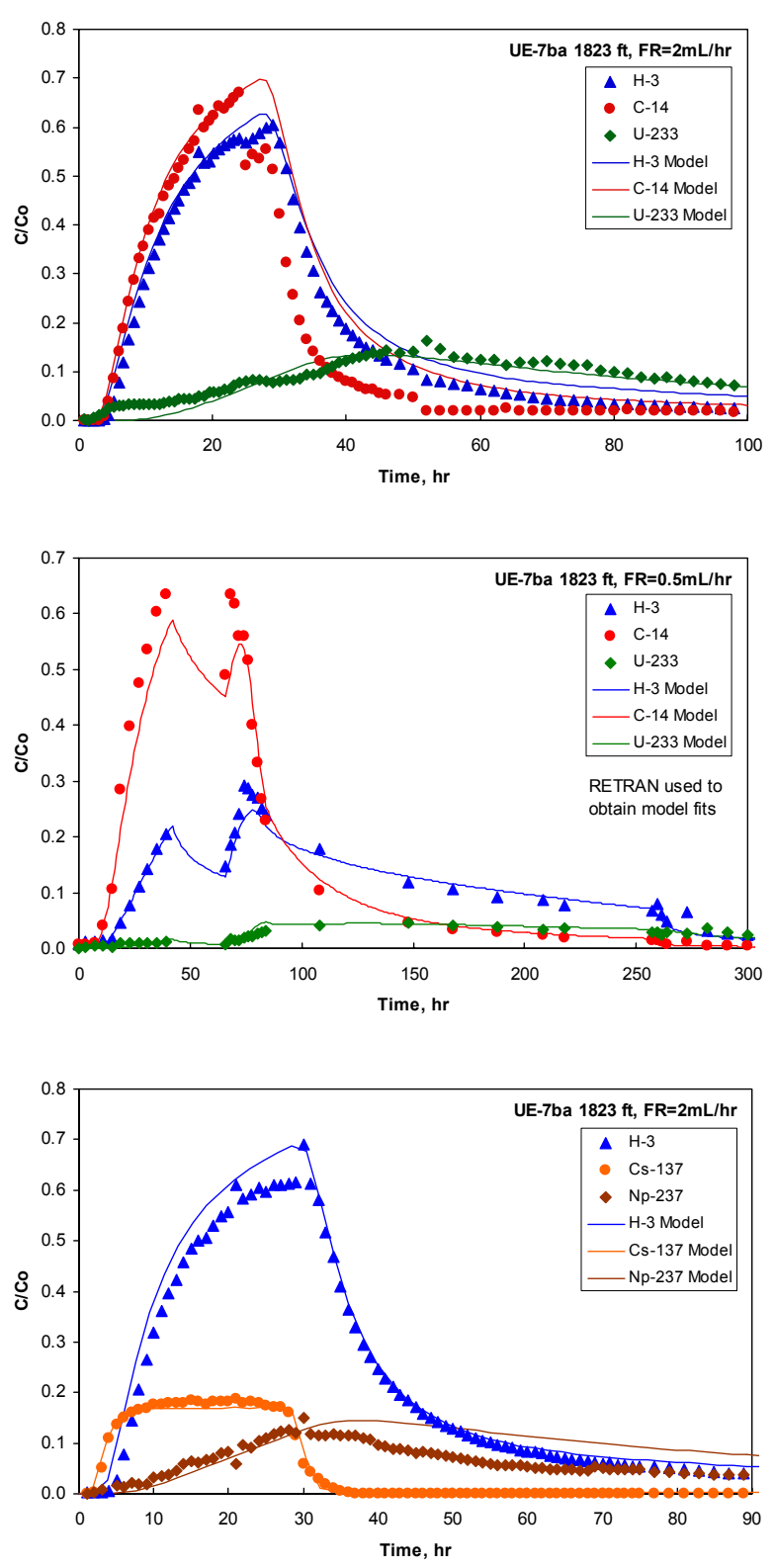
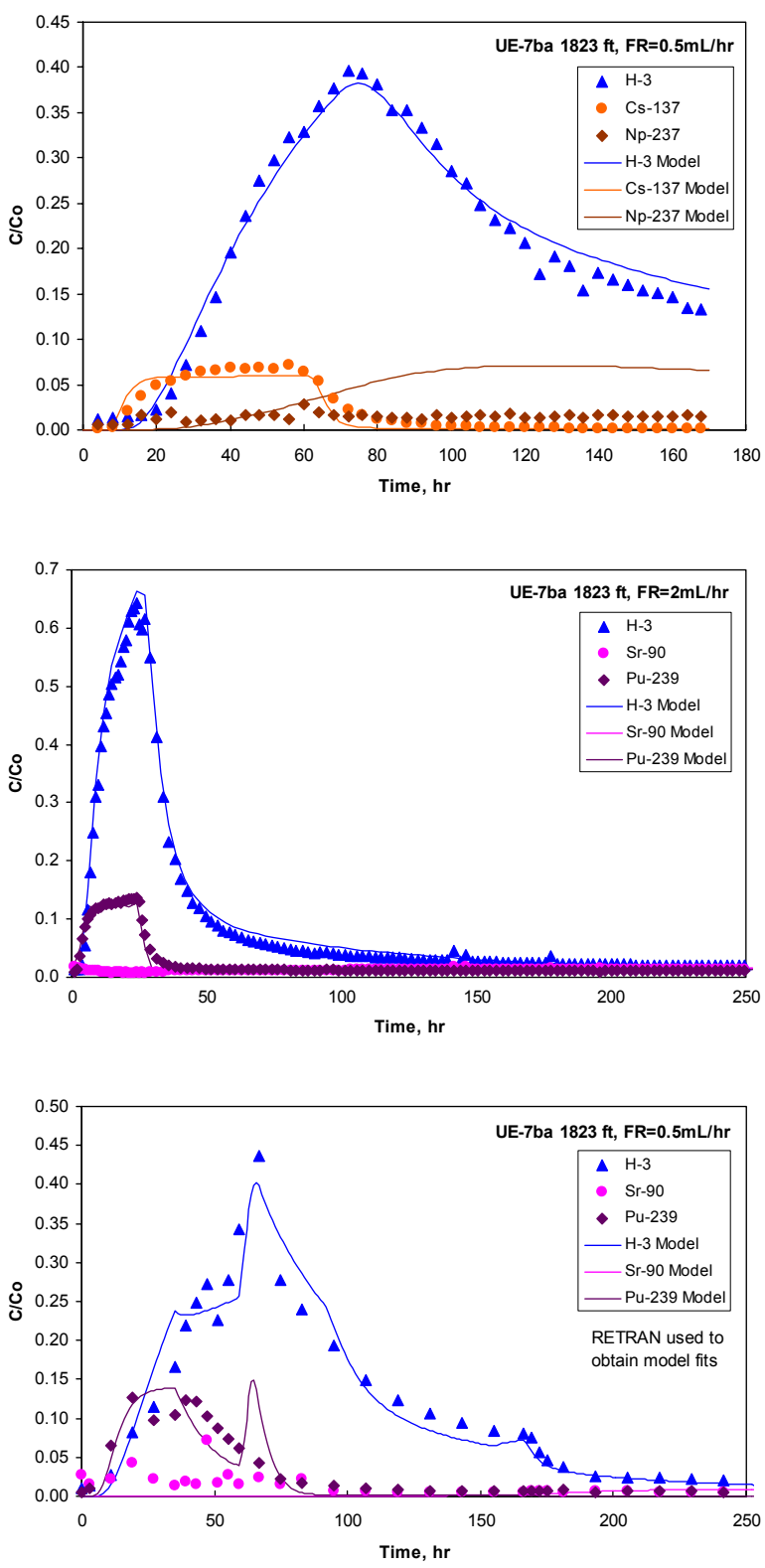

Figure C-3. Normalized breakthrough curves of ${ }^{3} \mathrm{HHO},{ }^{14} \mathrm{C},{ }^{233} \mathrm{U},{ }^{137} \mathrm{Cs},{ }^{237} \mathrm{~Np},{ }^{90} \mathrm{Sr}$, and ${ }^{239} \mathrm{Pu}$ in fracture from UE-7ba $1823 \mathrm{ft}$ (TCU) at flow rates of $0.5 \mathrm{~mL} / \mathrm{hr}$ and $2 \mathrm{~mL} / \mathrm{hr}$. RELAP was used to obtain model fits except where noted on plots. 

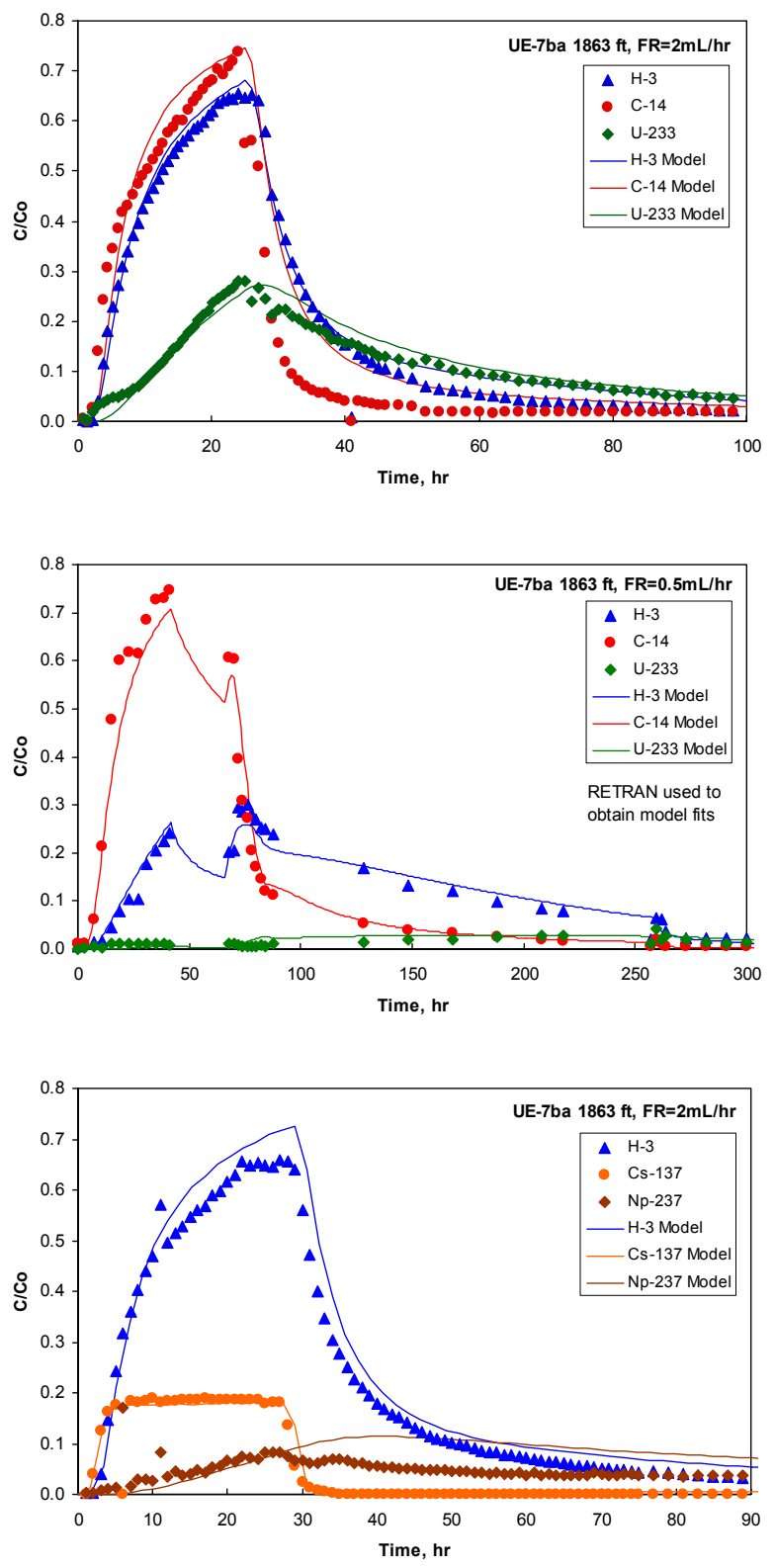
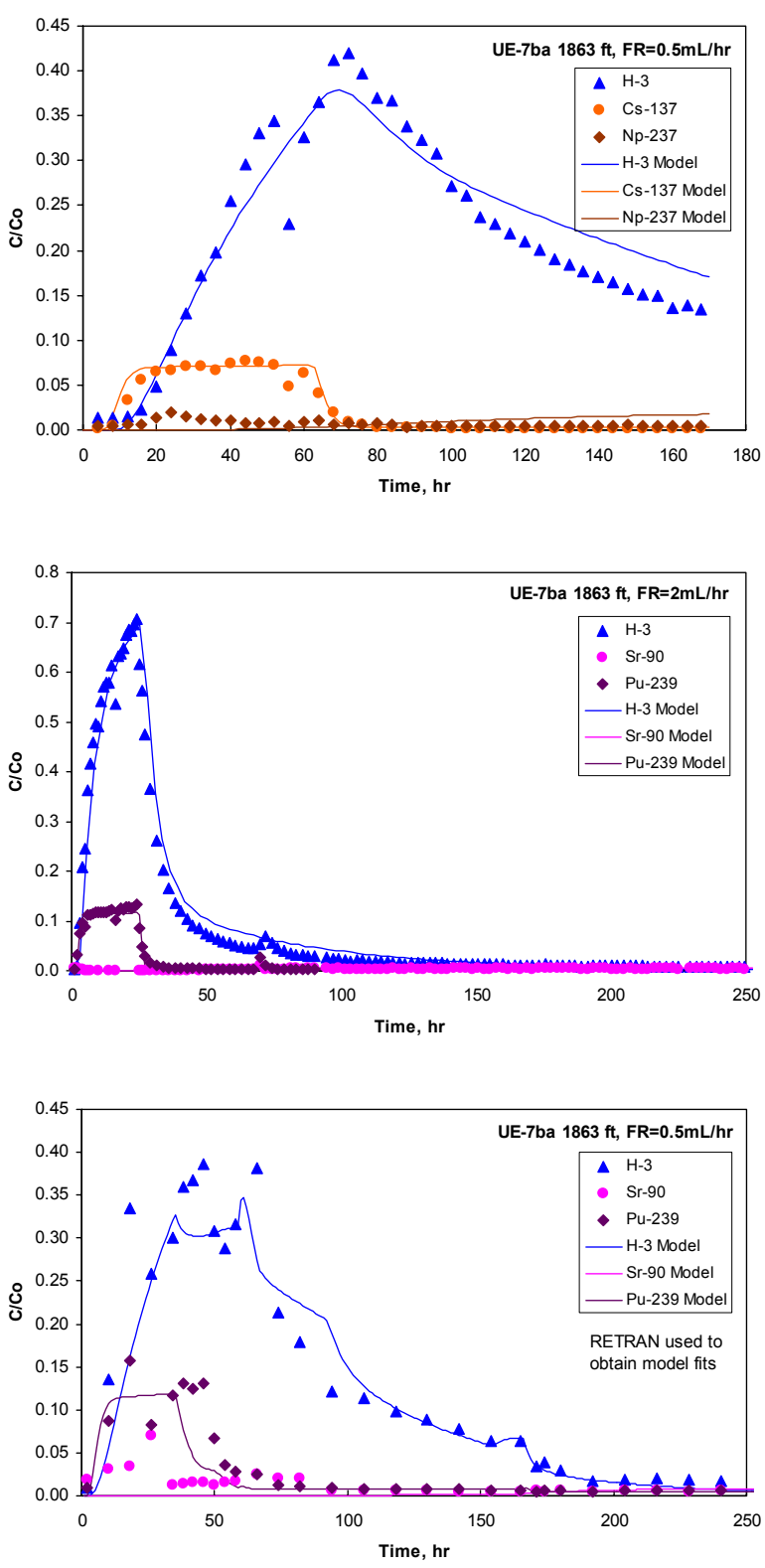

Figure C-4. Normalized breakthrough curves of ${ }^{3} \mathrm{HHO},{ }^{14} \mathrm{C},{ }^{233} \mathrm{U},{ }^{137} \mathrm{Cs},{ }^{237} \mathrm{~Np},{ }^{90} \mathrm{Sr}$, and ${ }^{239} \mathrm{Pu}$ in fracture from UE-7ba $1863 \mathrm{ft}$ (TCU) at flow rates of $0.5 \mathrm{~mL} / \mathrm{hr}$ and $2 \mathrm{~mL} / \mathrm{hr}$. RELAP was used to obtain model fits except where noted on plots. 


\section{APPENDIX D: MODEL FITS TO LANL CARBONATE FRACTURE TRANSPORT BREAKTHROUGH CURVES}
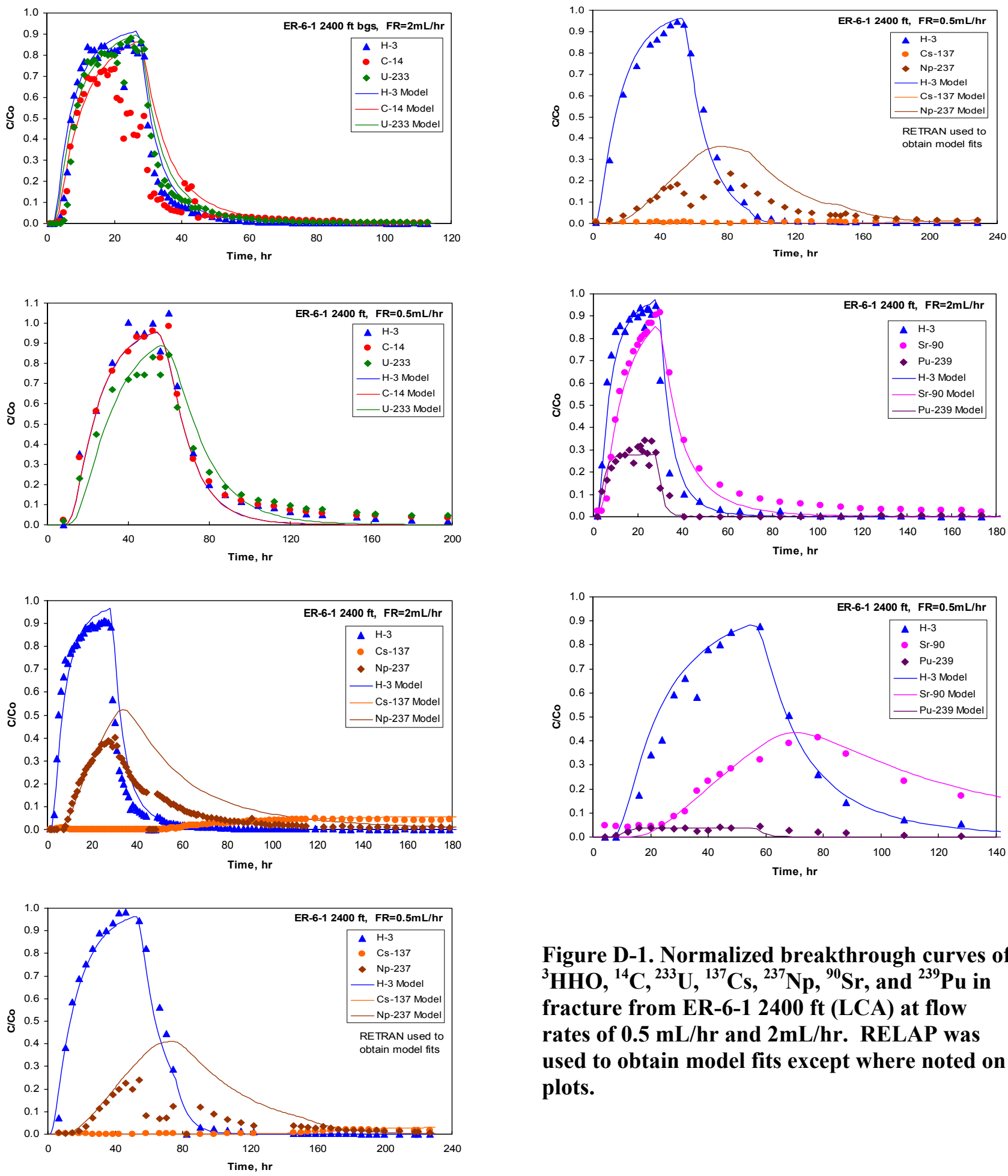

Figure D-1. Normalized breakthrough curves of ${ }^{3} \mathrm{HHO},{ }^{14} \mathrm{C},{ }^{233} \mathrm{U},{ }^{137} \mathrm{Cs},{ }^{237} \mathrm{~Np},{ }^{90} \mathrm{Sr}$, and ${ }^{239} \mathrm{Pu}$ in fracture from ER-6-1 $2400 \mathrm{ft}$ (LCA) at flow rates of $0.5 \mathrm{~mL} / \mathrm{hr}$ and $2 \mathrm{~mL} / \mathrm{hr}$. RELAP was used to obtain model fits except where noted on plots. 

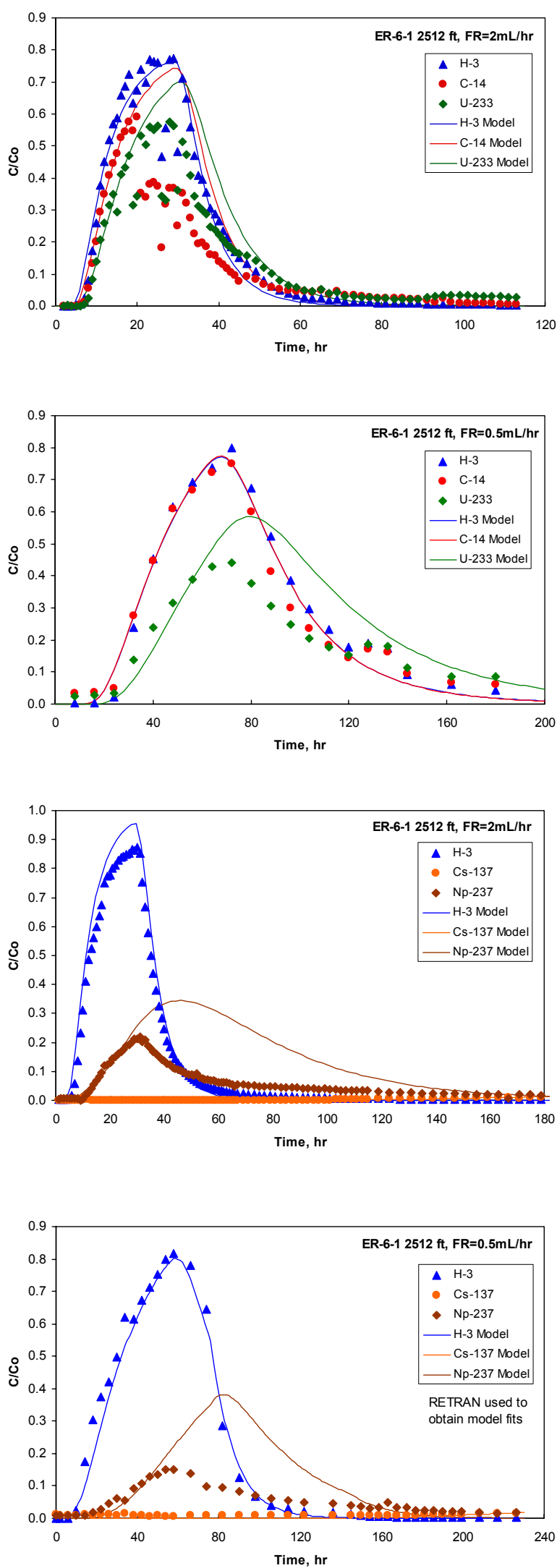
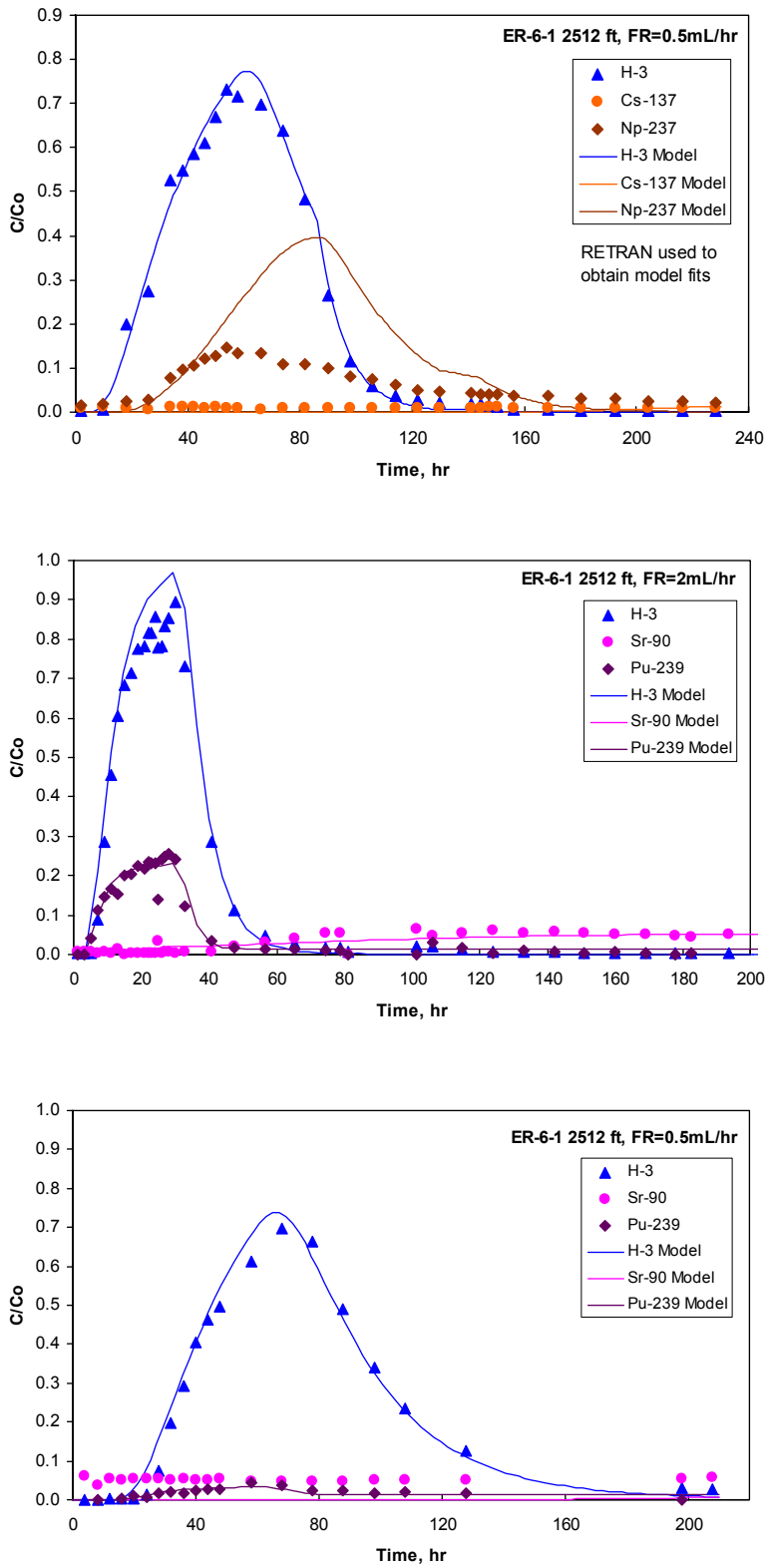

Figure D-2. Normalized breakthrough curves of ${ }^{3} \mathrm{HHO},{ }^{14} \mathrm{C},{ }^{233} \mathrm{U},{ }^{137} \mathrm{Cs},{ }^{237} \mathrm{~Np},{ }^{90} \mathrm{Sr}$, and ${ }^{239} \mathrm{Pu}$ in fracture from ER-6-1 $2512 \mathrm{ft}$ (LCA) at flow rates of $0.5 \mathrm{~mL} / \mathrm{hr}$ and $2 \mathrm{~mL} / \mathrm{hr}$. RELAP was used to obtain model fits except where noted on plots. 

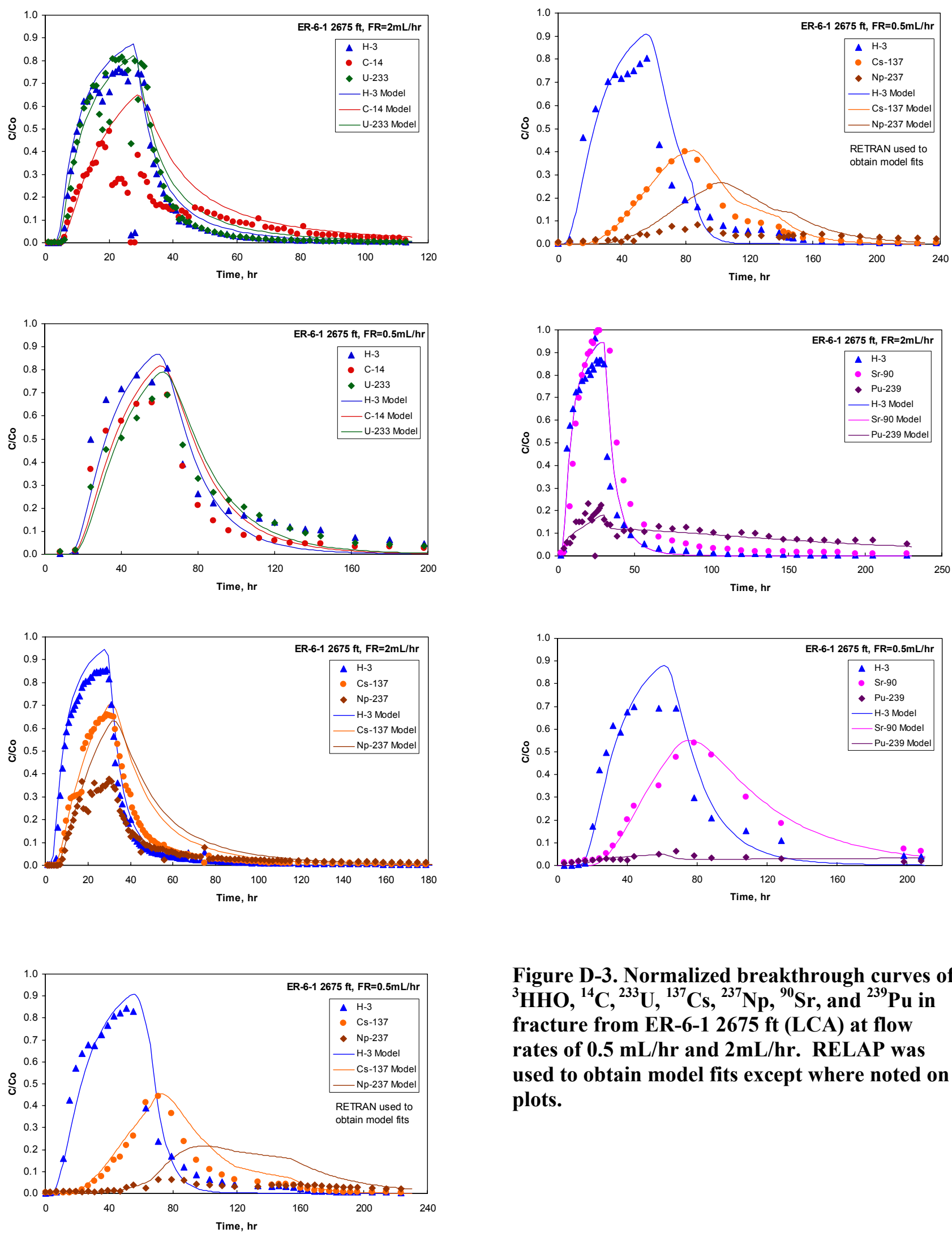

Figure D-3. Normalized breakthrough curves of ${ }^{3} \mathrm{HHO},{ }^{14} \mathrm{C},{ }^{233} \mathrm{U},{ }^{137} \mathrm{Cs},{ }^{237} \mathrm{~Np},{ }^{90} \mathrm{Sr}$, and ${ }^{239} \mathrm{Pu}$ in fracture from ER-6-1 $2675 \mathrm{ft}$ (LCA) at flow rates of $0.5 \mathrm{~mL} / \mathrm{hr}$ and $2 \mathrm{~mL} / \mathrm{hr}$. RELAP was used to obtain model fits except where noted on plots. 

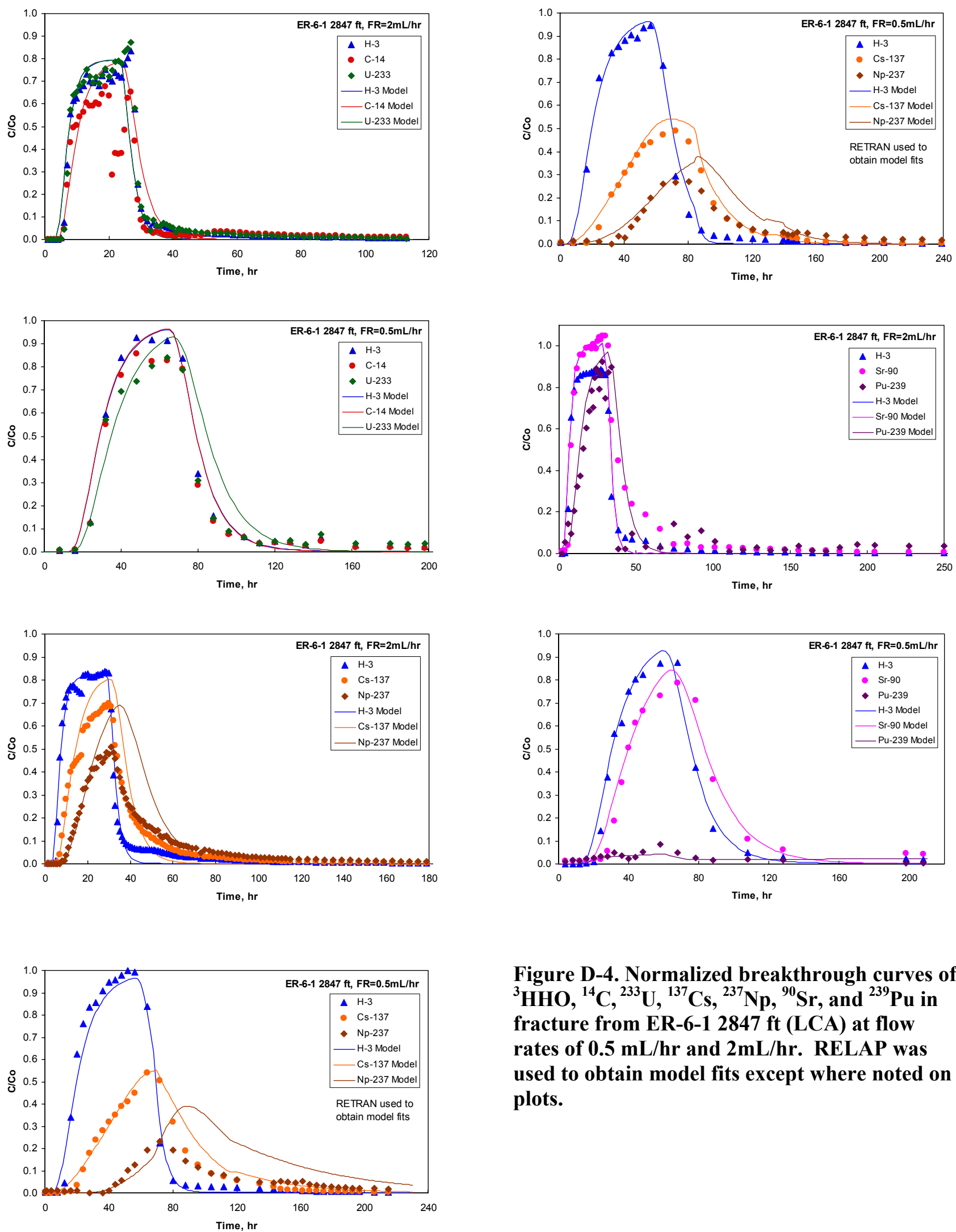

Figure D-4. Normalized breakthrough curves of ${ }^{3} \mathrm{HHO},{ }^{14} \mathrm{C},{ }^{233} \mathrm{U},{ }^{137} \mathrm{Cs},{ }^{237} \mathrm{~Np},{ }^{90} \mathrm{Sr}$, and ${ }^{239} \mathrm{Pu}$ in fracture from ER-6-1 $2847 \mathrm{ft}$ (LCA) at flow rates of $0.5 \mathrm{~mL} / \mathrm{hr}$ and $2 \mathrm{~mL} / \mathrm{hr}$. RELAP was used to obtain model fits except where noted on plots. 

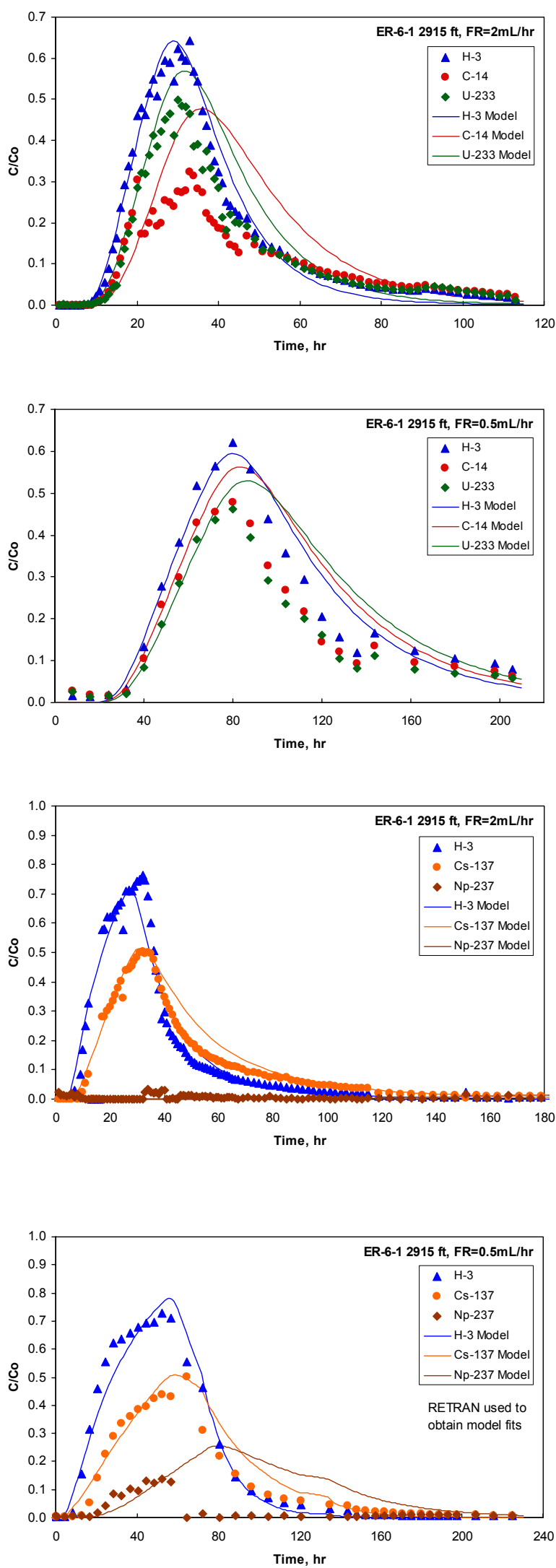
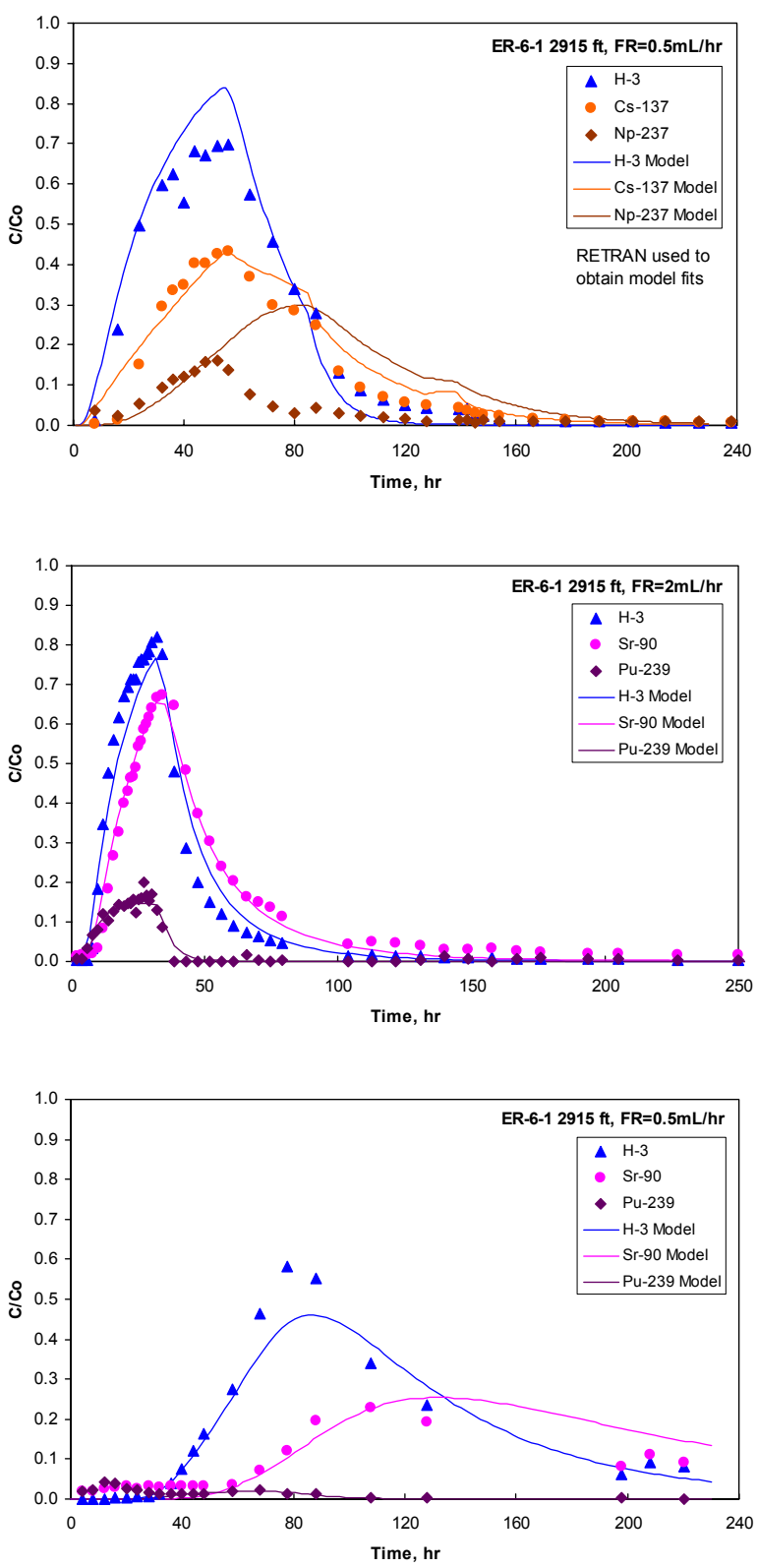

Figure D-5. Normalized breakthrough curves of ${ }^{3} \mathrm{HHO},{ }^{14} \mathrm{C},{ }^{233} \mathrm{U},{ }^{137} \mathrm{Cs},{ }^{237} \mathrm{~Np},{ }^{90} \mathrm{Sr}$, and ${ }^{239} \mathrm{Pu}$ in fracture from ER-6-1 $2915 \mathrm{ft}$ (LCA) at flow rates of $0.5 \mathrm{~mL} / \mathrm{hr}$ and $2 \mathrm{~mL} / \mathrm{hr}$. RELAP was used to obtain model fits except where noted on plots. 

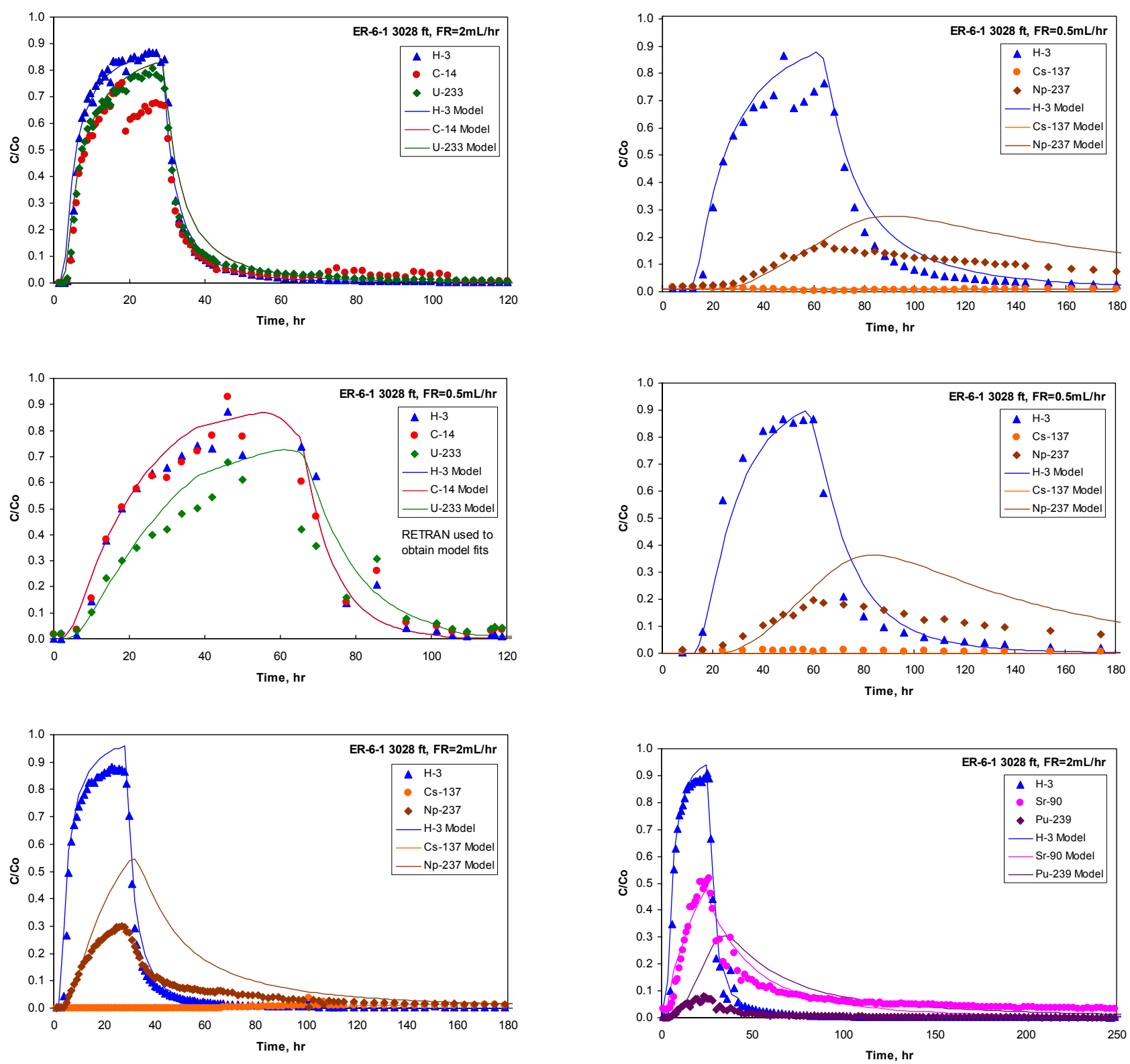

Figure D-6. Normalized breakthrough curves of ${ }^{3} \mathrm{HHO},{ }^{14} \mathrm{C},{ }^{233} \mathrm{U},{ }^{137} \mathrm{Cs},{ }^{237} \mathrm{~Np},{ }^{90} \mathrm{Sr}$, and ${ }^{239} \mathrm{Pu}$ in fracture from ER-6-1 $3028 \mathrm{ft}$ (LCA) at flow rates of $0.5 \mathrm{~mL} / \mathrm{hr}$ and $2 \mathrm{~mL} / \mathrm{hr}$. RELAP was used to obtain model fits except where noted on plots. 

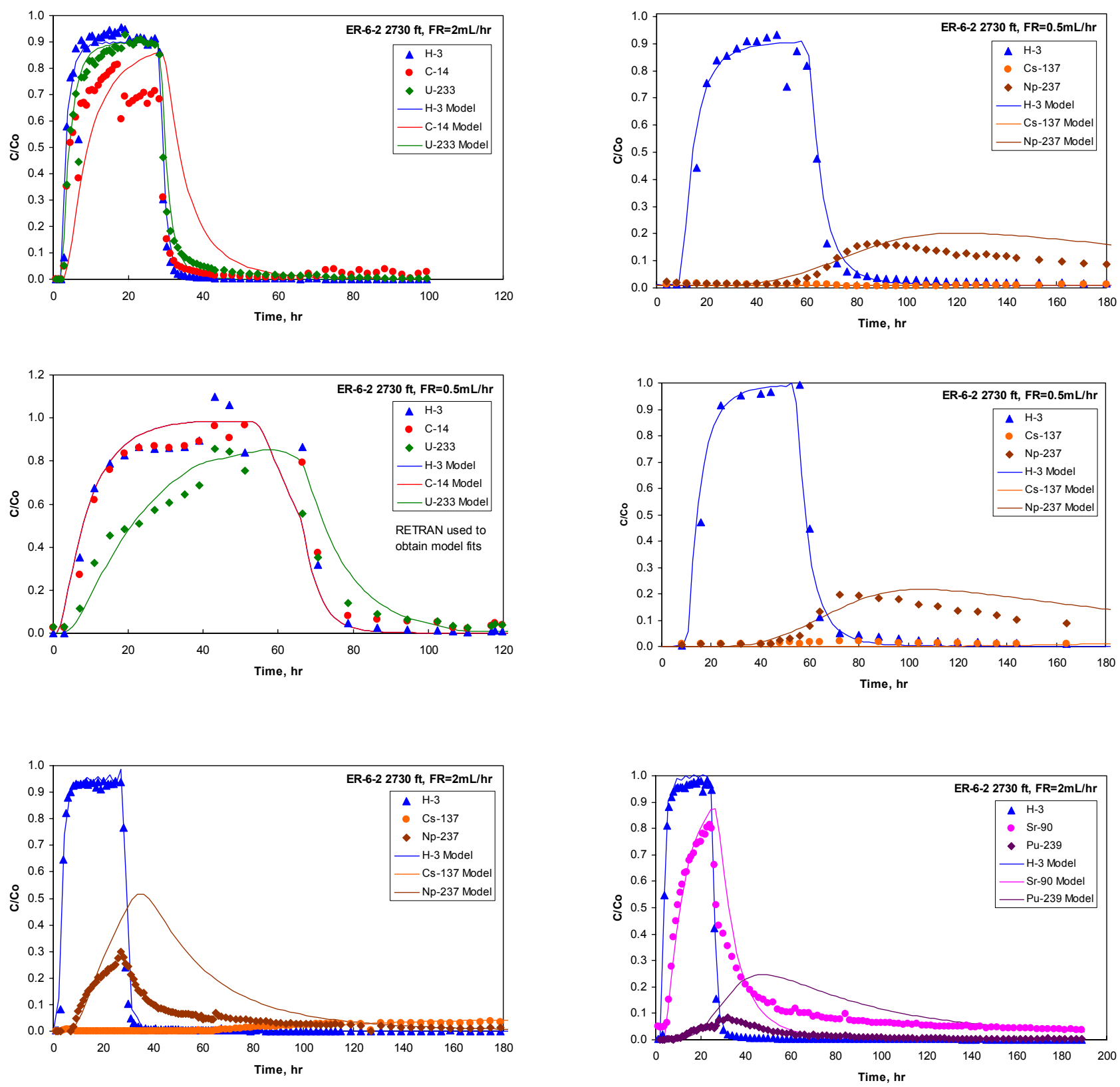

Figure D-7. Normalized breakthrough curves of ${ }^{3} \mathrm{HHO},{ }^{14} \mathrm{C},{ }^{233} \mathrm{U},{ }^{137} \mathrm{Cs},{ }^{237} \mathrm{~Np},{ }^{90} \mathrm{Sr}$, and ${ }^{239} \mathrm{Pu}$ in fracture from ER-6-2 $2730 \mathrm{ft}$ (LCA) at flow rates of $0.5 \mathrm{~mL} / \mathrm{hr}$ and $2 \mathrm{~mL} / \mathrm{hr}$. RELAP was used to obtain model fits except where noted on plots. 

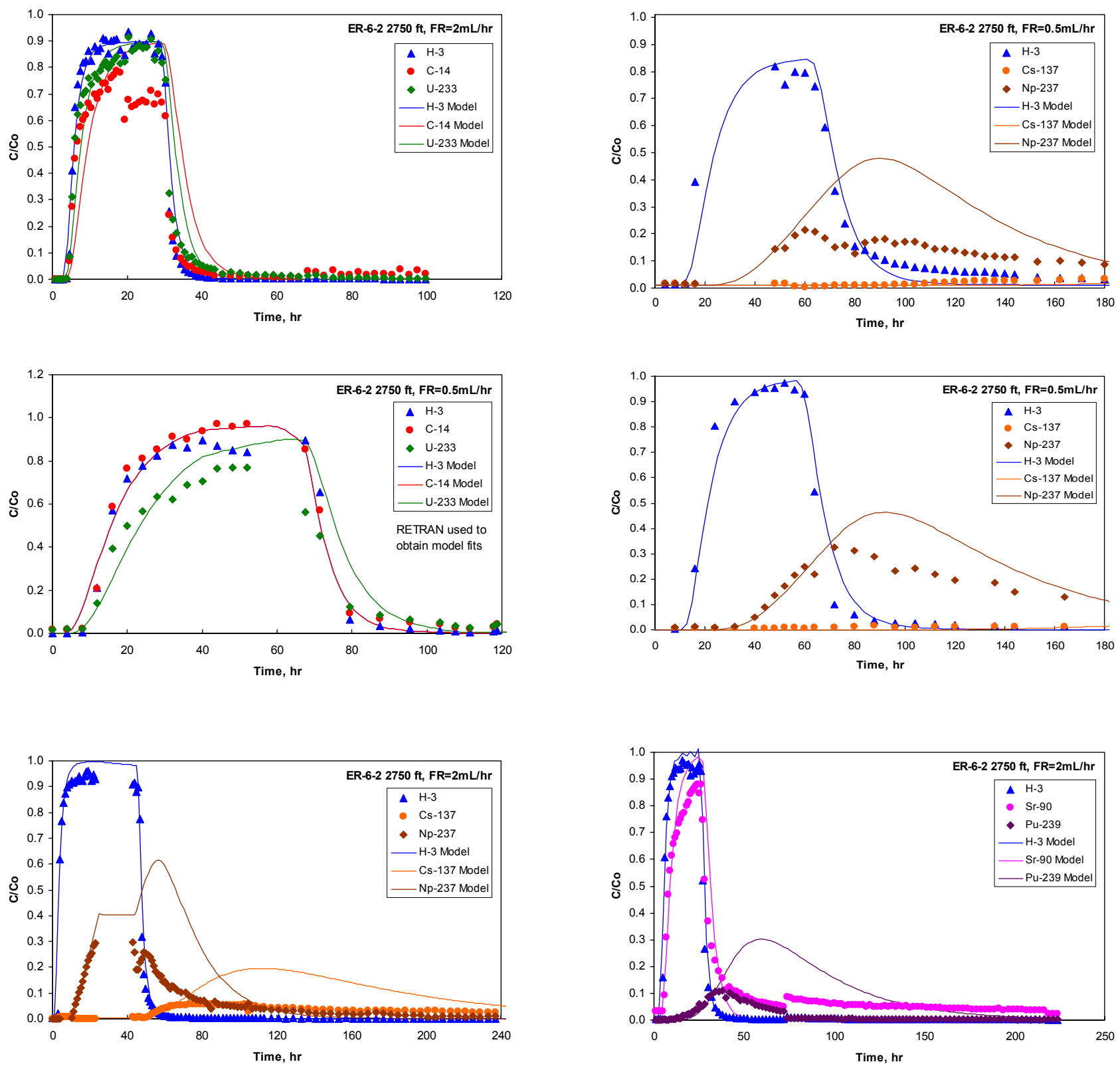

Figure D-8. Normalized breakthrough curves of ${ }^{3} \mathrm{HHO},{ }^{14} \mathrm{C},{ }^{233} \mathrm{U},{ }^{137} \mathrm{Cs},{ }^{237} \mathrm{~Np},{ }^{90} \mathrm{Sr}$, and ${ }^{239} \mathrm{Pu}$ in fracture from ER-6-2 $2750 \mathrm{ft}$ (LCA) at flow rates of $0.5 \mathrm{~mL} / \mathrm{hr}$ and $2 \mathrm{~mL} / \mathrm{hr}$. RELAP was used to obtain model fits except where noted on plots. 